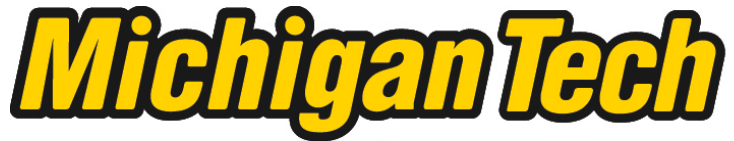 \\ Michigan Technological University Create the Future Digital Commons @ Michigan Tech
}

Dissertations, Master's Theses and Master's Reports - Open

Dissertations, Master's Theses and Master's

Reports

2013

Electrospun Quaternized Chitosan Fibers for Virus Removal from Drinking Water

Xue Mi

Michigan Technological University

Follow this and additional works at: https://digitalcommons.mtu.edu/etds

Part of the Chemical Engineering Commons

Copyright 2013 Xue Mi

\section{Recommended Citation}

Mi, Xue, "Electrospun Quaternized Chitosan Fibers for Virus Removal from Drinking Water", Master's Thesis, Michigan Technological University, 2013.

https://doi.org/10.37099/mtu.dc.etds/596

Follow this and additional works at: https://digitalcommons.mtu.edu/etds

Part of the Chemical Engineering Commons 


\title{
ELECTROSPUN QUATERNIZED CHITOSAN FIBERS FOR VIRUS REMOVAL FROM DRINKING WATER
}

\author{
By
}

Xue Mi

\begin{abstract}
A THESIS
Submitted in partial fulfillment of the requirements for the degree of MASTER OF SCIENCE

In Chemical Engineering
\end{abstract}

MICHIGAN TECHNOLOGICAL UNIVERSITY

2013

(C) 2013 Xue Mi 
This thesis has been approved in partial fulfillment of the requirements for the Degree of MASTER OF SCIENCE in Chemical Engineering.

\section{Department of Chemical Engineering}

Thesis Advisor: $\quad$ Caryn Heldt

Committee Member: $\quad$ Patricia A. Heiden

Committee Member: Adrienne Minerick

Department Chair: S. Komar Kawatra 


\section{Table of Contents}

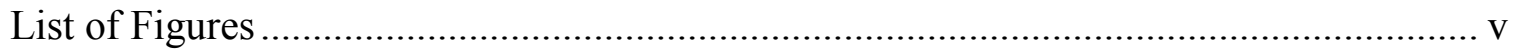

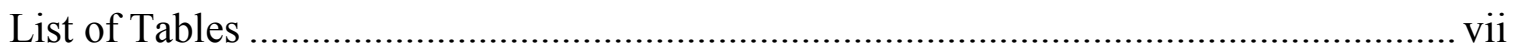

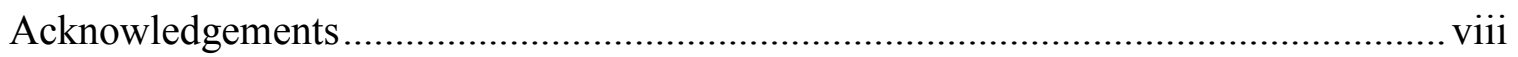

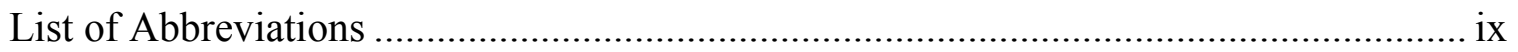

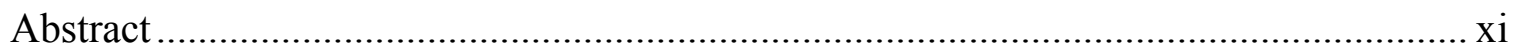

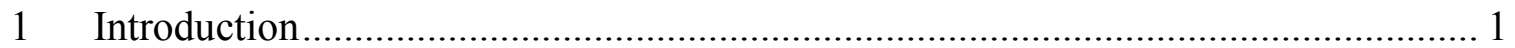

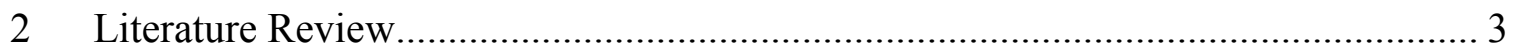

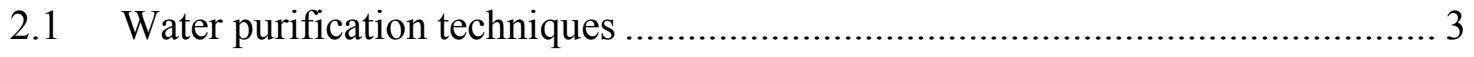

2.1.1 Chemical coagulation and flocculation and disinfection methods .............. 4

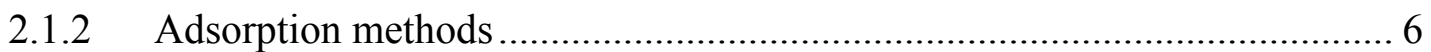

2.1.3 Physical membrane filtration methods..................................................... 7

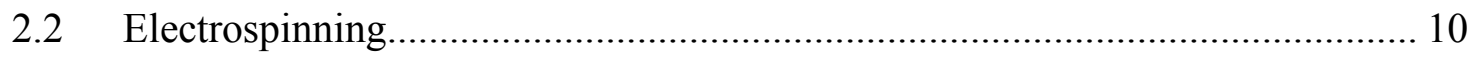

2.2.1 Functionalized Electrospun membrane as filtration media....................... 11

2.2.2 Setup and mechanism of electrospinning ............................................ 12

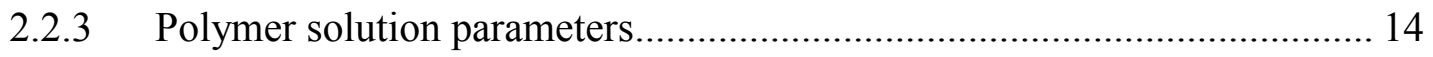

2.2.4 Electrospinning process parameters.................................................. 15

2.3 Chitosan and quaternized chitosan (HTCC)................................................ 15

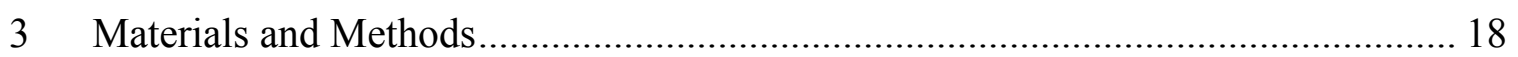

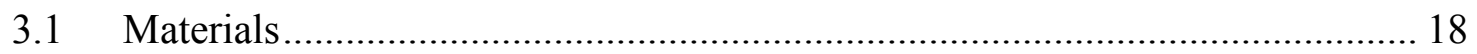

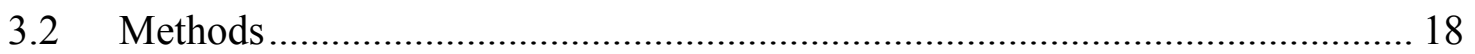

3.2.1 Synthesis and characterization of HTCC polymer................................... 18

3.2.2 Preparation, characterization and electrospinning of HTCC solution ........ 20

3.2.3 Crosslinking of the HTCC nanofibers ................................................... 21

3.2.4 Characterization of HTCC nanofibers ................................................. 22

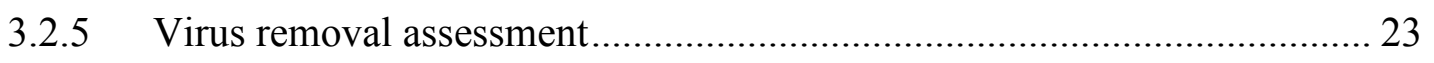

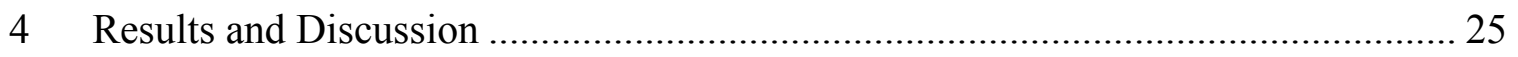

4.1 HTCC nanofibers without crosslinking .................................................... 25

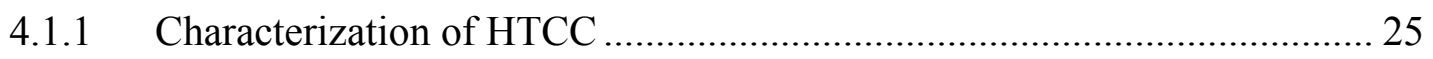

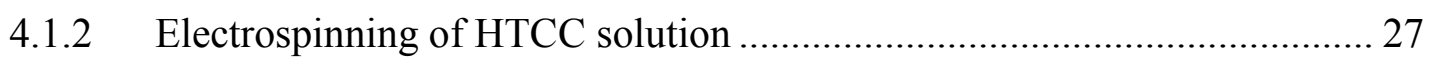

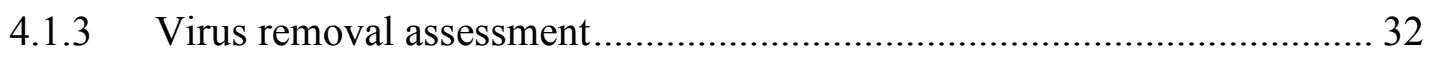




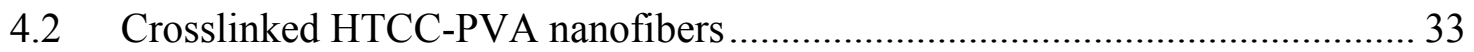

4.2.1 Characterization of the crosslinked HTCC-PVA nanofibers...................... 34

4.2.2 Virus removal of crosslinked HTCC-PVA nanofibers .............................. 44

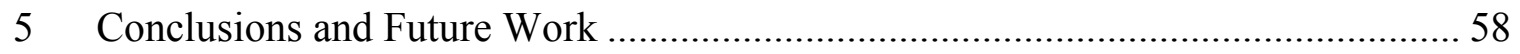

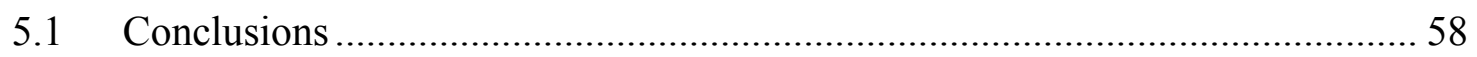

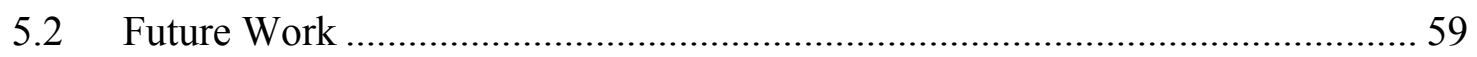

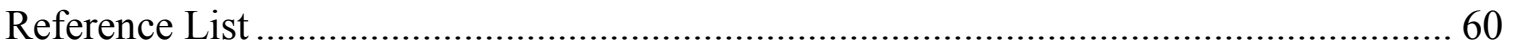




\section{List of Figures}

Figure 2.1 A typical municipal water purification system flow chart ........................... 4

Figure 2.2 Membrane filtration methods guide for pathogens removal ......................... 8

Figure 2.3 Schematic of a typical laboratory electrospinning setup ............................ 13

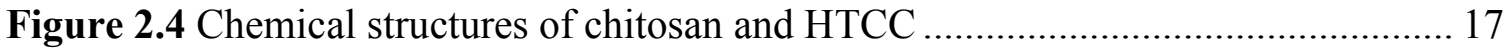

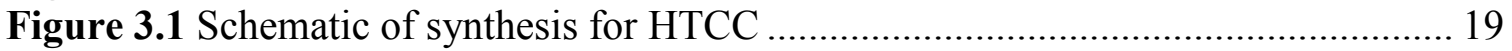

Figure 4.1 FTIR spectra of chitosan and HTCC. ...................................................... 25

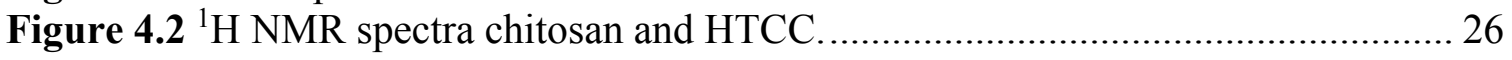

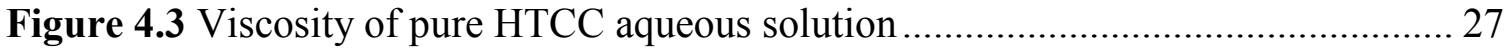

Figure 4.4 Viscosity of HTCC-graphene mixed solution of different compositions....... 28

Figure 4.5 SEM-micrographs of electrospun different concentrations of HTCC-additive

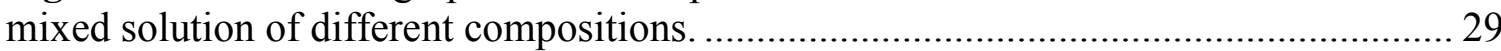

Figure 4.6 SEM-micrographs of 10\% (w/v) HTCC-PVA nanofibers of different

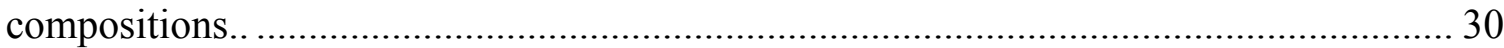

Figure 4.7 Average diameter distribution of 10\% (w/v) HTCC-PVA nanofibers of

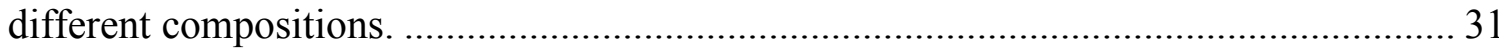

Figure 4.8 Viscosity and conductivity of 10\% (w/v) HTCC-PVA blend solution of

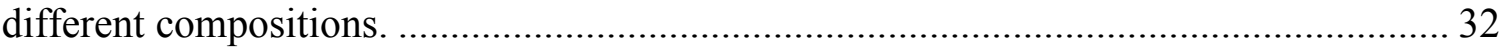

Figure 4.9 Virus removal of 10\% (w/v) HTCC-PVA nanofibers of different

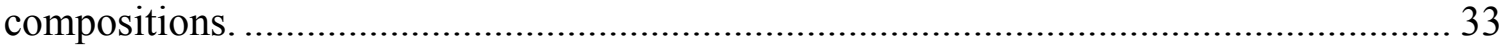

Figure 4.10 SEM-micrographs of 10\% (w/v) 3:7 HTCC-PVA nanofibers of different

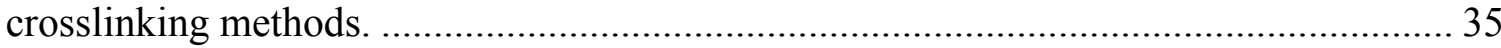

Figure 4.11 SEM-micrographs of 10\% (w/v) 4:6 glutaraldehyde vapor crosslinked

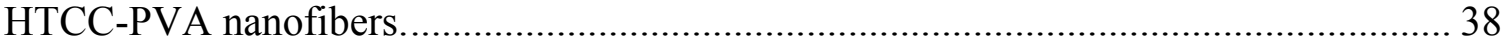

Figure 4.12 Average diameter distribution of 10\% (w/v) 4:6 glutaraldehyde vapor crosslinked HTCC-PVA nanofibers. ...................................................................... 38

Figure 4.13 SEM-micrographs of 10\% (w/v) 4:6 30\% 4h glutaraldehyde vapor crosslinked HTCC-PVA nanofibers of different lengths of contact with water.............. 39

Figure 4.14 Average diameter distribution and swelling degree of 10\% (w/v) 4:6 30\% 4h glutaraldehyde vapor crosslinked HTCC-PVA nanofibers of different lengths of contact with water.

Figure 4.15 SEM-micrographs of 10\% (w/v) 4:6 30\% 4h glutaraldehyde vapor crosslinked HTCC-PVA nanofibers of different electrospinning conditions.

Figure 4.16 Average diameter distribution of 10\% (w/v) 4:6 30\% 4h glutaraldehyde vapor crosslinked HTCC-PVA nanofibers of different electrospinning conditions......... 42

Figure 4.17 The relationship between pore size and fiber diameter. ........................... 43

Figure 4.18 Virus removal of crosslinked 10\% (w/v) 4:6 HTCC-PVA nanofibers........ 45

Figure 4.19 Virus removal of crosslinked 10\% (w/v) 4:6 HTCC-PVA nanofibers of

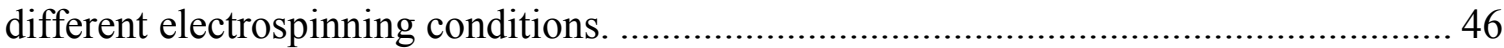

Figure 4.20 The kinetic adsorption of 30\% $4 \mathrm{~h}$ crosslinked 10\% (w/v) 4:6 HTCC-PVA nanofibers. 
Figure 4.21 The adsorption isotherms of PPV onto 30\% 4 h crosslinked 10\% (w/v) 4:6

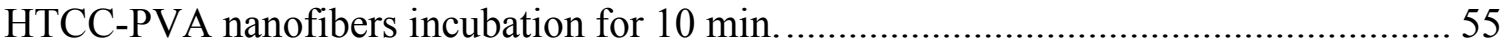

Figure 4.22 Virus removal of crosslinked 10\% (w/v) 4:6 HTCC-PVA nanofibers......... 56 Figure 4.23 Virus removal of 30\% 4 h crosslinked 10\% (w/v) 4:6 HTCC-PVA

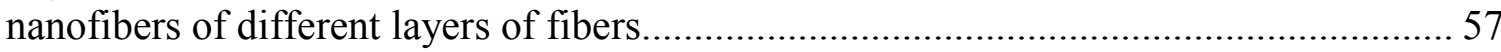




\section{List of Tables}

Table 2.1 Typical applications of electrospun nanofibers......................................... 10

Table 4.1 Parameters of the adsorption isotherm for PPV adsorption .......................... 55 


\section{Acknowledgements}

First and foremost, I would like to express my deepest gratitude to my advisor, Dr. Caryn Heldt, for her constant encouragement, guidance, patience and support. Her creative mind, serious attitude and great passion for the science deeply impressed and inspired me to overcome the difficulties I met in my research. Without her kind help, I couldn't finish my master's research study and my thesis writing. I would like to thank the Department of Chemical Engineering of MTU and NSF (CBET-1125585) for funding.

I would also like to thank Dr. Patricia A. Heiden and Dr. Adrienne Minerick for sitting on my thesis committee, and spending time reading and correcting my thesis. I also appreciate Dr. Heiden for the use of her electrospinning apparatus, Dr. Minerick for the use of her conductivity meter, Dr. Ching-An Peng for the use of his viscometer, Dr. Wenzhen Li for the use of his vacuum drying oven, Dr. Shiyue Fang for the use of his ultraviolet reactor, Dr. Ning Chen for training on the electrospinning apparatus and Mr. $\mathrm{Xu}$ Xiang for his gift of graphene.

I would also like to express my thanks to all my labmates. Especially thank K. Saagar Vijayaragavan for assistance with the SEM and Maria F. Tafur for guiding me forming a good lab etiquette.

Finally, I would like to express my deep thanks to my mother and father for their long time support and encouragement in my life. 


\section{List of Abbreviations}

\begin{tabular}{|c|c|}
\hline AD40 & Adenovirus 40 \\
\hline B.diminuta & Brevundimonas diminuta \\
\hline B. subtilis & Bacillus subtilis \\
\hline DMPA & 2, 2-Dimethoxy-2-phenylacetophenone \\
\hline DMSO & Dimethyl sulfoxide \\
\hline DQ & Degree of quaternization \\
\hline E.coli & Escherichia coli \\
\hline E.faecalis & Enterococcus faecali \\
\hline EPA & Environmental Protection Agency \\
\hline FBS & Fetal bovine serum \\
\hline $\mathrm{FCV}$ & Feline calicivirus \\
\hline FE-SEM & Field emission scanning electron microscope \\
\hline FTIR & Fourier transform infrared \\
\hline GAC & Granular activated carbon \\
\hline GTMAC & Glycidyltrimethylammonium chloride \\
\hline HAV & Hepatitis A virus \\
\hline HCoV-NL63 & Human coronavirus NL63 \\
\hline HTCC & $\mathrm{N}-[(2$-hydroxyl-3 trimethyl ammonium) propyl] chitosan chloride \\
\hline LRV & Log removal value \\
\hline MEM & Minimum essential medium \\
\hline MF & Microfiltration \\
\hline MHV & Murine hepatitis virus \\
\hline $\mathrm{MIC}$ & Minimum inhibitory concentrations \\
\hline MLV & Murine leukemia virus \\
\hline MMV & Mouse minute virus \\
\hline MWCO & Molecular weight cutoff \\
\hline $\mathrm{NF}$ & Nanofiltration \\
\hline NMR & Nuclear magnetic resonance \\
\hline NOM & Natural organic matter \\
\hline NV & Norwalk virus \\
\hline PA & Polyamide \\
\hline PAC & Powdered activated carbon \\
\hline PAN & Polyacrylonitrile \\
\hline PBS & Phosphate buffered saline \\
\hline PEI & Polyethylenimine \\
\hline PEO & Poly(ethylene oxide) \\
\hline $\mathrm{pI}$ & Isoelectric point \\
\hline PK-13 & Porcine kidney-13 \\
\hline PVA & Polyvinyl alcohol \\
\hline PVDF & Polyvinylidene fluoride \\
\hline PVP & Poly(vinyl pyrrolidone) \\
\hline PPV & Porcine parvovirus \\
\hline
\end{tabular}




$\begin{array}{ll}\text { Quat-12-PU } & \text { N, N-dodecyl, methyl-polyurethane } \\ \text { RO } & \text { Reverse osmosis } \\ \text { S. aureus } & \text { Staphylococcus aureus } \\ \text { SDS } & \text { Sodium dodecyl sulfate } \\ \text { Sf9 } & \text { Spodoptera frugiperda 9 } \\ \text { S-PAC } & \text { Super-powdered activated carbon } \\ \text { SV40 } & \text { Simian virus } \\ \text { TEGDA } & \text { Triethylene glycol diacrylate } \\ \text { UF } & \text { Ultrafiltration } \\ \text { UV } & \text { Ultraviolet } \\ \text { YHV } & \text { Yellow head virus }\end{array}$




\section{Abstract}

Membrane filtration has become an accepted technology for the removal of pathogens from drinking water. Viruses, known to contaminate water supplies, are too small to be removed by a size-exclusion mechanism without a large energy penalty. Thus, functionalized electrospun membranes that can adsorb viruses have drawn our interest. We chose a quaternized chitosan derivative (HTCC) which carries a positivelycharged quaternary amine, known to bind negatively-charged virus particles, as a functionalized membrane material. The technique of electrospinning was utilized to produce nanofiber mats with large pore diameters to increase water flux and decrease membrane fouling. In this study, stable, functionalized, electrospun HTCC-PVA nanofibers that can remove $3.6 \operatorname{logs}(99.97 \%)$ of a model virus, porcine parvovirus (PPV), from water by adsorption and filtration have been successfully produced. This technology has the potential to purify drinking water in undeveloped countries and reduce the number of deaths due to lack of sanitation. 


\section{Introduction}

Clean drinking water is essential for life. However, about 1 billion people currently lack access to safe drinking-water and more than 2 million deaths each year are attributable to unsafe water (WHO. 2011). These deaths from water-borne diseases are mainly caused by pathogenic contamination, including bacteria, viruses and parasites (e.g. protozoa and helminthes) (WHO. 2013). Currently, municipal systems purify water in a multistep process of chemical coagulation and flocculation, chemical disinfection, activated carbon adsorption, ion exchange and adsorption and physical membrane filtration (WHO. 2011). These techniques have many of the serious drawbacks like potential carcinogenic disinfection by-products, high capital and operating costs, and high backpressures and rapid fouling of the small pore-sized membrane components. There is a high potential that small viruses and heavy metals escape the system. Thus, it is of significance to develop efficient and cost-effective water purification methods for the removal of pathogens from drinking water.

In recent decades, membrane filtration has become an accepted technology for the removal of pathogens from drinking water (Brehant et al. 2010). Particulate contaminants like sand, silt and clays, and pathogenic contaminates like bacteria and parasites are easily removed from drinking water by microfiltration (MF) membranes with low operating pressure exerted (Bjorge et al. 2009). Yet, many enteroviruses like hepatitis A virus (HAV, about 25-30 nm) (Morrica et al. 2003) and norovirus (30-40 nm) (Sano et al. 2006), known to contaminate water supplies, are too small to be removed by sizeexclusion alone without high backpressures. Therefore, functionalized electrospun membranes that can remove viruses by adsorption and filtration have drawn our interest. We want to produce large pore-sized and functionalized membranes with a high surface to volume ratio to increase adsorption while maintaining a high water flux and decreasing membrane fouling.

Electrospinning is a technique for producing continuous fibers on the nanometer scale using an external electric field on the polymer solution (Ignatova et al. 2007) and a promising method to fabricate nanofibers. The electrospun nanofibers process the properties of high surface-to-volume ratios, large pore sizes and easy surface functionality (Frenot and Chronakis 2003; Huang et al. 2006; Ma et al. 2011), which are suitable to be used as filtering media in water filtration applications. More specified, they can be used in MF due to the pore sizes of electrospun nanofibers in the range of typical MF membranes (0.1-10 $\mu \mathrm{m})$ (Bjorge et al. 2009). MF has the advantages of high water flux, low membrane fouling and low backpressures due to its large pore size, can remove particulate contaminants and microbe-like bacteria larger than $0.2 \mu \mathrm{m}$ in diameter, but is not suitable for virus removal (Sato et al. 2011).

In this study, functionalized nanofibers made from quaternized chitosan $(\mathrm{N}-[(2-$ hydroxyl-3 trimethyl ammonium) propyl] chitosan chloride) (HTCC) and polyvinyl 
alcohol (PVA) have been produced to overcome the drawbacks of MF while keeping its benefits. PVA was utilized as an effective additive to HTCC to improve fiber spinnability. The high charge of HTCC creates a repulsion between HTCC polymer chains and the addition of PVA increases chain entanglement, which is needed to form electrospun fibers (Ignatova et al. 2006). The HTCC-PVA nanofibers were stabilized against water by chemical crosslinking with glutaraldehyde vapor due to the aldehyde groups of glutaraldehyde reacting with the unbound hydroxyl groups of both the HTCC and PVA to form crystallizations zone (Young and Lovell 2011). Functionalized electrospun membranes based on MF may have an appropriate pore sizes to sieve bacteria and parasites and a positive static charge to adsorb viruses while maintaining high flux permeation of filtration.

Porcine parvovirus (PPV), one of the smallest known mammalian viruses (18-26 $\mathrm{nm}$ in diameter) (Morrica et al. 2003), has been extensively used as a model virus in viral clearance studies (Furuya et al. 2006; Heldt et al. 2008; Miesegaes et al. 2012; Yokoyama et al. 2004). It is an icosahedral, single-stranded, non-enveloped DNA virus (Halder et al. 2012), infecting the intestines of pigs and causes swine productive failure (Boisvert et al. 2010). In this study, PPV has been used in a model virus to determine the virus removal ability of the electrospun HTCC-PVA membranes. We chose PPV as our model virus since it is difficult to inactivate by chemical and heat treatment (Kempf et al. 2007) and can be removed by only small pore-sized membranes, which foul easily and have high pressure drops (Furuya et al. 2006; Marques et al. 2009).

The thesis begins with an introduction of this project stated here as chapter 1 . Chapter 2 contains a literature review that states why this research is needed and the principal background of the research. Chapter 3 describes the materials and methods of the research. The experiment results and discussion of this research are presented in chapter 4. Chapter 5 concludes the research and recommends future work.

In this study, stable, functionalized, electrospun HTCC-PVA nanofibers that can remove 3.6 logs $(99.97 \%)$ of viruses from water by adsorption and filtration have been successfully produced. Fiber diameter, density and morphology and pore size of membrane were studied to characterize the functionalized electrospun membrane. The effects of membrane preparation methods and virus concentration on virus removal results were studied to analyze and model the virus capture of functionalized electrospun membranes. The kinetic adsorption and adsorption isotherm of PPV onto HTCC-PVA nanofibers was explored to provide us some insight into the adsorption process of virus.

Functionalized electrospun nanofibers, which have pores that are orders of magnitude greater in size than the virus, have the potential to greatly improve membrane filtration techniques to remove pathogens from drinking water. This will likely benefit areas in need of fresh drinking water. 


\section{Literature Review}

\subsection{Water purification techniques}

Biological and chemical contaminants present in drinking water are a constant concern for human health. These contaminates include viruses, bacteria, parasites, heavy metals, natural organic matter (NOM) and pollutants from human activities (WHO. 2011). Currently, removal of most of the contaminants, especially pathogens, from drinking water with a safe, efficient and cost-effective process is still a great challenge (WHO. 2011). Overcoming this challenge would be a great improvement to the lives of millions of people. The United States Environmental Protection Agency (EPA) requires that the minimum virus reduction is $4 \log$ removal value (LRV), the minimum Giardia reduction is 3 LRV and the minimum Cryptosporidium reduction is 2 LRV (EPA. 1974; EPA. 2005). The LRV is calculated by equation 2.1,

$$
L R V=-\log _{10}\left(c_{f} / c_{i}\right)
$$

where, $c_{f}$ is the pathogen concentration after water purification and $c_{i}$ is the initial pathogen concentration.

There are a variety of water purification techniques commonly used, including chemical coagulation and flocculation, chemical disinfection, activated carbon adsorption, ion exchange and adsorption and physical membrane filtration (sizeexclusion) (WHO. 2011; Yang et al. 2010). A typical municipal water purification system is shown in Figure 2.1. However, these methods have many difficulties handling pathogens. The methods that are most effective against pathogens are physical membrane filtration and chemical disinfectants. However, MF and ultrafiltration (UF) do not effectively remove small-sized pathogens (Antony et al. 2012; NDWC. 1999; WHO. 2011). Nanofiltration (NF) and reverse osmosis (RO) require high operating pressures as well as suffering from membrane fouling problems (Antony et al. 2012; NDWC. 1999; WHO. 2011). Chemical disinfectants can break down into carcinogenic by-products when in contact with NOM. Most municipal systems have high capital and operating costs, as well as large, multistep systems (Antony et al. 2012; NDWC. 1999; WHO. 2011). These methods are not capable to work in remote areas where clean drinking water is scarce. Due to these limitations, there is a need for improved water purification techniques. 


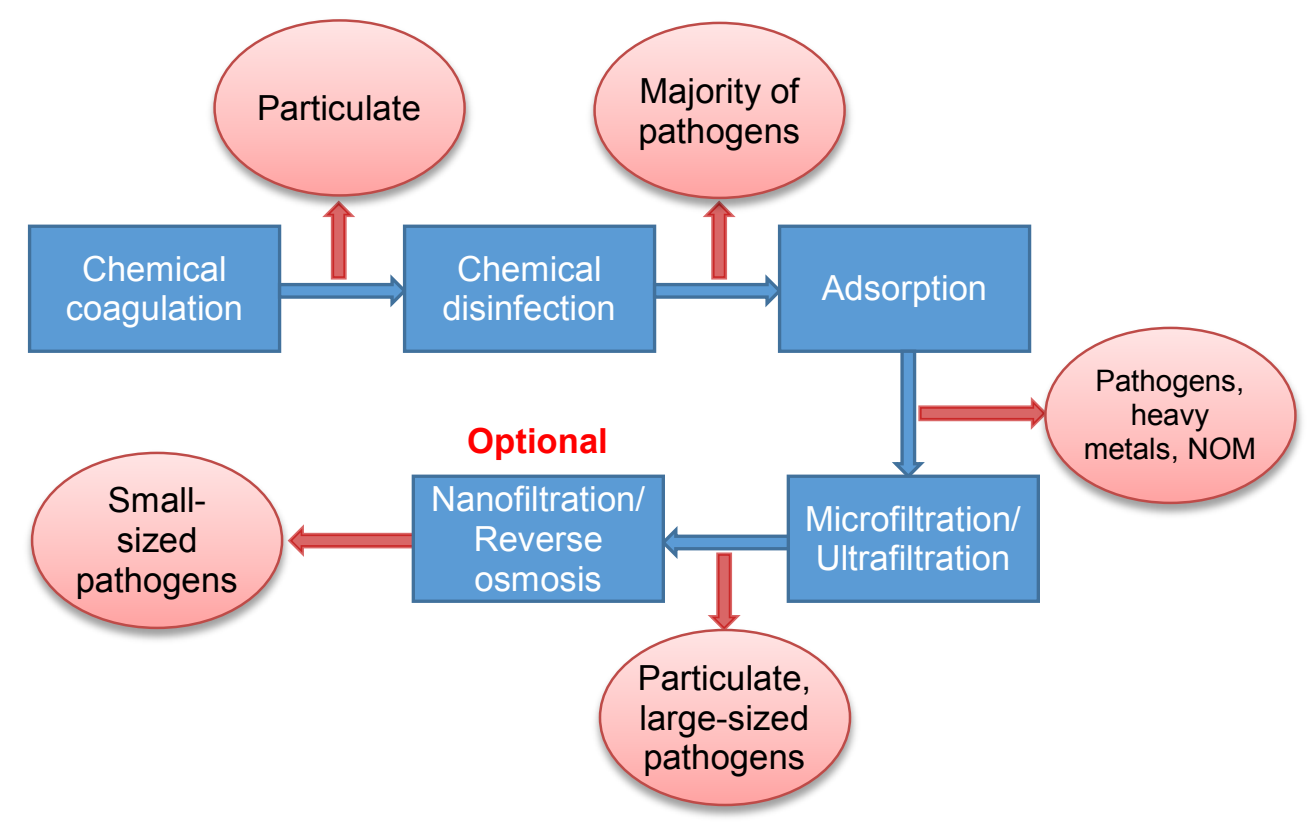

Figure 2.1 A typical municipal water purification system flow chart

\subsubsection{Chemical coagulation and flocculation and disinfection methods}

Chemical coagulation and flocculation methods are common pretreatments for purifying water. Water purification is achieved by adding inorganic coagulants, usually aluminum or iron salts, to water, which forms a solid flocculent metal hydroxide (Alexander et al. 2012; Lee et al. 2008). The precipitated floc can be removed by subsequent sedimentation or filtration (Alexander et al. 2012). Coagulation and flocculation is effective for the removal of particulate contaminants like sand, silt and clays and bound microorganisms, some heavy metals and low-soluble organic chemicals like certain organochlorine pesticides but not for other organic chemicals (WHO. 2011). Chemical coagulation and flocculation to remove contaminates from drinking water are achieved by mechanisms of charge neutralization, chemical and physical adsorption and entrapment (Lee et al. 2008; WHO. 2011). More than 6 LRV of MS2 virus (a virus with an icosahedral structure and an isoelectric point (pI) of 3.5-3.9 (Langlet et al. 2009; Sato et al. 2011)) from a virus solution with high NOM content were achieved by $4 \mathrm{mg} \mathrm{Al} / \mathrm{L}$ of polyaluminum chloride coagulant at $\mathrm{pH}$ from 6.5 to 5.5 and $8 \mathrm{mg} \mathrm{Fe} / \mathrm{L}$ of iron chloride coagulant at pH 5 following with ceramic MF (100 nm pore size) (Meyn et al. 2012). However, this resulted in high residual metal concentrations which were higher than the legal regulations (Meyn et al. 2012). However, only 2.3 LRV of MS2 virus removal from DI water was reported by $10 \mathrm{mg} / 1$ concentration of Fe at $\mathrm{pH}$ 7.3-8.3 in DI water followed by a $0.22 \mu \mathrm{m}$ pore size, modified polyvinylidene fluoride (PVDF) membrane filter (Zhu et al. 2005). A total of $3 \mathrm{LRV}$ of MS2 virus removal was achieved by $10 \mathrm{mg} / \mathrm{l}$ 
concentration of Fe by decreasing the $\mathrm{pH}$ value of the iron solution to 6.3 , followed by MF (Zhu et al. 2005).

The most commonly used disinfection agents are chlorine and ozone, which have been tested to effectively inactivate pathogens from drinking water. Chlorination can be achieved by using chlorine or its compounds such as chloramine or chlorine dioxide (Samson et al. 2012; Schmidt et al. 2000). Chlorine is a strong oxidant which can effectively kill many pathogens in drinking water. Liquefied chlorine gas is dosed into water by a chlorinator that can control and measure the gas flow rate (WHO. 2011). To avoid the potential release of toxic chlorine gas, sodium hypochlorite and calcium hypochlorite are more widely utilized. Hypochlorite releases free chlorine on contact with water (Schmidt et al. 2000; WHO. 2011). Three doses (8, 16, and $30 \mathrm{mg} / \mathrm{l})$ of free chlorine released by $14 \%(\mathrm{w} / \mathrm{v})$ sodium hypochlorite were studied for inactivation of bacteria model Escherichia coli (E.coli) and Enterococcus faecali (E. faecalis) and virus model MS2 virus and poliovirus (Tree et al. 2003). It was reported that chlorine can rapidly and completely inactivate E.coli and E. faecalis by more than 5 LRV (Tree et al. 2003). However, for virus, chlorine at all three doses can only inactivate poliovirus by 2.8 LRV and inactivate MS2 virus by 0.2 to 1 LRV (Tree et al. 2003). Chlorine dioxide $\left(\mathrm{ClO}_{2}\right)$ was reported to effectively inactivate adenovirus 40 (AD40, an enteric adenoviruses present in ground water) and feline caliciviruses (FCV, a surrogate for noroviruses present in ground water) from buffered, disinfectant free water by 4 LRV (Thurston-Enriqueza et al. 2005). In addition, the viral inactivation was improved at a higher $\mathrm{pH}$ value of 8 and higher temperature of $15^{\circ} \mathrm{C}$ (Thurston-Enriqueza et al. 2005). In addition to pathogenic disinfection, chlorine also acts as an oxidant and can oxidize some dissolved pollutants (e.g. manganese (II) and arsenite) to form insoluble products which can be removed by subsequent filtration (WHO. 2011). However, one major drawback of chlorination is that chlorine can react with NOM in the water to form trihalomethanes and other halogenated disinfection by-products, which are suspected to be carcinogenic (Komulainen 2004).

Ozone is an unstable molecule which readily gives up one atom of oxygen. It is a powerful oxidant acting as a very strong, broad spectrum disinfectant against pathogens from drinking water and a reactant with NOM to increase the biodegradability of NOM (Geering 1999; WHO. 2011). To use ozone as a disinfectant, the ozone-enriched air is dosed directly into the water through specially-designed porous diffusers at the base of baffled contactor tanks (WHO. 2011). It was reported that ozone is very effective in inactivating FCV and AD40 in treated water (Thurston-Enriqueza et al. 2005). FCV was reduced by $1.85 \mathrm{LRV}$ within $15 \mathrm{~s}$ by $0.06 \mathrm{mg} / \mathrm{l}$ of ozone and achieved more than 4.28 LRV when exposing to $1.00 \mathrm{mg} / 1$ of ozone within $15 \mathrm{~s}$ (Thurston-Enriqueza et al. 2005). $0.3 \mathrm{ml} / 1$ of ozone was able to inactivate AD 40 by $2.63 \mathrm{LRV}$ within $15 \mathrm{~s}$ and achieved 3.28 LRV of AD 40 with longer contact time to 2 min (Thurston-Enriqueza et al. 2005). $0.37 \mathrm{mg} / \mathrm{l}$ of ozone was reported to inactivate Norwalk virus (NV) in drinking water at $\mathrm{pH} 7$ by 3 LRV within a contact time of $10 \mathrm{~s}$ and by 4 LRV within 5 min (Shin and Sobsey 2003). $0.37 \mathrm{mg} / \mathrm{l}$ of ozone showed a higher inactivation of poliovirus 1 by $5 \mathrm{LRV}$ 
and MS2 virus in water by 7 LRV within a contact time of $10 \mathrm{~s}$ (Shin and Sobsey 2003). Though fewer by-products are formed by ozonation, ozone can react with bromide ions in water to produces concentrations of the suspected carcinogen bromate (Neemann et al. 2004).

\subsubsection{Adsorption methods}

Activated carbon and ions adsorption methods have been use for the removal of pathogens and NOM (Gerba et al. 2008; You et al. 2005). Activated carbon is a porous material used in either powdered or granular form with a large surface and a high affinity for organic compounds (Gerba et al. 2008; Huhn 1985). Powdered activated carbon (PAC) can be dosed as a slurry into the water and removed by subsequent filtration techniques. Granular activated carbon (GAC) is typically found in fixed-bed absorbers more efficiently than PAC. Activated carbons are typically utilized for taste and odor control (Huhn 1985; WHO. 2011). GAC filtration was reported to not be able to remove MS2 virus, but removed the protozoan cysts of Cryptosporidium parvum and Giardia lamblia by 1.3 to $2.7 \mathrm{LRV}$ (Hijnen et al. 2010). A type of super-powdered activated carbon (S-PAC) achieved 4 LRV of MS2 virus after contacting for $8 \mathrm{~h}$ (Matsushita et al. 2013). In general, chemicals with low-solubility are well adsorbed by activated carbon but this is not considered a typical virus removal step (Yang et al. 2010).

Ion exchange and adsorption method can remove dissolved ions and other charged contaminates from drinking water (You et al. 2005). Ion exchange is a process in which dissolved contaminated ions in water are replaced with other similarly charged beneficial ions by reversible chemical reactions (WHO. 2011). Most ion exchange and adsorption processes in water purification operate in a continuous mode and occur as water passes through a packed-bed of ion exchange resin or adsorption media (WHO. 2011). Anion exchange can be used for removal of contaminants such as nitrate, fluoride, arsenate and uranium and NOM (Katsoyiannis and Zouboulis 2013), while cation exchange can be used for removal of certain heavy metals (Choong et al. 2007). Ion adsorption processes can also be used to adsorb charged contaminates like bacteria and viruses (Gutierrez et al. 2009; You et al. 2005). Studies have shown that positivelycharged surfaces can adsorb negatively-charged bacteria and virus (Bjorge et al. 2009; Gutierrez et al. 2009; Li et al. 2009). For virus, it has been reported that hydrophobic polycationic coatings of $\mathrm{N}, \mathrm{N}$-dodecyl,methyl-PEI were able to quickly and efficiently disinfect aqueous solutions of non-enveloped poliovirus or rotavirus (Larson et al. 2011) and inactivate enveloped influenza virus (Hsu et al. 2011). A novel ion adsorber was capable of greater than 4 LRV of mouse minute virus (MMV), xenotropic murine leukemia virus (MLV) and simian virus 40 (SV40)) (Phillips et al. 2005). The adsorber contained eight layers of hydrophilic PVDF base membrane, derivatized with a quaternary amine ligand providing anion exchange capacity to the filter matrix (Phillips et al. 2005). Also explored were trimeric peptide ligands (WRW and KYY), which removed all detectable porcine PPV from solutions by 4.5 to 5.5 LRV (Heldt et al. 2008). The small peptides have two hydrophobic and one positively charged amino acid (Heldt 
et al. 2008). For bacteria, the cationic sites of the N, N-dodecyl, methyl-polyurethane (Quat-12-PU) were able to adsorb anionic sites of the cell-wall of microbes by electrostatic interactions (Park et al. 2013). Quat-12-PU nanoparticles coated on glass slides were reported to have a $7.78 \mathrm{LRV}$ for waterborne staphylococcus aureus ( $S$. aureus) and 7.76 LRV for E. coli bacteria (Park et al. 2013). However, for the negatively charge adsorber, it showed poor virus removal result. A $0.22 \mu \mathrm{m}$ pore size, modified PVDF membrane filter with a negatively-charged surface was reported to remove less than 0.5 LRV MS2 virus (Zhu et al. 2005). One negatively-charged commercial GS9034 microfilter was reported to remove only 1 LRV of MS2 virus from water (Ma et al. 2011). The major disadvantage of ion absorber is the low pathogen capacity of the adsorbers.

\subsubsection{Physical membrane filtration methods}

In recent decades, membrane filtration has been widely used for the reduction of contaminates from drinking water. The main advantages of physical membrane filtration methods are no disinfection by-product production, relatively high efficiency, low-cost and low-energy consumptions (Sato et al. 2011). Major membrane filtration methods for purification of water can be categorized as MF, UF, NF and RO, according to their pore sizes of membranes (Sato et al. 2011). Historically, membranes have also been characterized by a molecular weight cutoff (MWCO), expressed in units of Dalton (Da), showed the ability of membranes to retain larger organic macromolecules (EPA. 2005).

The ability of each of type of membrane filtration method to remove pathogens of viruses, bacteria, Cryptosporidium, and Giardia cysts from drinking water based on sizes is illustrated in Figure 2.2 (Antony et al. 2012; EPA. 2005; NDWC. 1999). It shows that MF, UF, NF, RO remove pathogens which are showed approximate size range by sizeexclusion filtration. Overlap of the range covered by a membrane filtration method with a given pathogen size range indicates the ability of the membrane to remove the pathogen. Noted that the MWCO listed roughly depicted as a result of the fact that NF, UF and RO filtration methods rated. 


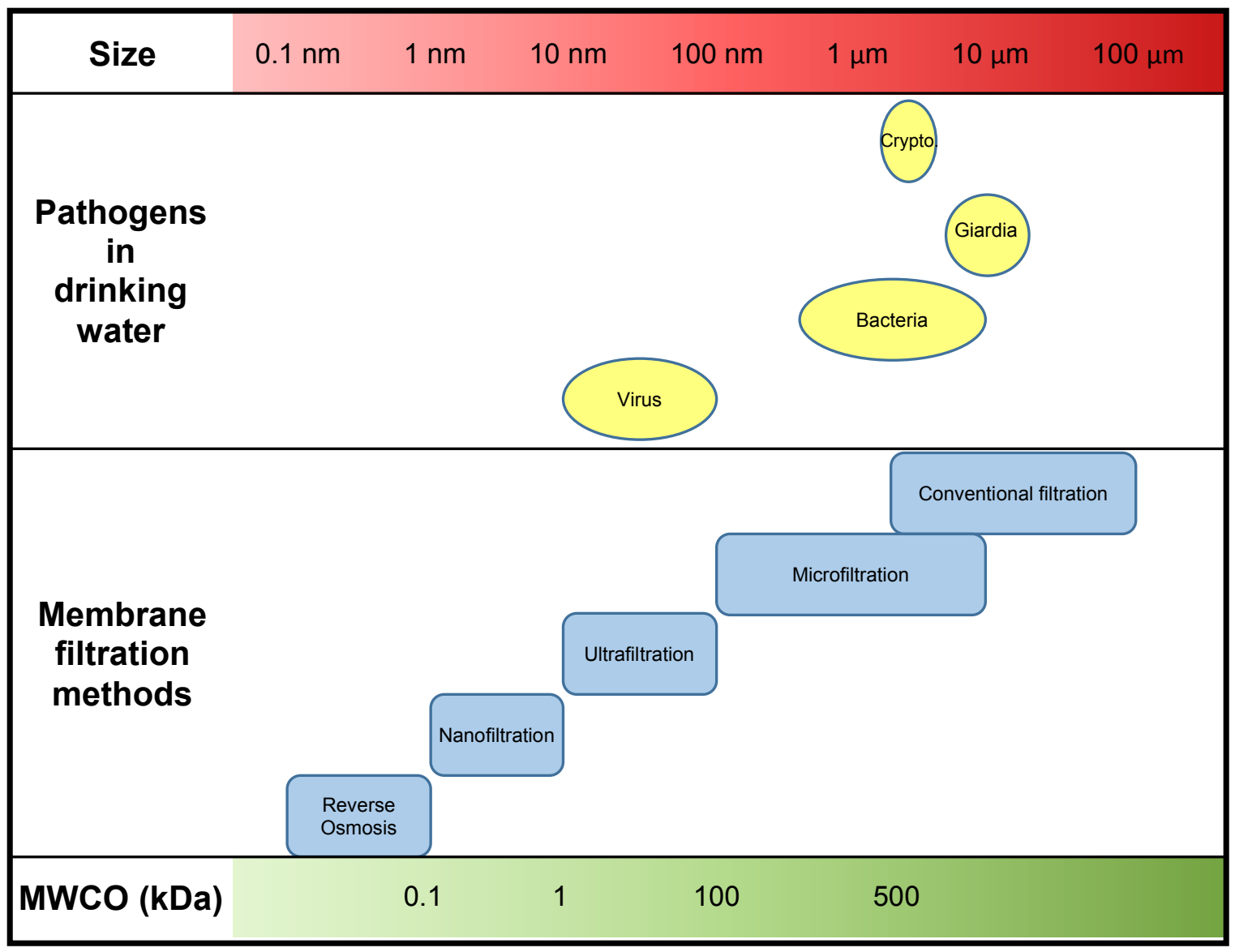

Figure 2.2 Membrane filtration methods guide for pathogens removal

MF membranes generally have an average pore size range of 0.1-10 $\mu \mathrm{m}$ (Bjorge et al. 2009), a MWCO of greater than $100 \mathrm{kDa}$ (Antony et al. 2012) and a relatively low trans-membrane pressure ranging from 100 to $400 \mathrm{kPa}$ (15 to $60 \mathrm{psi}$ ) (NDWC. 1999). MF can utilize a pressurized system but a pressure driven flow is not required for MF operation. MF can remove particulate contaminants like sand, silt and clays from drinking water and it can remove some selected bacteria and parasites (Bjorge et al. 2009). However, it is not an absolute barrier to virus (10-100 nm) based on size-exclusion filtration (Bjorge et al. 2009; NDWC. 1999). Earlier studies showed that MF membranes (pore size $0.45 \mu \mathrm{m}$ ) were able to reduce 2 to $4 \mathrm{LRV}$ of bacteria (Ghayeni et al. 1999; Gomez et al. 2006) but was not able to remove MS2 virus (Fiksdal and Leiknes 2006).

UF membranes are usually considered to have an average pore size range of 0.01 $0.1 \mu \mathrm{m}$ (Sato et al. 2011), an MWCO approximately 10 to $100 \mathrm{kDa}$ (EPA. 2005) and a feed-water operating membrane pressure ranging from 200 to $700 \mathrm{kPa}$ (30 to $100 \mathrm{psi}$ ) (NDWC. 1999). UF membranes appear to act as an absolute barrier to all bacteria and parasites by size-exclusion filtration but is not capable of removing all virus (Antony et al. 2012). Cellulose UF membrane (pore size $10 \mathrm{~nm}$ ) was able to remove more than 6 
LRV of MS2 virus (diameter $25-30 \mathrm{~nm}$ ) as well as Q $\beta$ virus (diameter $25 \mathrm{~nm}$ and $\mathrm{pI} 5.3$ (Antony et al. 2012)) (Langlet et al. 2009). Polyethersulfone UF membrane (pore size 25 $\mathrm{nm}$ ) achieved more than 4.89 LRV of MS2 virus and 3.25 LRV of Q $\beta$ virus (Langlet et al. 2009). Both the MS2 virus removal and $Q \beta$ virus removal increase with the decrease of mean pore size. A $20 \mathrm{~nm}$ planova filters were reported to remove PPV (diameter 18-26 $\mathrm{nm}$ ) by 5.1 LRV and HAV (diameter 25-30 nm) by 3.4 LRV (Furuya et al. 2006). However, there is significant fouling of these small-pored UF membranes that can lead to reductions in production rates. In addition, UF membranes are effective for removal of some NOM and have the problems of membrane fouling mainly due to accumulation of NOM (Matilainen et al. 2011).

$\mathrm{NF}$ is a pressure driven membrane separation process for removal contaminates within submicron scales (Patterson et al. 2012). NF membranes have a MWCO of 200 to $1,000 \mathrm{Da}$ and a rather high operating pressure of 600 to $1,000 \mathrm{kPa}(90$ to $150 \mathrm{psi})$ (NDWC. 1999). NF membranes can remove parasites, bacteria, viruses and human wastes but they require a rather high operating pressure and have serious problem of membrane fouling (Marques et al. 2009; NDWC. 1999). Composite thin-film polypeprizine NF membrane (140-300 Da) was reported to remove 5.4-6.1 LRV of MS2 virus and remove 6.1- 6.5 LRV PRD1 phage (100 nm) (Lovins et al. 2002). A type of ES404 NF membrane (MWCO of 4,000 Da) showed a 4.1 LRV, up to complete removal, which was more than 5.3 LRV of MS2 virus and an AFC30 membrane with MWCO of 350 Da showed 4.2 LRV of MS2 virus from source water in Minnesota (Patterson et al. 2012). The field tests in Minnesota also showed that all the NF membrane (MWCO ranging from 350 to $4,000 \mathrm{Da}$ ) tested are capable of removing a Bacillus subtilis (B. subtilis) by $4.3 \mathrm{LRV}$, up to complete removal, which was more than 6.9 LRV (Patterson et al. 2012).

Both MF, UF and NF remove contaminates from water by a sieving mechanism based on the size of the membrane pores relative to that of contaminates (EPA. 2005; Van der Bruggen and Vandecasteele 2003). But RO operate on the principle of diffusion rather than sieving as with MF and UF membranes (EPA. 2005). RO uses a semipermeable membranes to separate contaminates from drinking water (EPA. 2005; NDWC. 1999). RO is the reversal of the natural osmotic process. The process of RO is accomplished by applying high pressure, which is in excess of the osmotic pressure, to force the water from the more concentrated solution to lower concentrated solution on the opposite side (EPA. 2005; Mazloomi et al. 2009). RO membranes have a MWCO of less than $100 \mathrm{Da}$ and a higher exerted pressure on the high concentration side of membranes up to 1000 psi (EPA. 2005; Mazloomi et al. 2009). An RO membrane was reported to have a high, although incomplete, removal of MS2 virus up to 4.8 LRV (Kruithof et al. 2001). RO can effectively remove all of the contaminates from drinking water but it has a high capital and operating costs, requiring high exerted pressure and is prone to high membrane fouling (EPA. 2005; NDWC. 1999; Plakas and Karabelas 2012). 


\subsection{Electrospinning}

Electrospinning is a technique for producing continuous polymeric fibers on the nanometer scale using an external electric field (Ignatova et al. 2007). Electrospinning has not been extensively studied until 1990s, though it was patented by Formhals in 1934 (Tucker et al. 2012). It was possibly due to a large variety of polymers that were found that can be successfully electrospun, an improvement in analytical tools allowing for observing and characterizing nanofibers and the unique advantages of electrospinning to produce nanofibers compared with other techniques for producing nanofibers that accounted for its growth (Schiffman and Schauer 2008).

Electrospinning was found to be one of the most efficient, simple, controlled and versatile techniques to fabricate nanofibers, though other techniques like drawing, template synthesis, phase separation and self-assembly can also be used to produce nanofibers (Subbiah et al. 2005; Zhang et al. 2005). Nanofibers are desired due to their high surface-to-volume ratios, large pore sizes and easy surface functionality (Frenot and Chronakis 2003; Huang et al. 2006; Ma et al. 2011). The diameters of nanofibers can be easily controlled by changing the polymer solution and electrospinning process parameters. These nanofibers are of considerable interest for diverse applications in filtration, tissue engineering, wound dressing, drug delivery, enzyme immobilization, biosensors and other industrial area (Desai et al. 2009; Haider and Park 2009; Huang et al. 2007; Jiang et al. 2004; Lu et al. 2012; Manesh et al. 2007; Yang et al. 2008). The applications except for filtration have been summarized in the following Table 2.1. Obviously, as shown in the following table, there is great potential for the electrospun nanofibers to be used as ingredient carriers, as packaging materials and as sensors.

Table 2.1 Typical applications of electrospun nanofibers

\begin{tabular}{|c|c|c|c|}
\hline $\begin{array}{c}\text { Application } \\
\text { area }\end{array}$ & Examples & Characteristics & Reference \\
\hline $\begin{array}{c}\text { Tissue } \\
\text { engineering }\end{array}$ & $\begin{array}{c}\text { The growth and attachment of } \\
\text { mouse fibroblast on the surface of } \\
\text { chitosan/PVA/Hydroxyapatite } \\
\text { nanofibrous scaffolds showed } \\
\text { that the nanofibrous structure can } \\
\text { mimic the nanoscale features of } \\
\text { the extracellular matrix. }\end{array}$ & $\begin{array}{c}\text { Composite } \\
\text { membranes can } \\
\text { positively mimic } \\
\text { natural extracellular } \\
\text { matrices and show } \\
\text { the potential for } \\
\text { tissue regeneration } \\
\text { scaffolds. }\end{array}$ & (Yang et \\
Wound \\
dressing
\end{tabular}




\begin{tabular}{|c|c|c|c|}
\hline & & $\begin{array}{l}\text { the reduction of } \\
\text { wound. }\end{array}$ & \\
\hline Drug delivery & $\begin{array}{l}\text { Quaternized chitosan/poly (L- } \\
\text { lactide-co-D, L-lactide) } \\
\text { containing antitumor drug } \\
\text { doxorubicin hydrochloride } \\
\text { nanofibers led to significant } \\
\text { reduction in the HeLa cells } \\
\text { viability and increase the } \\
\text { antitumor efficacy. }\end{array}$ & $\begin{array}{c}\text { Electrospun } \\
\text { nanofibers are } \\
\text { better drug delivery } \\
\text { system than the } \\
\text { bulk materials } \\
\text { because of high } \\
\text { specific surface } \\
\text { area, short diffusion } \\
\text { passage length and } \\
\text { controlled drug } \\
\text { release profile. }\end{array}$ & $\begin{array}{l}\text { (Ignatova } \\
\text { et al. } \\
2010 \text { ) }\end{array}$ \\
\hline $\begin{array}{c}\text { Enzyme } \\
\text { immobilization }\end{array}$ & $\begin{array}{c}\text { Lipase from Candida rugosa was } \\
\text { immobilized on the chitosan/PVA } \\
\text { membranes utilizing } \\
\text { glutaraldehyde as coupling } \\
\text { reagent showed an improvement } \\
\text { in thermal stability, reusability } \\
\text { and storage stability. }\end{array}$ & $\begin{array}{l}\text { Large pore sizes } \\
\text { tailored to protein } \\
\text { molecules } \\
\text { dimensions, } \\
\text { functionalized } \\
\text { surfaces, multiple } \\
\text { sites form } \\
\text { interaction or } \\
\text { attachment of } \\
\text { electrospun } \\
\text { membrane made it } \\
\text { excellent supports } \\
\text { for enzyme } \\
\text { immobilization. }\end{array}$ & $\begin{array}{l}\text { (Huang et } \\
\text { al. 2007) }\end{array}$ \\
\hline Biosensors & $\begin{array}{c}\text { Electrospun PVDF and poly } \\
\text { (aminophenylboronic acid) } \\
\text { nanofibrous membrane sensor } \\
\text { showed an accuracy with an error } \\
\text { of less than 5\% and an extremely } \\
\text { rapid glucose response. }\end{array}$ & $\begin{array}{l}\text { Large surface areas } \\
\text { of nanofibers } \\
\text { adsorbed high } \\
\text { concentrations of } \\
\text { analyte rapidly, } \\
\text { thus making them } \\
\text { more sensitive than } \\
\text { conventional } \\
\text { system. }\end{array}$ & $\begin{array}{l}\text { (Manesh } \\
\text { et al. } \\
\text { 2007) }\end{array}$ \\
\hline
\end{tabular}

\subsubsection{Functionalized Electrospun membrane as filtration media}

Recently, functionalized electrospun membranes that can remove several contaminates from drinking water by adsorption and filtration have been explored.

Electrospun nanofibers are suitable to be used as filtering media in water filtration applications due to their unique properties. More specified, they can be used in low 
pressure filtration due to the pore sizes of electrospun nanofibers belonging to the range of average pore sizes of MF (0.1-10 $\mu \mathrm{m})$ (Bjorge et al. 2009). MF has the advantages of high water flux, low membrane fouling and low backpressures (Bjorge et al. 2009). MF can remove particulate contaminants and bacteria larger than $0.2 \mu \mathrm{m}$ in diameter (Sato et al. 2011). However, it cannot remove virus, smaller in size by a factor of 10 or more, based on size-exclusion filtration (Sato et al. 2011). Thus, functionalized electrospun membranes can overcome the drawbacks of MF by removing virus with an adsorption mechanisms while keeping the benefits of a MF membrane. Functionalized electrospun membranes based on MF have an appropriate pore sizes to sieve bacteria and a suitable static charge to adsorb viruses while maintaining high fluxes.

Electrospun polyacrylonitrile (PAN) nanofibers with a pore size of $0.3 \mu \mathrm{m}$ infused with ultra-fine cellulose-nanofibers with a negatively charged surface showed a reduction of MS2 virus by $1.6 \pm 0.2 \mathrm{LRV}$ at $\mathrm{pH} 7.2$ when MS2 was negatively charged (Ma et al. 2011). Moreover, the nanofibrous membranes exhibited an LRV of 3.7 against MS2 virus when MS2 was slightly positively charged at pH 3.5 (Ma et al. 2011). Furthermore, electrospun PAN (pore size $0.2 \mu \mathrm{m}$ ) infused with polyethylenimine (PEI) modified ultrafine cellulose-nanofibers reached a removal of MS2 virus to 4 LRV (Sato et al. 2011). The increase of the virus capture was because the PEI imparted the membrane with a positively charged surface which can bind negatively charged MS2 virus in water (Sato et al. 2011).

For removal of bacteria, the impregnated negatively-charged ultra-fine cellulosenanofibers into electrospun PAN nanofibers (pore size of $0.3 \mu \mathrm{m}$ ) showed a full retention capability against $E$. coli bacteria $(2.0 \mu \mathrm{m}$ long and $0.5 \mu \mathrm{m}$ in diameter) by $6 \mathrm{LRV}$ and against Brevundimonas diminuta (B. diminuta, $0.9 \mu \mathrm{m}$ long and $0.3 \mu \mathrm{m}$ in diameter) by 6 LRV (Ma et al. 2012). The electrospun PAN nanofibers (pore size of $0.2 \mu \mathrm{m}$ ) infused with PEI modified ultra-fine cellulose-nanofibers had a retention rate of $6 \mathrm{LRV}$ for $E$. coli bacteria removal (Sato et al. 2011). Silver functionalized electrospun polyamide (PA) (pore size $0.2-0.4 \mu \mathrm{m}$ ) membrane was reported to achieve $4 \mathrm{LRV}$ of coliform bacteria in rainwater compared to non-functionalized electrospun PA membrane for removal of 2.24 LRV of coliform bacteria in rainwater (Bjorge et al. 2009). The increase of bacterial capture by functionalized membrane was due to the adsorption of the negatively charged bacterial cell wall by silver ion $\left(\mathrm{Ag}^{+}\right)$on nanofibers leading to disrupting membrane permeability and lysis of the cell (Bjorge et al. 2009).

\subsubsection{Setup and mechanism of electrospinning}

A schematic setup of a typical laboratory electrospinning apparatus is shown in Figure 2.3 (Wallace et al. 2012). In this setup, a polymer solution is placed in a syringe with a needle. The syringe is placed in a syringe pump which allows adjustment and precise control of the flow rates of the polymeric electrospinning solution. The polymer solution is pumped through the needle, which is connected to a positive DC high voltage power supply. The ground is connected to a target rotating drum collector or a target plate 
(not shown in Figure 2.3) and this creates an electric field between the needle tip and the target. When the described electrospinning apparatus is utilized, defect-free nanofibers can be collected on the target (Schiffman and Schauer 2008).

The mechanism of creating defect-free electrospun nanofibers is due to a balance of forces. Initially, the polymer surface at the end of the needle forms a droplet and the droplet is held at the needle tip by the surface tension of the liquid prior to application of the external electric field (Schiffman and Schauer 2008). When a high voltage is applied to the droplet, the surface tension is overcome by the electrostatic forces and the droplet is stretched. At a critical voltage, the stretched droplet develops into a cone, known as a "Taylor Cone" (Pillay et al. 2013; Taylor. 1969). When the applied voltage is sufficient high for the electrostatic forces to overcome the surface tension of the liquid, a charged polymer solution jet is ejected from the tip of the Taylor Cone (Liang et al. 2007). As the jet travels through the air, the charges accumulate on the jet and may be unevenly distributed leading to a whipping or bending motion of the jet ( $\mathrm{Li}$ and Xia 2004; Schiffman and Schauer 2008). The solvent rapidly evaporates and uniform fibers are collected on the grounded collector (Vondran et al. 2008). It should be noted that the jet may break apart into little droplets in which case polymer particles rather than fibers collected on the target if the surface tension is too low (Hogan and Biswas 2008).

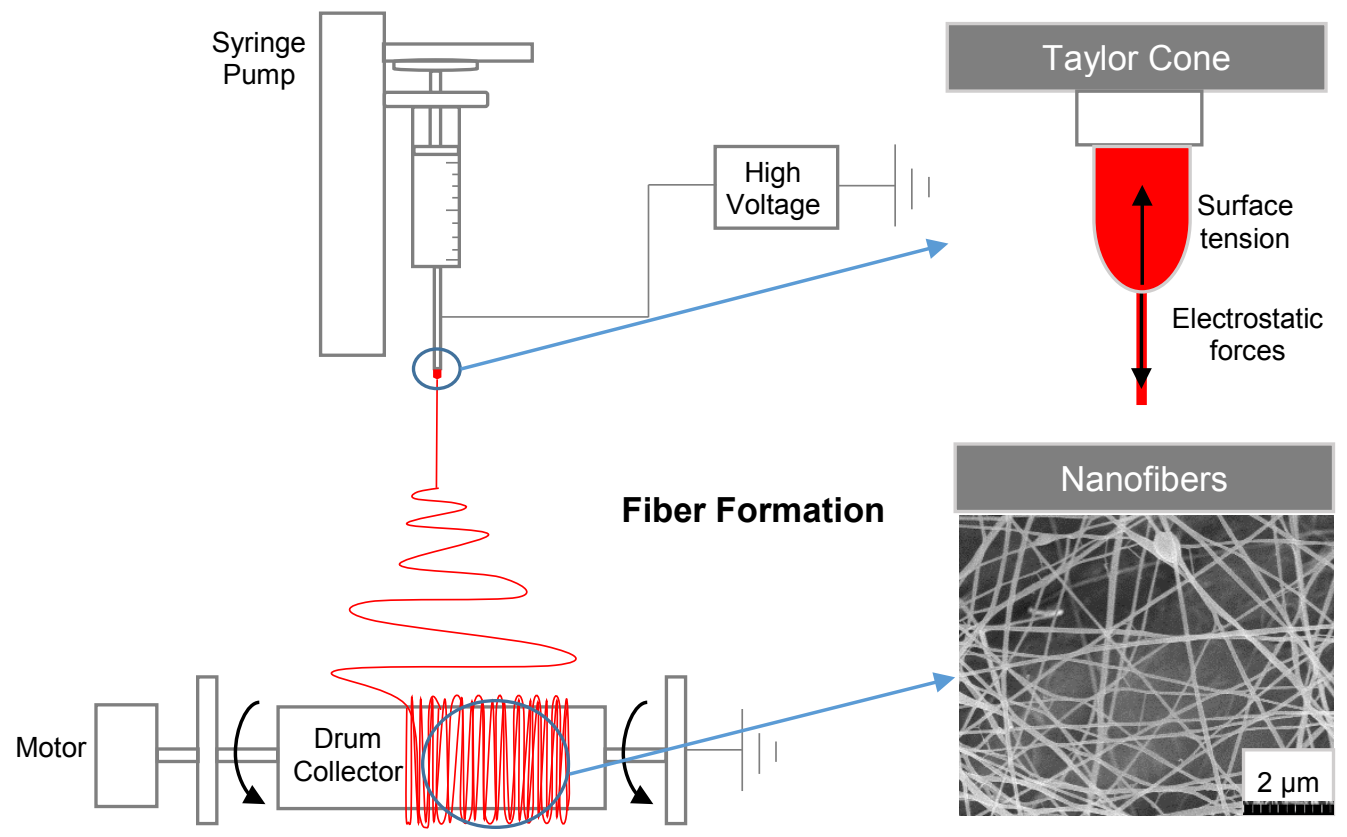

Figure 2.3 Schematic of a typical laboratory electrospinning setup 


\subsubsection{Polymer solution parameters}

There are many solution and process parameters that govern the outcome of morphology of collected nanofibers. Polymer solution parameters mainly include viscosity, conductivity and surface tension.

One of the principal parameters that impacts the process of electrospinning is viscosity of the polymer solution, which depends on polymer concentration and polymer type. The process of electrospinning is based on stretching of a charged jet of polymer solution (Greiner and Wendorff 2007). If the viscosity of polymer solution is low, the charged jet may break apart into discreet droplets before reaching the target collector. The low viscosity results in low surface tension, which cannot counter-balance the electrostatic forces (Duan et al. 2004; Hogan and Biswas 2008). A more viscous solution has a higher surface tension. At an increased viscosity, the chain entanglement between polymer chains increases and improves the creation of nanofibers (Ignatova et al. 2007). However, if the viscosity of the polymer solution is beyond a certain limit, it will obstruct the flow of the polymer solution through the capillary (Duan et al. 2004; Greiner and Wendorff 2007). It was reported that an aqueous poly(ethylene oxide) (PEO) solutions can be successfully electrospun to nanofibers between 800 and $4000 \mathrm{cp}$ (Doshi and Reneker 1995). The nanofiber jet breaking into droplets was observed below $800 \mathrm{cp}$ and failure of forming nanofibers appeared beyond $4000 \mathrm{cp}$ (Doshi and Reneker 1995). In addition, the viscosity of poly (desaminotyrosyl-tyrosine ethyl ester carbonate) electrospinning solution on fiber formation was also studied. Mainly droplets were reported to form at a low viscosity of $2.5 \mathrm{cp}$ (Meechaisue et al. 2006). Nanofibers were collected with the increase of viscosity to $14.8 \mathrm{cp}$ and $50.5 \mathrm{cp}$ (Meechaisue et al. 2006). Thus, successful electrospinning of nanofibers only occur in an optimum range of solution viscosity.

Another key parameter that affects electrospinning process is conductivity of the polymer solution. An increase of conductivity by the addition of ionic salts or polyelectrolytes will lead to more charges carrying along the jet and an increase in electrostatic repulsion between surface charges or elongation forces (Son et al. 2004). As a result, the jet is further stretched and this reduces the fiber diameters (Alipour et al. 2009). An increase of conductivity of $8 \%$ (w/w) N-butyl-N, N-dimethyl chitosan iodide/PVA electrospinning solution due to addition of ionic composition led to a significant decrease of the electrospun nanofibers from $200 \mathrm{~nm}$ to $70 \mathrm{~nm}$ at $1.5 \mathrm{kV} / \mathrm{cm}$ (Ignatova et al. 2006).

In general, a successful electrospinning of polymer solutions must be the result of the proper balance of viscosity, surface tension and conductivity that can lead to the formation of continuous fibers. 


\subsubsection{Electrospinning process parameters}

Electrospinning process parameters include voltage, feed rate and tip-to-collector distance. As previous mentioned, the applied voltage is crucial to ensure the stability of the Taylor Cone and determines the Coulombic force that induces the expulsion of a polymer jet (Li and Xia 2004; Liang et al. 2007; Taylor. 1969). An increase in the applied voltage will increase the charge density and cause the jet to accelerate faster and to stretch more, usually resulting in a reduction in the fiber diameter (Ignatova et al. 2006;

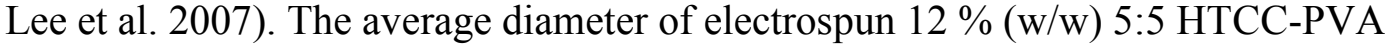
nanofibers was found to increase significantly from $140 \mathrm{~nm}$ to $315 \mathrm{~nm}$ with a decrease in applied voltage from 20 to $10 \mathrm{kV}$ (Alipour et al. 2009). However, in some cases an increase of the applied voltage results in an increase in the fiber diameter (Ignatova et al. 2007). It was reported that an increase of the voltage if all other variables except the applied voltage remained constant, will lead to an increase of N-butyl-N, N-dimethyl chitosan iodide/poly(vinyl pyrrolidone) (PVP) fiber diameters(Ignatova et al. 2007). This may be due to an increase flight speed of the jet and allowing for less time for the jet to evaporate the solvent, resulting in an increase in the diameter of fibers (Zhao et al. 2004).

An increase in the flow rate usually result in an increase in fiber diameter (Han et al. 2008). High feed rates exceeding a critical value can result in forming junction zones, where fibers interact each other, between the collected polymer strands (Megelski et al. 2002). It may be due to insufficient time available for all of the nanofibers to dry completely before reaching the collector, which will cause the fusion of fibers (Megelski et al. 2002). On the contrary, if the feed rates of the polymer solution is too low, there will be no consistent replacement of the lost solution which was withdrawn into nanofibers to maintain the Taylor Cone shape at the needle tip (Pillay et al. 2013). This will result in lower fiber formation on the collected target.

The tip-to-collector distance affects the morphology of the collected nanofibers but its effect is less profound compared with the previous two processing parameters. It was found that elongated beads started to form along the electrospun polystyrene fibers after reducing the working distance by only $5 \mathrm{~cm}$, though the fiber diameter did not change significantly (Megelski et al. 2002). In previous report, the voltage combined with the tip-to-collector distance, which changes the overall voltage density, can influence the morphology of formed nanofibers (Cramariuc et al. 2013). It has been reported that the diameter of electrospun $8 \%(\mathrm{w} / \mathrm{w}) 3: 2 \mathrm{~N}$-butyl-N, N-dimethyl chitosan iodide/PVA fibers slightly decreased from $70 \mathrm{~nm}$ to $60 \mathrm{~nm}$ on increasing the voltage density from 1.5 $\mathrm{kV} / \mathrm{cm}$ to $3.5 \mathrm{kV} / \mathrm{cm}$ (Ignatova et al. 2006).

\subsection{Chitosan and quaternized chitosan (HTCC)}

Chitosan (chemical structure shown in Figure 2.4A) is a polycationic polymer and the $\mathrm{N}$-deacetylated derivative of the natural polymer chitin, the second most abundant polysaccharide found on earth next to cellulose (Alipour et al. 2009; Ignatova et 
al. 2007). Chitosan is insoluble in water and common organic solvents because of its rigid crystalline structure. It is soluble in acidic aqueous solution if the $\mathrm{pH}$ value is less than 6.5 (No et al. 2007). At a higher $\mathrm{pH}$ value, the molecule of chitosan may precipitate out of the solution and lose its charges because of deprotonation of the amine groups (No et al. 2007).

Chitosan is well known to be non-toxic, biocompatible, biodegradable, biofunctional and hydrophilic. (Deng et al. 2012; Huang et al. 2007; Ignatova et al. 2006; Li et al. 2008). Chitosan could be used as an antimicrobial and antiviral material in the field of biotechnology, pharmaceutics, wastewater treatment, cosmetics, agriculture, food science, and textiles because of its advantageous biological properties ( $\mathrm{Li}$ et al. 2008; Lim and Hudson 2004; Lu et al. 2012). However, this activity of chitosan against pathogens is limited to acidic conditions due to its poor solubility above $\mathrm{pH}$ value of 6.5 , where chitosan starts to lose its polycationic nature (Alipour et al. 2009; Li et al. 2008). Therefore, the preparation of water-soluble chitosan derivatives with an improved water solubility over a wide $\mathrm{pH}$ range was studied for their antimicrobial and antiviral activity (Alipour et al. 2009; Ignatova et al. 2007; Ignatova et al. 2006).

Among the various chitosan derivatives, the derivatives with quaternary ammonium groups have shown higher efficient activity against bacteria as compared to those of chitosan (Ignatova et al. 2007; Ignatova et al. 2006; Li et al. 2008). Quaternized chitosan HTCC (chemical structure shown in Figure 2.4B) (Alipour et al. 2009; Deng et al. 2012; Lim and Hudson 2004), N-N-propyl-N, N-dimethyl chitosan (Jia et al. 2001) and N-butyl-N,N-dimethyl chitosan iodide (Ignatova et al. 2007; Ignatova et al. 2006) showed enhanced antimicrobial activity compared with chitosan (Lim and Hudson 2004; Rabea et al. 2003). It was reported that the minimum inhibitory concentrations (MIC) of HTCC against $S$. aureus and $E$. coli were $400 \mu \mathrm{g} / \mathrm{ml}$ and $600 \mu \mathrm{g} / \mathrm{ml}$ compared with the MIC of chitosan for $S$. aureus and E. coli were $1500 \mu \mathrm{g} / \mathrm{ml}$ and $3000 \mu \mathrm{g} / \mathrm{ml}$, respectively (Alipour et al. 2009). This indicates that the antibacterial activity of HTCC was much stronger than that of chitosan. Besides, the antibacterial activity of N-N-propyl-N, Ndimethyl chitosan against $E$. coli was shown 20 times that of chitosan (Jia et al. 2001). This may be due to enhanced positively charged quaternary amine group, known to targeted on the negatively charged cytoplasmic membrane of microbes, altering membrane properties and impeding nutrients entering the cells ( $\mathrm{Li}$ et al. 2008; Rabea et al. 2003).

Chitosan as well as chitosan derivative showed anti-pathogenic effects towards bacteria, viruses and fungi (Deng et al. 2012; Elsabee et al. 2012; Li et al. 2008; Li et al. 2011; Lu et al. 2012; Rabea et al. 2003), but exact mechanism of the anti-pathogenic activity of chitosan and its derivative is still uncertain (Deng et al. 2012). Various mechanisms have been proposed (Li et al. 2008; Rabea et al. 2003). One reasonable mechanism involves interaction between positively charged chitosan and quaternized chitosan molecules and negatively charged microbial cell membranes, causing a change in membrane permeability and the leakage of intracellular constituents of microbial cells 
(Li et al. 2008). Another mechanism is that at a lower concentration, the positively charged molecule probably bind to the negatively charged bacterial or virus surface to cause agglutination, while at higher concentrations, larger amounts of positive charges possibly impart a net positive charge to the bacterial or virus surfaces to keep them in suspension (Rabea et al. 2003).

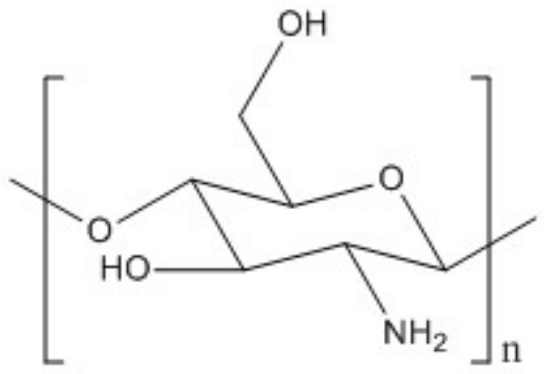

(A) Chitosan

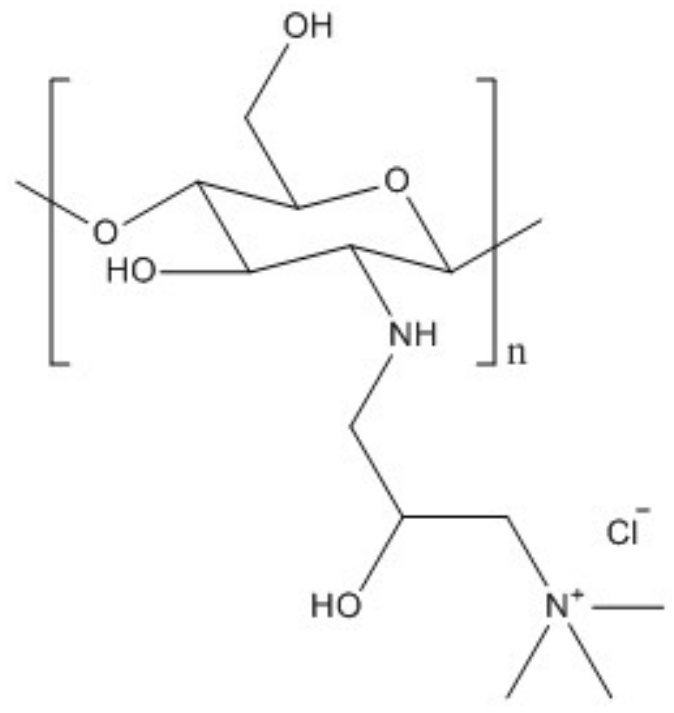

(B) HTCC

Figure 2.4 Chemical structures of chitosan and HTCC

HTCC and hydrophobically-modified HTCC compounds were shown to inhibit the replication of the human coronavirus NL63 (HCoV-NL63). Furthermore, both polymers also showed an inhibition activity against murine hepatitis virus (MHV) (Milewska et al. 2013). Long double-stranded (ds) RNA formulated with quaternized chitosan derivative was shown to inhibit yellow head virus (YHV) propagation in Spodoptera frugiperda 9 (Sf9) cells with minimal cytotoxicity (Theerawanitchpan et al. 2012).

This thesis describes functionalized electrospun membranes based on MF with a suitable electrostatic charge to adsorb viruses while maintaining high flux permeation. HTCC carries a positively charged quaternary amine, known to bind negatively charged microbes and virus, which can be used as a functionalized membrane material. To determine the ability of electrospun membranes to remove virus from water, PPV, one of the smallest known mammalian viruses, was chosen as a model virus in virus clearance studies. The electrospun HTCC nanofibers were studied for their physical characterization and virus removal ability. 


\section{Materials and Methods}

\subsection{Materials}

Chitosan (75-85\% deacetylated, $\left.\mathrm{M}_{\mathrm{w}}=190,000-310,000 \mathrm{Da}\right)$, glycidyltrimethylammonium chloride (GTMAC) (technical grade, $\geq 90 \%$ ), silver nitrate (ACS grade, $\geq 99.0 \%$ ), potassium chromate (ACS grade, $\geq 99.0 \%$ ), deuterium oxide $(99.9$ atom \% D) and trifluoroacetic acid-d (99.5 atom \% D) were all purchased from Sigma-Aldrich (St. Louis, MO).

For electrospinning, PVA (99\% hydrolyzed, $\left.\mathrm{M}_{\mathrm{w}}=89,000-98,000 \mathrm{Da}\right)$ and sodium dodecyl sulfate (SDS) (for molecular biology, $\geq 98.5 \%$ ) were purchased from Sigma-Aldrich (St. Louis, MO).

To crosslink HTCC nanofibers, triethylene glycol diacrylate (TEGDA) was purchased from VWR (Radnor, PA). 2, 2-dimethoxy-2-phenylacetophenone (DMPA) (99\%), ammonium persulfate (ACS grade, $\geq 98.0 \%$ ), maleic acid ( $\geq 99.0 \%$ ), glutaraldehyde solution (Grade I, 70\% in $\mathrm{H}_{2} \mathrm{O}$ ) and glycine (for molecular biology, $\geq$ 99.0\%) were purchased from Sigma-Aldrich (St. Louis, MO).

Minimum essential medium (MEM), penicillin-streptomycin, trypsin $(0.25 \%)$ and phosphate buffered saline (PBS) $(\mathrm{pH}=7.2)$ were purchased from Life Technologies (Grand Island, NY). Fetal bovine serum (FBS) was purchased from Atlanta Biologicals (Grand Island, NY). MTT agent, thiazolyl blue tetrazolium bromide ( $\geq 97.5 \%)$ was purchased from Sigma-Aldrich (St. Louis, MO). Hydrochloric acid (HCl) (12.1 M) was purchased from VWR (Radnor, PA).

All aqueous solutions were prepared using purified water with a resistivity of $\geq 18$ $\mathrm{M} \Omega \cdot \mathrm{cm}$ with a Nanopure filtration system (Fisher Scientific, Pittsburgh, PA).

\subsection{Methods}

\subsubsection{Synthesis and characterization of HTCC polymer}

HTCC was synthesized according to a known method (Lim and Hudson 2004). The scheme for the synthesis of HTCC is shown in Figure 3.1 (Alipour et al. 2009). First, chitosan (6 g, $37.0 \mathrm{mmol})$ was dispersed in Nanopure water $(240 \mathrm{ml})$ in a $500 \mathrm{ml}$ three-neck round-bottom flask. GTMAC (16.82 g, $21.3 \mathrm{ml}, 111 \mathrm{mmol})$ was added in three portions $\left(7.1 \mathrm{ml}\right.$ each) at 2 -h intervals, and the mixture was stirred at $85^{\circ} \mathrm{C}$ with an oil bath for $10 \mathrm{~h}$. Then, the reaction solution was dialyzed for 3 days with Fisherbrand 3.5 kDa MWCO regenerated cellulose dialysis tubing (Fisher Scientific, Pittsburg, PA), against water to remove any unreacted GTMAC. Unreacted chitosan was removed by vacuum filtered with a Buchner funnel containing a fine porosity fritted disc. The clear 
solution was concentrated under vacuum with a Buchi R-200 rotavapor (New Castle, DE) at $70^{\circ} \mathrm{C}$. The concentrated solution was precipitated in cold acetone $(250 \mathrm{ml})$ using an ice bath and washed twice with acetone. The precipitate was dried at $110^{\circ} \mathrm{C}$ for $12 \mathrm{~h}$ to obtain the final product.

GTMAC

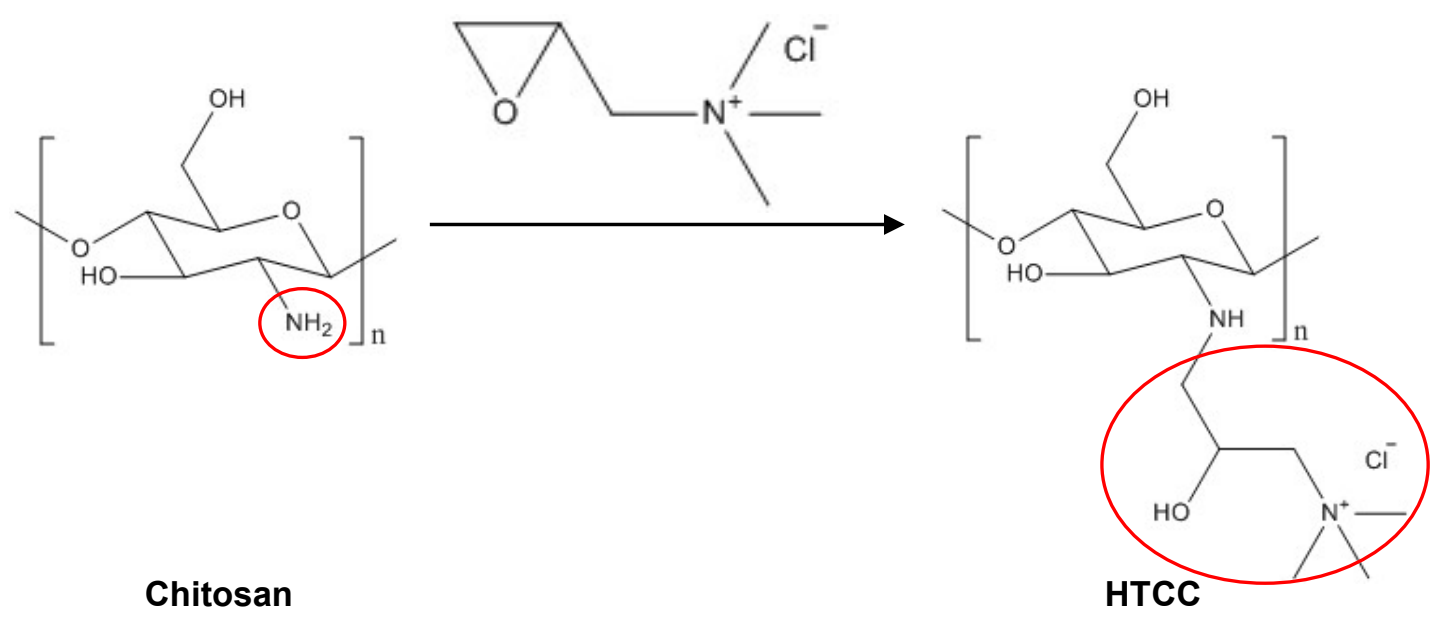

Figure 3.1 Schematic of synthesis for HTCC

To measure the degree of quaternization (DQ) of HTCC, the amount of chloride on the HTCC was titrated with aqueous silver nitrate solution at room temperature. $1 \%$ $(\mathrm{w} / \mathrm{v})$ silver nitrate $\left(\mathrm{AgNO}_{3}\right)$ solution was poured into a $25 \mathrm{ml}$ burette. Then, $5.0 \mathrm{ml}$ of $1 \%(\mathrm{w} / \mathrm{v}) \mathrm{HTCC}$ solution and $4.0 \mathrm{ml}$ of $1 \%(\mathrm{w} / \mathrm{v})$ potassium chromate $\left(\mathrm{K}_{2} \mathrm{CrO}_{4}\right)$ solution were transferred to a $125 \mathrm{ml}$ Erlenmeyer flask. The silver nitrate solution was added to the $1 \%(\mathrm{w} / \mathrm{v})$ HTCC solution slowly drop by drop with swirling the flask until the entire solution in the flask turned a very light orange-red color, indicating the endpoint had been reached. The total volume of the titrant (silver nitrate solution) was recorded and the corresponding amount of chloride on the HTCC was calculated. Each sample was titrated three times to obtain an average DQ value. The DQ is calculated by equation 3.1,

$$
D Q=\frac{0.01 \frac{\mathrm{g}}{\mathrm{ml}} \times \mathrm{V}_{\mathrm{AgNO}_{3}} / \mathrm{M}_{\mathrm{AgNO}_{3}}}{0.01 \frac{\mathrm{g}}{\mathrm{ml}} \times V_{\mathrm{HTCC}} / M_{\mathrm{HTCC}}}
$$

$V_{\mathrm{AgNO}_{3}}=$ total volume of $\mathrm{AgNO}_{3}=$ inital volume of $\mathrm{AgNO}_{3}-$ final volume of $\mathrm{AgNO}_{3}$ $V_{\text {HTCC }}=$ volume of HTCC $=5 \mathrm{ml}$ $M_{\mathrm{AgNO}_{3}}=$ molecular weight of $\mathrm{AgNO}_{3}=170 \frac{\mathrm{g}}{\mathrm{mol}}$ $M_{\text {HTCC }}=$ molecular weight of HTCC $=312.5 \frac{\mathrm{g}}{\mathrm{mol}}$ 
Fourier transform infrared (FTIR) spectra were obtained using a Perkin Elmer Spectrum One FTIR spectrometer (Shelton, CT). Both HTCC crystals and chitosan powder were measured in the solid state. Nuclear magnetic resonance (NMR) spectra were obtained using a Varian $400 \mathrm{MHz}$ NMR wide-bore spectrometer (Santa Clara, CA). HTCC $(\mathrm{c}=10 \mathrm{mg} / \mathrm{ml})$ was dissolved in $0.7 \mathrm{ml} \mathrm{D}_{2} \mathrm{O}$, and chitosan $(\mathrm{c}=5 \mathrm{mg} / \mathrm{ml})$ was dissolved in $0.7 \mathrm{ml} \mathrm{CF}_{3} \mathrm{COOD}$.

\subsubsection{Preparation, characterization and electrospinning of HTCC solution}

To electrospin HTCC solutions, HTCC was dissolved in Nanopure water at room temperature with gentle stirring for a day in order to prepare a homogeneous solution. A concentration ranging from $5 \%(\mathrm{w} / \mathrm{v})$ to $10 \%(\mathrm{w} / \mathrm{v})$ of pure $\mathrm{HTCC}$ solution was prepared. Various additives (graphene, SDS and PVA) at various weight ratios were added into the HTCC solution to aid the fiber formation of HTCC. A broad concentration range (from 5 to $15 \%$ ) of mixed solution was sonicated in a FS-20 sonicator (Fisher Scientific, Pittsburg, PA) at room temperature.

After several trials, PVA was chosen as a suitable additive for producing electrospun HTCC nanofibers. The HTCC-PVA blend electrospinning solution was prepared by mixing $10 \%(\mathrm{w} / \mathrm{v}) \mathrm{HTCC}$ solution, with a $10 \%(\mathrm{w} / \mathrm{v})$ PVA solution that was dissolved in Nanopure water at $85^{\circ} \mathrm{C}$ with gentle stirring for $5 \mathrm{~h}$, at the weight ratios (HTCC: PVA) ranging from 3:7, 4:6, 5:5, 6:4 and 7:3. The total polymer concentration of the electrospinning solution was $10 \%(\mathrm{w} / \mathrm{v})$.

Prior to electrospinning, the viscosity of the electrospinning solution was measured using a SV-10 viscometer (Malvern, United Kingdom). The conductivity of the electrospinning solution was measured using an AB-30 conductivity meter (Fisher Scientific, Pittsburg, PA).

The schematic diagram for home-made electrospinning apparatus has been illustrated in the Figure 2.3. The electrospinning solutions were placed into a $3 \mathrm{ml}$, disposal, plastic syringe with a detachable needle $(0.6 \mathrm{~mm} \times 40 \mathrm{~mm})$ (Fisher Scientific, Pittsburgh, PA). The needle was connected to a Glassman positive DC high voltage power supply (High Bridge, NJ), capable of generating voltages in the range of $0-30$ $\mathrm{kV}$, while the ground was connected to a rotating drum collector covered with aluminum foil running by an Electro Craft Torque power pump (Gallipolis, OH). The electrospun nanofibers were collected on Whatman filter papers circles (West Chester, PA; grade 1, diameter $=1.5 \mathrm{~cm} \&$ grade 4 , diameter $=55 \mathrm{~mm}$ ), which were taped on the aluminum foil and used to support the nanofibers. A Multi Speed syringe pump (Braintree Scientific Inc., Braintree, MA) was used to feed the solution at a constant speed.

The applied voltage was $20 \mathrm{kV}$, the tip-to-collector distance was $10 \mathrm{~cm}$ and the feed rate of solution was 7.5 or $7.8 \mathrm{ml} / \mathrm{h}$ for the HTCC-additive (graphene, SDS and 
PVA) mixed solution. For the HTCC-PVA blend solutions, the electrospinning apparatus parameters were set as $20 \mathrm{kV}, 5 \mathrm{~cm}$ tip-to-collector distance and $4.5 \mathrm{ml} / \mathrm{h}$, unless otherwise stated. The rotational speed of drum collector was set at $1500 \mathrm{rpm}$ for all the solutions.

\subsubsection{Crosslinking of the HTCC nanofibers}

\subsubsection{Photo-mediated crosslinking}

Photo-crosslinked HTCC-PVA nanofibers were made as follows (Ignatova et al. 2006). $0.107 \mathrm{~g}$ TEGDA, $0.01 \mathrm{~g}$ DMPA and $0.01 \mathrm{~g}$ ammonium persulfate were dissolved in $0.79 \mathrm{ml}$ dimethyl sulfoxide (DMSO) for final solution concentrations of TEGDA $(10.7 \%)(\mathrm{w} / \mathrm{w})$, DMPA (1\%) (w/w) and ammonium persulfate (1\%) (w/w). $10 \mathrm{ml} \mathrm{10 \%}$ (w/w) of HTCC: PVA (3:7) homogeneous electrospinning solution was mixed with the $0.79 \mathrm{ml}$ DMSO homogeneous solution or $0.79 \mathrm{ml}$ of pure DMSO as a control. The total polymer concentration in the electrospinning solution with photo-crosslinkers was $10 \%$ $(\mathrm{w} / \mathrm{w})\left(\mathrm{H}_{2} \mathrm{O} / \mathrm{DMSO}=92: 8 \mathrm{w} / \mathrm{w}\right)$. Electrospinning of the mixed electrospinning solutions were conducted immediately after the mixed solutions became homogenous with the same conditions as stated in Section 3.2.2 for HTCC-PVA blend solutions. In order to perform the photo-crosslinking, both the electrospun membranes with photo-crosslinkers and the membrane containing DMSO solvent were irradiated with a Rayonet RPR-100 ultraviolet (UV) reactor $(350 \mathrm{~nm}, 120 \mathrm{~W}$, Branford, CT) at a distance of $12.7 \mathrm{~cm}$ at room temperature for $10 \mathrm{~h}$.

\subsubsection{Maleic acid crosslinking}

To produce maleic acid crosslinked HTCC-PVA electrospinning solution, a $25 \mathrm{ml}$ $8 \%(\mathrm{w} / \mathrm{w})$ of HTCC: PVA (3:7) electrospinning solutions was made as previous described (Han et al. 2003; Qin and Wang 2008). $0.5 \mathrm{~g}$ maleic acid was added to the solution to make the total content of solution come to $10 \%(\mathrm{w} / \mathrm{w})$, and several drops of $98 \%$ sulfuric acid were added as a catalyst. The solution was heated at $100^{\circ} \mathrm{C}$ for $1 \mathrm{~h}$ with vigorous stirring. After cooling to room temperature, $3 \mathrm{ml}$ of the maleic acid crosslinked homogenous solution was electrospun as stated in Section 3.2.2 for HTCC-PVA blend solutions.

\subsubsection{Glutaraldehyde crosslinking}

Both glutaraldehyde solution and glutaraldehyde vapor were attempted to crosslink the HTCC-PVA nanofibers. For the glutaraldehyde solution crosslinking method, the HTCC-PVA electrospun nanofibers were suspended in $25 \mathrm{ml} 10 \%(\mathrm{v} / \mathrm{v})$ glutaraldehyde aqueous solution for $12 \mathrm{~h}$.

To crosslink the electrospun HTCC-PVA nanofibers with glutaraldehyde vapor (Alipour et al. 2009), the nanofibers on filter paper were adhered to the top of a petri dish, 
and various concentrations of $400 \mu$ glutaraldehyde was dropped in the bottom of the petri dish. The petri dish was placed on top of a digital dry bath (USA Scientific, Ocala, FL) at $37^{\circ} \mathrm{C}$ for various times. The crosslinked membranes needed pre-treatment to remove the unreacted glutaraldehyde on the filter papers prior to virus removal. The electrospun mats after crosslinking with glutaraldehyde vapor were washed with water for $20 \mathrm{~min}$ or washed with $0.1 \mathrm{M}$ glycine (Alipour et al. 2009) for $10 \mathrm{~min}$ and water for 10 min, respectively. All the treated samples were dried in a Gold Series DP-32 vacuum drying oven (Ontario, Canada) at $120^{\circ} \mathrm{C}$ for $1 \mathrm{~h}$.

To determine the stability of crosslinked electrospun HTCC-PVA nanofibers against water, they were filtered with water and were immersed in water for $10 \mathrm{~min}$. All the treated samples were dried in a Gold Series DP-32 vacuum drying oven (Ontario, Canada) at $120^{\circ} \mathrm{C}$ for $1 \mathrm{~h}$.

\subsubsection{Characterization of HTCC nanofibers}

The morphology of HTCC nanofibers was observed by a Hitachi S-4700 field emission scanning electron microscope (FE-SEM) (Tustin, CA) which is a cold field, emission high resolution scanning electron microscope. The electrospun fibers on the filter paper were coated with a $5 \mathrm{~mm}$ layer of platinum/ palladium using a Hummer 6.2 Sputter Coater (Union City, CA) before examined by FE-SEM. The accelerating voltage for the FE-SEM was $5 \mathrm{kV}$, and the magnification was from $1,000 \times$ to $80,000 \times$. Each sample was captured with three SEM images at the same magnification. To determine the fiber diameter distribution, 50 random points on the fibers on each SEM-micrographs were calculated with a Nano Measurer and OriginLab software. Three images were used for each sample to get the average diameter and the standard deviation of fibers.

To study the relationship between pore size and fiber diameter, HTCC electrospun membranes were assessed by filtration with $1.01 \mu \mathrm{m}$ and $4.16 \mu \mathrm{m}$ diameter polystyrene latex beads containing Dragon Green fluorescent dye (Bangs Laboratories, Fishers, IN). First, the standard curve of fluorescent polymer beads solution concentration vs. fluorescence was obtained by plotting a known concentration vs. fluorescence obtained with a Synergy Mx monochromator-based multi-mode microplate reader (Winooski, VT) at $480 \mathrm{~nm}$ excitation and $520 \mathrm{~nm}$ emission wavelengths. Then, a $2 \mathrm{ppm}$ bead solution was prepared, and $1 \mathrm{ml}$ of the beads solution was filtered with each different HTCC electrospun nanofiber mat by vacuum suction. The concentration of the polystyrene latex beads solution was determined before and after filtration, and the percent removal of the beads was calculated. 


\subsubsection{Virus removal assessment}

To assess virus removal, PPV strain NADL-2 and porcine kidney-13 (PK-13) cells were a gift from Dr. Ruben Carbonell, North Carolina State University. The MTT assay (Heldt et al. 2006; Tafur et al. 2013) was performed to determine the virus removal result of the electrospun HTCC-PVA membranes. The MTT assay is a colorimetric cell viability method, based on the reaction of MTT agent (thiazolyl blue tetrazolium bromide) with the mitochondria of metabolically active cells (Heldt et al. 2006).

\subsubsection{Cell propagation and virus titration}

The PK-13 cells were propagated in $75 \mathrm{~cm}^{2}$ flasks at $37^{\circ} \mathrm{C}, 5 \% \mathrm{CO}_{2}$ and $100 \%$ humidity. A confluent flask of cells were washed with $3 \mathrm{ml}$ of PBS and detached with 3 $\mathrm{ml}$ of trypsin. Then $3 \mathrm{ml}$ of completed medium which was supplemented with $10 \% \mathrm{FBS}$ and $1 \%$ penicillin-streptomycin was added. The mixed cells, medium and trypsin were centrifuged by a ST 16R Centrifuge (Thermo Scientific, Asheville, NC) at $1500 \mathrm{rpm}$ for 3 min at $19^{\circ} \mathrm{C}$ to separate the cells. The supernatant was removed, and $5 \mathrm{ml}$ of completed medium was added and mixed up with cells (for the split ratio 1:5). Finally, $1 \mathrm{ml}$ of cells was added to the flask containing $15 \mathrm{ml}$ of completed medium. PK-13 cells were propagated every 3-4 days.

The virus was titrated with the MTT assay (Tafur et al. 2013). The PK-13 cells were seeded into 96-well cell culture plates at a concentration of $8 \times 10^{4}$ cell $/ \mathrm{ml}$ and 100 $\mu \mathrm{l} /$ well. After $24 \mathrm{~h}$, the plates were infected by adding $25 \mu \mathrm{l} /$ well of PPV solution to the first column of wells in quadruplicates. 5-fold serial dilutions across the entire plate were made by mixing the virus solution and medium together by pipetting up and down at least 5 times with an 8-channel pipette, and $25 \mu \mathrm{l}$ was transferred from each well to the next column with fresh tips. The extra $25 \mu \mathrm{l}$ from the last column of wells was removed so that all of the wells had $100 \mu \mathrm{l}$ in them. The plates were returned to the incubator. Controls containing only cells and medium, as well as 6 logs (MTT/ml) of PPV solution were conducted every time. After 5 days incubation, $10 \mu \mathrm{l} / \mathrm{well}$ of $5 \mathrm{mg} / \mathrm{ml} \mathrm{MTT}$ salt in PBS was added to all of the plates, and the plates were returned to the incubator. After 4 $\mathrm{h}, 100 \mu \mathrm{l} /$ well of solubilizing agent $(0.01 \mathrm{M} \mathrm{HCl}$ with $10 \%(\mathrm{w} / \mathrm{v}) \mathrm{SDS}$ in water) was added. The plates were incubated at $37^{\circ} \mathrm{C}$ overnight and read on a Synergy $\mathrm{Mx}$ monochromator-based multi-mode microplate reader (Winooski, VT) at $550 \mathrm{~nm}$. The virus titer, determined to be the virus dilution that reduced the cells density to $50 \%$ of the control cells, was defined as the $\mathrm{MTT}_{50}$.

The LRV was used to determine the amount of virus that adsorbed to the nanofibers and is found in equation 2.1. 


\subsubsection{Sample preparation and virus infection}

Both the Fresh HTCC-PVA electrospun nanofibers without crosslinking and the HTCC-PVA electrospun nanofibers crosslinked with glutaraldehyde vapor were assessed for virus removal with an MTT assay. PPV was contacted with HTCC-PVA nanofibers with either incubation or filtration.

For incubation, 1 layer of $0.5024 \mathrm{~cm}^{2}$ punched filter paper with HTCC-PVA nanofibers was placed into a $1.5 \mathrm{ml}$ non-stick surface micro-centrifuge tube contained $500 \mu 1$ of $6 \operatorname{logs}(\mathrm{MTT} / \mathrm{ml})$ (unless otherwise stated) of PPV in water. One layer of the same size of punched blank filter paper was also put into a separate tube as a control. Tubes containing fibers and blank were rotated for $10 \mathrm{~min}$ (unless otherwise stated) on a Roto-shake Genie rocker (Scientific Industries Inc., Bohemia, NY). Then, the nanofibers were taken out of the tubes, and the virus solutions after incubation were centrifuged for $30 \mathrm{~min}$ at the speed of $14000 \mathrm{rpm}$ to remove the suspected remaining fibers in the tubes. The supernatant was removed and tested with the MTT assay (Section 3.3.5.1) to determine the concentration of infectious virus.

For filtration, 5 layers (unless otherwise stated) of $0.3167 \mathrm{~cm}^{2}$ punched filter paper with HTCC-PVA nanofibers was placed into one well of a 96-well filter plate (1.0 $\mu \mathrm{m}$ pore size) (Pall Corporation, Ann Arbor, MI). Five layers of the same size of punched blank filter paper was also put into one well as a control. Then $500 \mu$ of $6 \operatorname{logs}(\mathrm{MTT} / \mathrm{ml})$ of PPV in water was added to each well and was incubated for $1 \mathrm{~min}$. Afterwards the filter plate was centrifuged at the force of $400 \times \mathrm{g}$ for $10 \mathrm{~min}$. The virus solutions after filtration were tested with the MTT assay (Section 3.3.5.1) to determine the concentration of infectious virus. 


\section{Results and Discussion}

\subsection{HTCC nanofibers without crosslinking}

\subsubsection{Characterization of HTCC}

HTCC, was prepared by the reaction of chitosan with GTMAC in an aqueous solution. As shown in Figure 3.1, the primary amine group in chitosan was modified to a quaternary ammonium salt group in HTCC. To confirm the successful synthesis of HTCC, FTIR spectra and NMR spectra of chitosan and HTCC are shown in Figure 4.1 and Figure 4.2, respectively. Figure 4.1 shows that a new peak at $1478 \mathrm{~cm}^{-1}$, representing the $\mathrm{C}-\mathrm{H}$ bending of trimethylammonium group can be found in HTCC. It should also be noted that the peak at $1590 \mathrm{~cm}^{-1}$ in chitosan, which is the $\mathrm{N}-\mathrm{H}$ bending of the primary amine, disappeared in HTCC due to the change of primary amine in chitosan to secondary amine in HTCC. The evidence of successful introduction of the quaternary ammonium salt group on chitosan backbone is further verified by NMR spectra, shown in Figure 4.2. A strong peak at $3.1 \mathrm{ppm}$, assigned to the methyl groups in the quaternary ammonium side chains, appeared in the HTCC. Both the results of FTIR and NMR spectra are in agreement with the previous reports (Deng et al. 2012; Lim and Hudson 2004; Xiao et al. 2012).

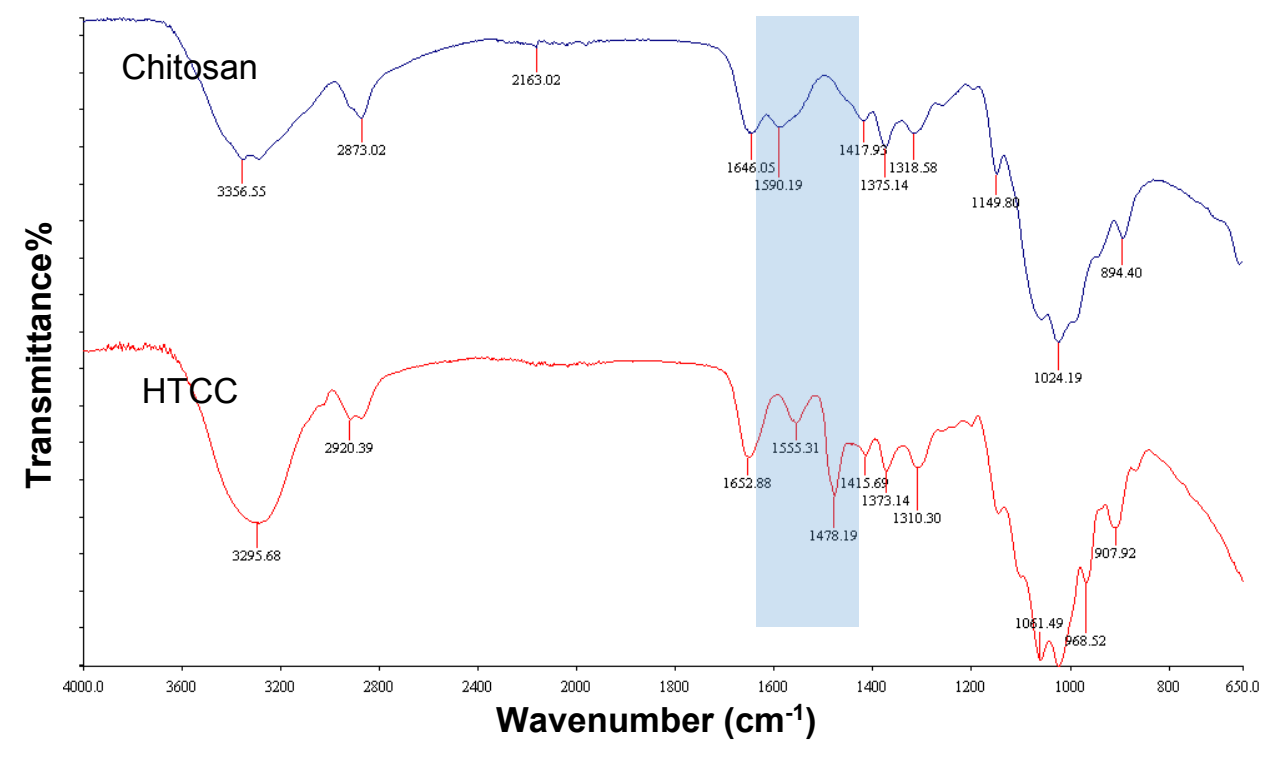

Figure 4.1 FTIR spectra of chitosan and HTCC. 
A
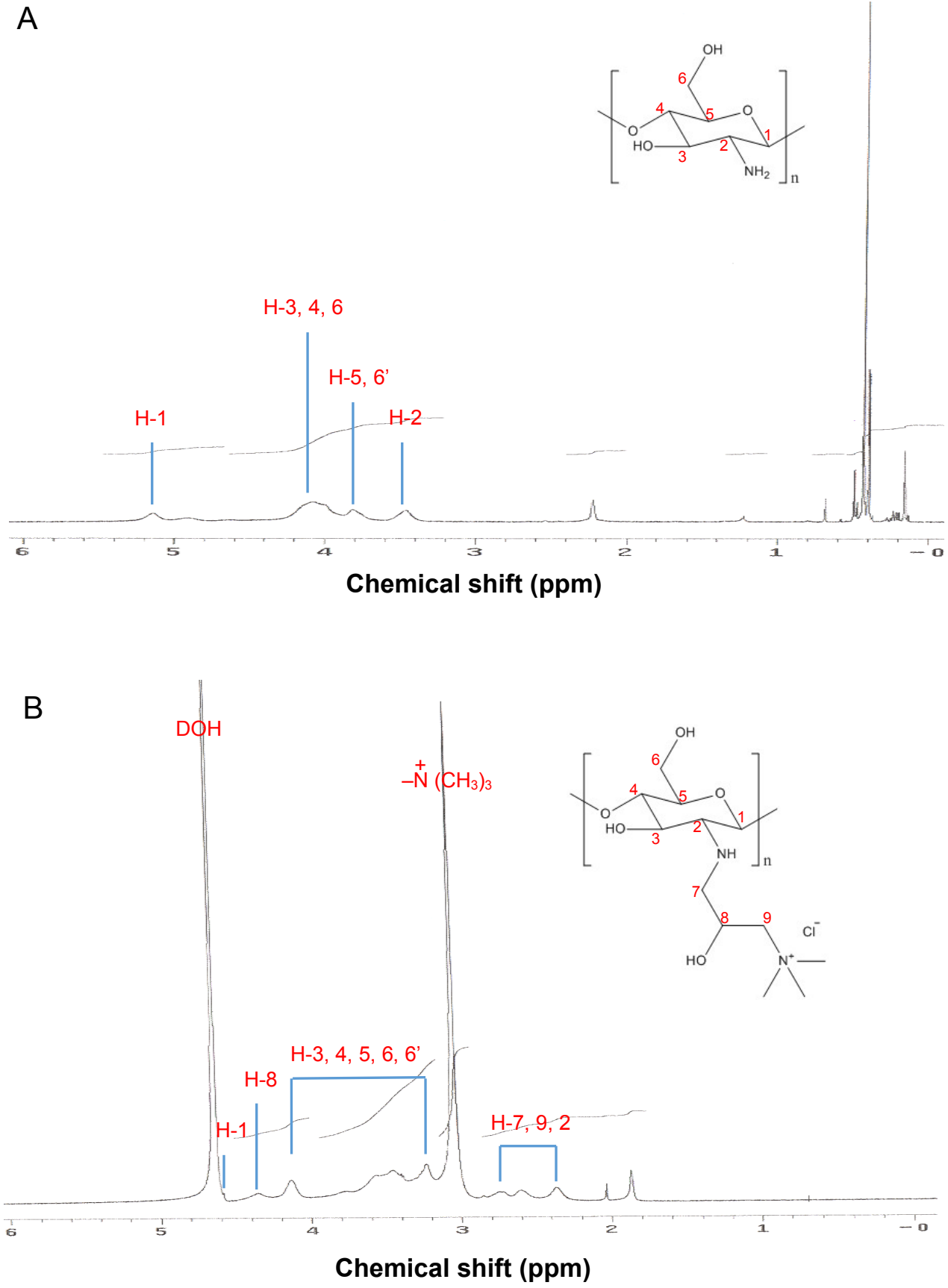

Figure 4.2 ${ }^{1} \mathrm{H}$ NMR spectra chitosan and HTCC. (A) Chitosan ( $\left.\mathrm{c}=5 \mathrm{mg} / \mathrm{ml}\right)$ was dissolved in $\mathrm{CF}_{3} \mathrm{COOD}$. (B) $\mathrm{HTCC}(\mathrm{c}=10 \mathrm{mg} / \mathrm{ml})$ was dissolved in $\mathrm{D}_{2} \mathrm{O}$.

The calculated DQ of HTCC was $76.4 \pm 4.3 \%$, based on titration of three separate batches of HTCC aqueous solution and three titrations for each batch. This DQ value 
demonstrates that the majority of the amino groups on chitosan were substituted by quaternary ammonium salt groups.

\subsubsection{Electrospinning of HTCC solution}

Pure HTCC solution failed to be electrospun into nanofibers over a concentration range (from 5 to $10 \%(\mathrm{w} / \mathrm{v})$ ). This could be attributed to its high repelling interaction between ionogenic groups of HTCC (Deng et al. 2012). Viscosity is a principal rheological property to impact the electrospinning process due to its relationship to the polymer molecule chain entanglement of the solution. In general, there is a critical viscosity for a solution to form fibers. Below this critical viscosity, beads or droplets, instead of fibers, are typically formed on the collector. The beads are likely caused by low chain entanglements that cannot stabilize the Coulombic repulsive forces within the ejected jet. Thus, the viscosity of pure HTCC solution was studied and shown in Figure 4.3. The result shows that the viscosity of HTCC increased with the increase of HTCC concentration in solution. In addition to viscosity, HTCC is a cationic polysaccharide, ionizable in neutral aqueous solution, thus the repelling interaction between ionogenic groups could affect fiber formation in the electrospinning process (Alipour et al. 2009).

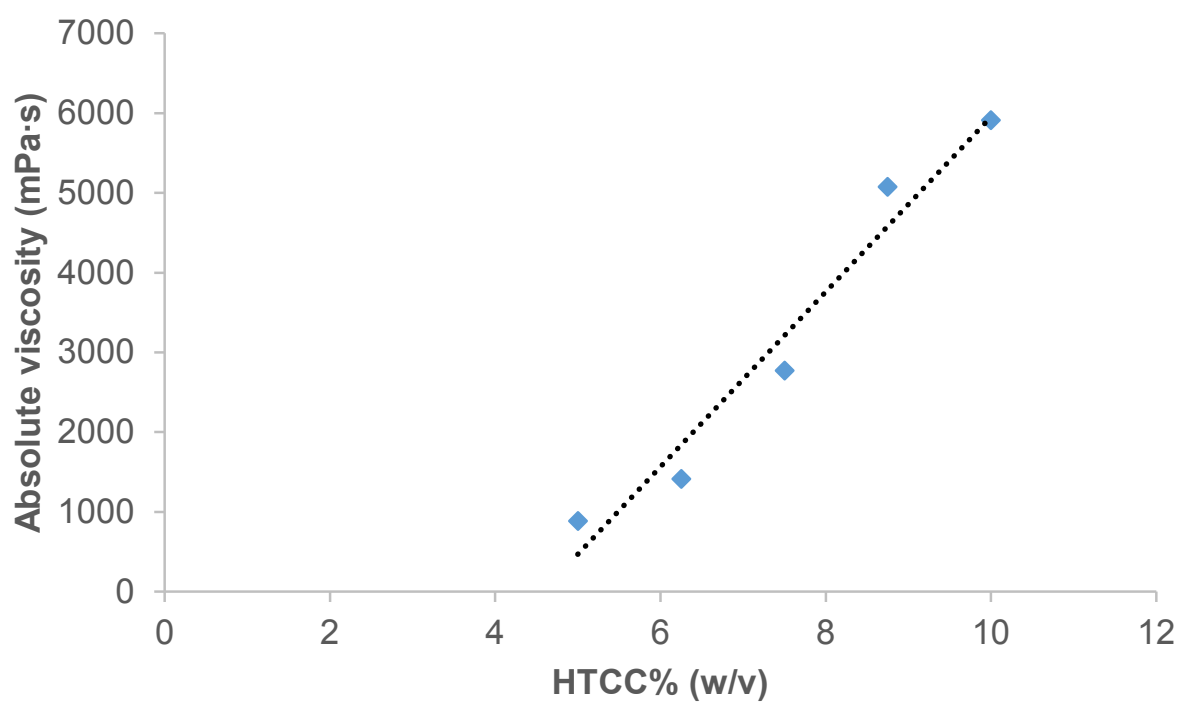

Figure 4.3 Viscosity of pure HTCC aqueous solution

To aid the fiber formation of HTCC, various additives (graphene, SDS and PVA) at different weight ratios (HTCC: additive 9:1 and 8:2) were added into the HTCC solution at room temperature, making the total polymer concentrations in mixed solution ranging from 7.5 to $15 \%$. A selected viscosity of HTCC-graphene mixed solution of different compositions was tested and shown in Figure 4.4. In order to repeat the 
successful electrospinning of HTCC-graphene mixed solutions, we tried to change the concentrations and ratios to obtain the same viscosity $(2980 \mathrm{mPa} \cdot \mathrm{s})$ and conductivity $(6.01 \mathrm{mS} / \mathrm{cm})$ of $10 \%$ of HTCC: graphene (9:1) solution as reported (Bai 2012).

However, our attempts to obtain defect-free nanofibers from HTCC-additive (graphene, SDS and PVA) mixed solution prepared at room temperature were unsuccessful and the selected results of electrospinning are shown in Figure 4.5. Only fluffy fibers of the support layer filter paper and a few polymer beads (panel A) can be observed from the SEM images. This is possibly due to the high content of HTCC in the mixed solution resulting in high repulsive forces existing between the ionogenic groups of polyelectrolytes.

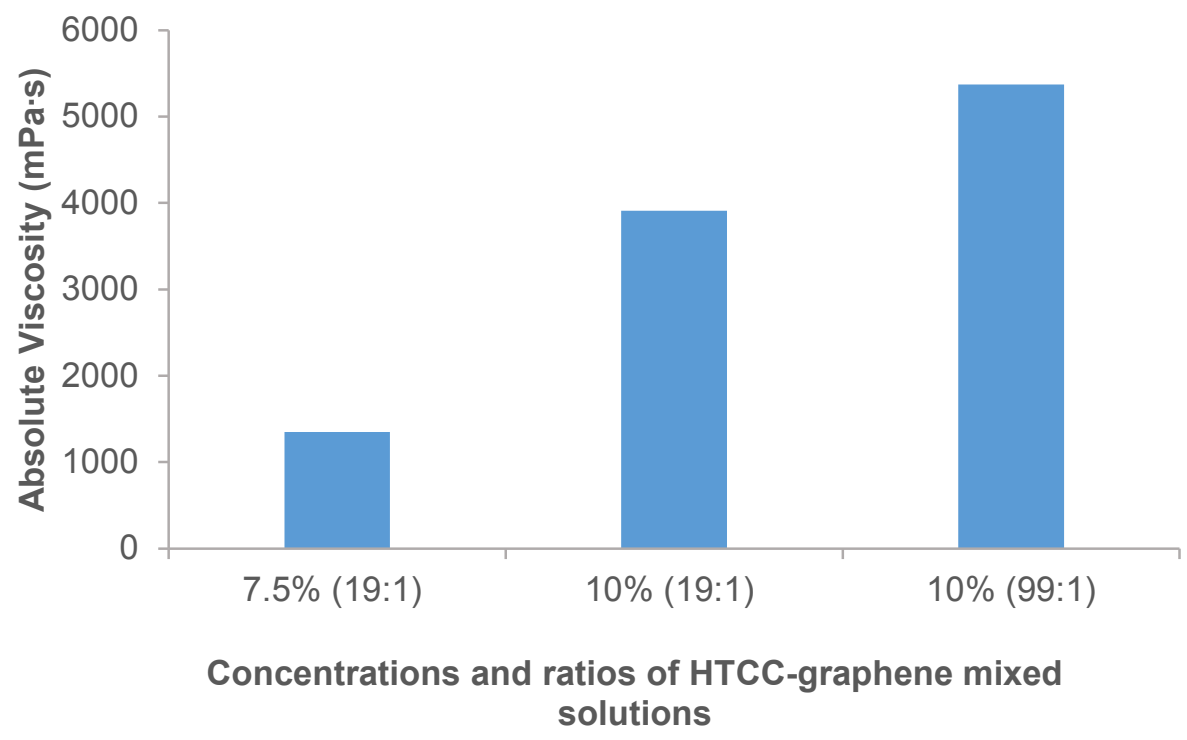

Figure 4.4 Viscosity of HTCC-graphene mixed solution of different compositions 

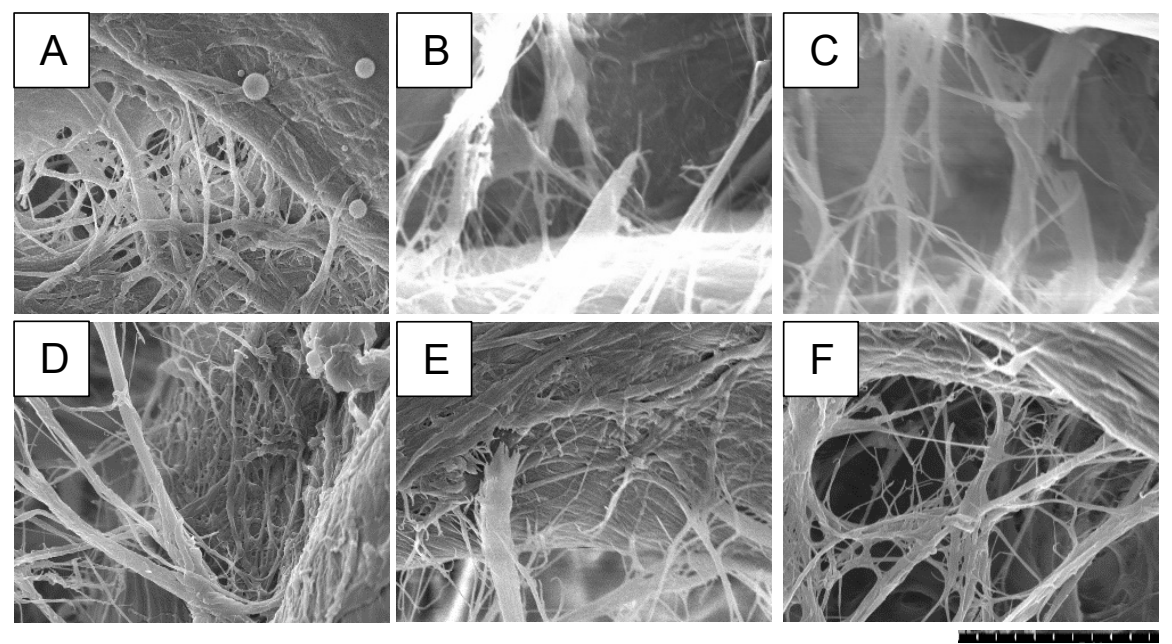

$5 \mu \mathrm{m}$

Figure 4.5 SEM-micrographs of electrospun different concentrations of HTCC-additive mixed solution of different compositions. (A) 10\% (w/v) of HTCC: PVA 8:2, (B) 15\% (w/v) of HTCC: SDS 9:1, (C) 15\% (w/v) of HTCC: graphene 9:1, (D) 12\% (w/v) of HTCC: graphene 9:1, (E) 10\% (w/v) of HTCC: graphene 19:1, (F) blank filter paper. The applied voltage was $20 \mathrm{kV}$, tip-to-collector distance was $10 \mathrm{~cm}$, feed rate was $7.5 \mathrm{ml} / \mathrm{h}$ and rotation speed of drum collector was $1500 \mathrm{rpm}$.

After several trials, PVA was chosen as a suitable non-ionogenic partner for producing electrospun HTCC nanofibers. The additive PVA solution was heated at $85^{\circ} \mathrm{C}$ for $5 \mathrm{~h}$ to increase the solubility of the PVA. The HTCC-PVA blend electrospinning solutions (from $30 \%(\mathrm{w} / \mathrm{v})$ HTCC to $70 \%(\mathrm{w} / \mathrm{v}) \mathrm{HTCC}$ in a total $10 \%(\mathrm{w} / \mathrm{v})$ polymer concentration) were electrospun. As shown in Figure 4.6, obvious smooth nanofibers were obtained at an HTCC-PVA content of 3:7 (Figure 4.6A) and the fiber formation ability was decreased with the increase of HTCC content. PVA was added to improve fiber formation, and was likely able to moderate the high repulsion force between HTCC molecules (Ignatova et al. 2006). PVA is also known to easily form fibers and films (Ignatova et al. 2006). The average diameters of the electrospun HTCC-PVA nanofibers were in the range of $84 \mathrm{~nm}$ to $113 \mathrm{~nm}$ and a decrease in the average diameter of nanofibers with the increase of HTCC content in blend solution was observed in Figure 4.7. Obviously, the content of polyelectrolyte had a significant effect on the morphology and average diameter distribution of electrospun fibers.

The viscosity and conductivity of HTCC-PVA blend solution is shown in Figure 4.8. The result shows that the viscosity and conductivity increased linearly with an increase in HTCC content. This result of viscosity is in accordance with the previous result that an increase in viscosity was found with an increase in HTCC in Figure 4.3 and 4.4. For the conductivity, it should increase with an increase in content of polyelectrolyte HTCC; thus more mutual charge repulsion within the jet can stretch the 
jet further and reduce the fiber diameter (Alipour et al. 2009). Improving chain entanglement because of increase of viscosity, could induce a higher resistance towards orientation by stretching forces applied during electrospinning process to increase fiber ability (Duan et al. 2004). However, too high viscosity to a point where the flow through the capillary is obstructed may again lower the fiber formation ability (Duan et al. 2004).
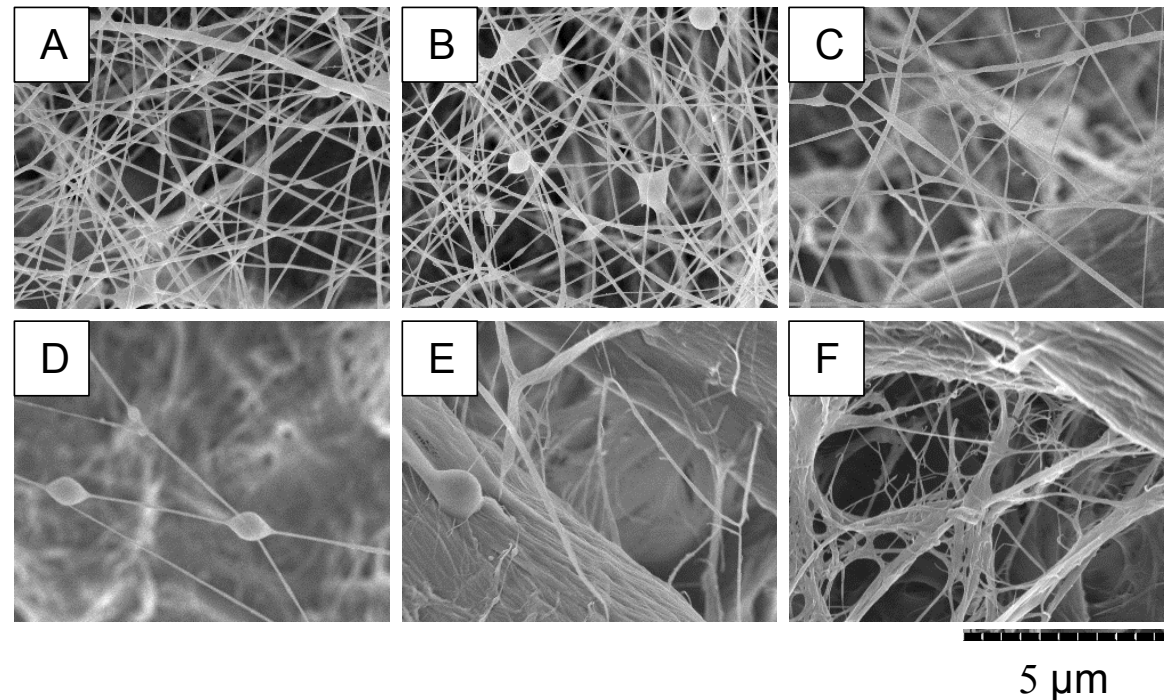

Figure 4.6 SEM-micrographs of 10\% (w/v) HTCC-PVA nanofibers of different compositions. Mass ratios of HTCC: PVA was (A) 3:7, (B) 4:6, (C) 5:5, (D) 6:4, (E) 7:3. (F) Blank filter paper. The applied voltage was $20 \mathrm{kV}$, tip-to-collector distance was $5 \mathrm{~cm}$, feed rate was $4.5 \mathrm{ml} / \mathrm{h}$, rotation speed of drum collector was $1500 \mathrm{rpm}$ and volume of electrospinning solution was $2 \mathrm{ml}$. 


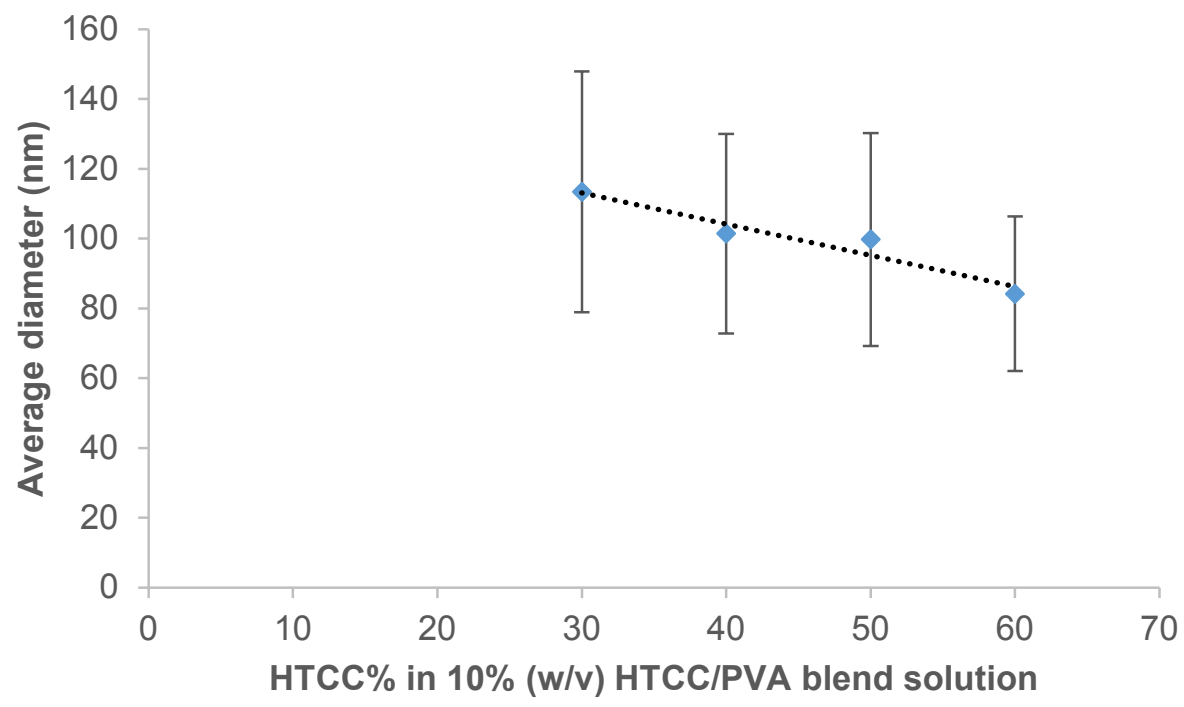

Figure 4.7 Average diameter distribution of 10\% (w/v) HTCC-PVA nanofibers of different compositions. The applied voltage was $20 \mathrm{kV}$, tip-to-collector distance was 5 $\mathrm{cm}$, feed rate was $4.5 \mathrm{ml} / \mathrm{h}$, rotation speed of drum collector was $1500 \mathrm{rpm}$ and volume of electrospinning solution was $2 \mathrm{ml}$. Error bars are the standard deviation of 150 fibers measured.

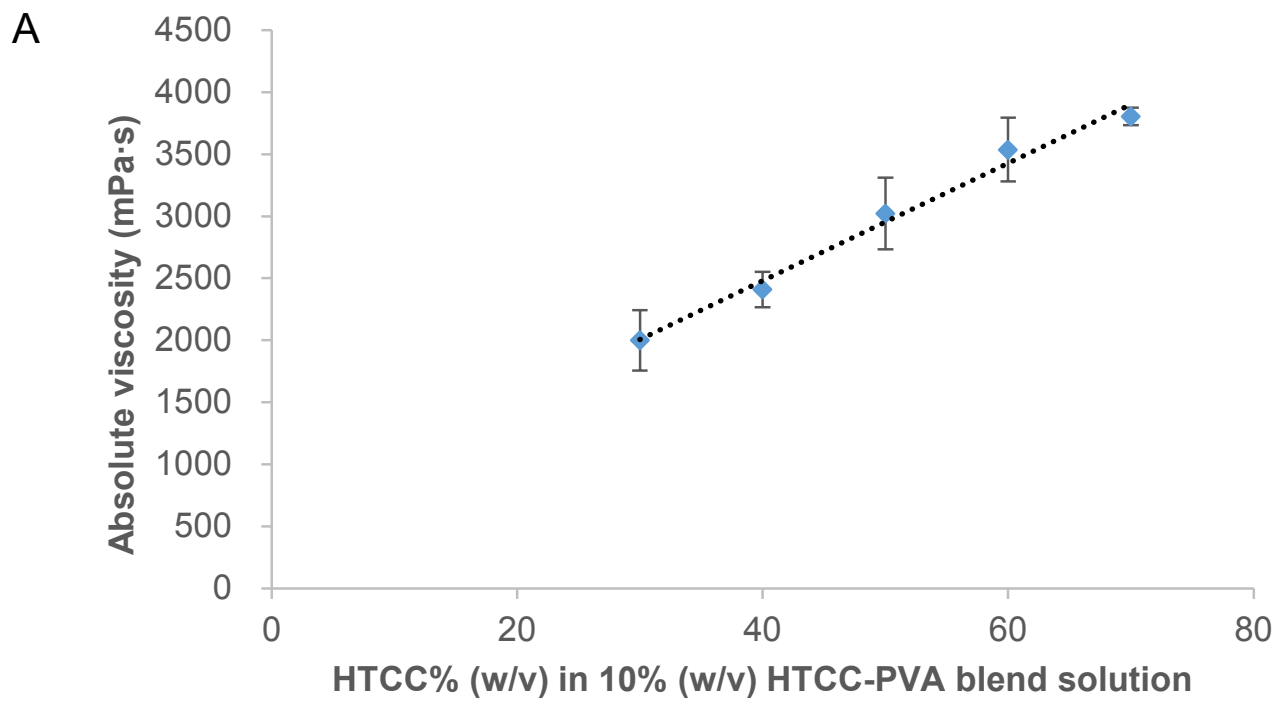




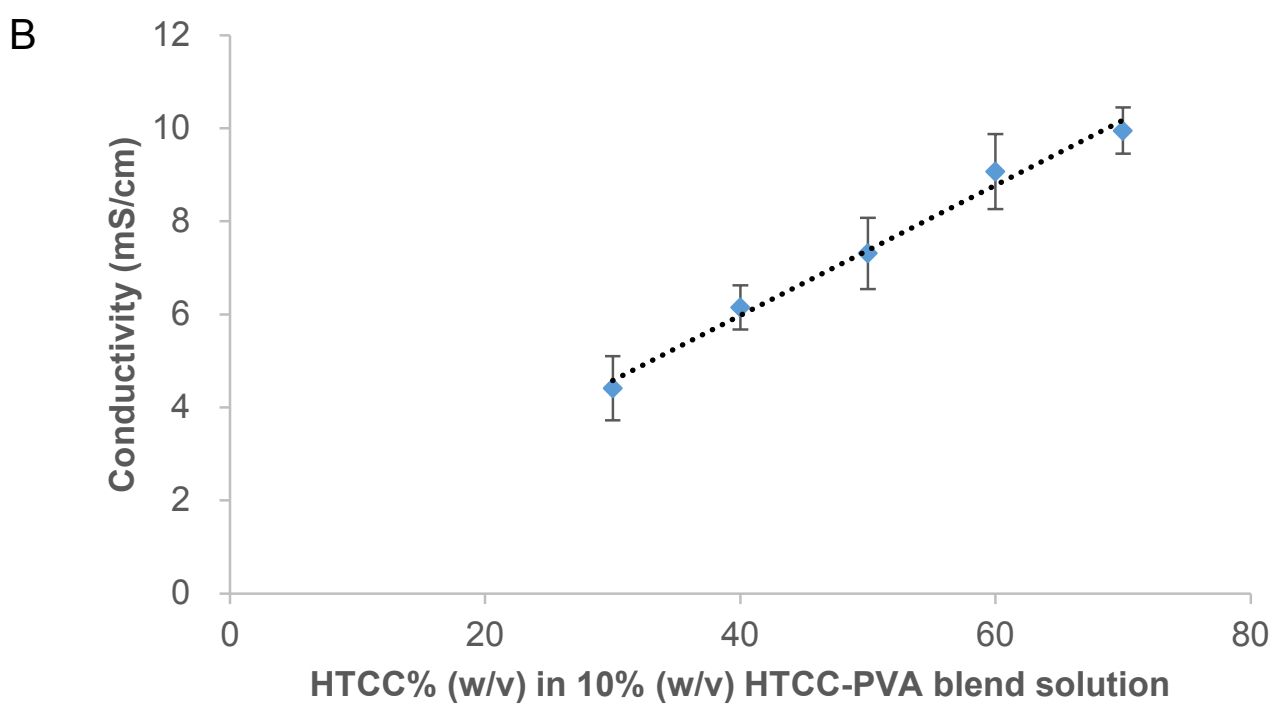

Figure 4.8 Viscosity and conductivity of 10\% (w/v) HTCC-PVA blend solution of different compositions. (A) Viscosity, (B) Conductivity. Error bars are the variance of two separate tests.

\subsubsection{Virus removal assessment}

To determine the virus removal ability of the electrospun HTCC-PVA membranes, PPV, one of the smallest known mammalian viruses, is used as a model virus in the virus clearance study. We chose PPV as our model virus since it is difficult to inactivate by chemical and heat treatment (Kempf et al. 2007) and can be removed by only small pore-sized membrane which fouls easily and has high pressure drops (Furuya et al. 2006; Marques et al. 2009). The large pore-sized and functionalized membranes with a high surface to volume ratio that we are creating, which can increase water flux and decrease membrane fouling, is hypothesized to remove viruses by adsorption.

Fresh HTCC-PVA electrospun nanofibers without crosslinking were assessed for virus removal with an MTT assay (Tafur et al. 2013). After a 10 min incubation with PPV, one group was centrifuged to remove fibers suspected to suspend in virus solution and the other was not. Both of the supernatant virus solutions were titrated and the virus removal is shown in Figure 4.9. The 40\% (w/v) HTCC sample after centrifugation showed the highest virus removal at $85 \%$. The centrifuged group showed a higher virus removal result, possible due to the virus along with remaining fibers was precipitated to the bottom of the centrifuge tube while the supernatant was titrated. Centrifuged $40 \%$ $(\mathrm{w} / \mathrm{v})$ of HTCC sample showed a higher virus removal result than $50 \%(\mathrm{w} / \mathrm{v})$ or $60 \%$ $(\mathrm{w} / \mathrm{v})$ is possibly because of more fiber formation at this ratio compared with the other two ratios. $30 \%(\mathrm{w} / \mathrm{v})$ of HTCC in electrospinning solution showed a similar fiber 
formation ability as the $40 \%(\mathrm{w} / \mathrm{v})$ solution in Figure 4.6, but the HTCC content is likely too low to bind virus. In addition, the filter paper could bind $29 \%$ (highest) of the virus. All of the electrospun samples were able to bind greater than $29 \%$ of the virus, therefore it was assumed that the additional virus binding was due to the electrospun HTCC-PVA nanofibers.

From this virus removal result, the best condition can be obtained as $40 \%(\mathrm{w} / \mathrm{v})$ of HTCC in total $10 \%(\mathrm{w} / \mathrm{v})$ HTCC-PVA nanofibers with centrifugation after the incubation step.

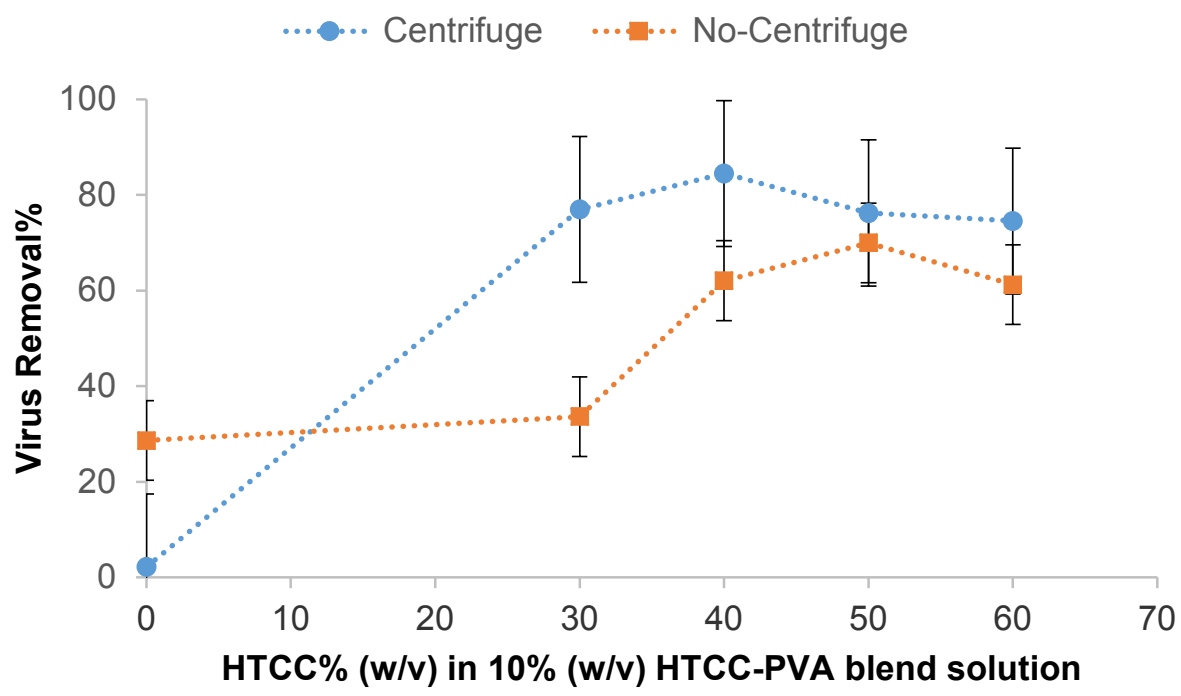

Figure 4.9 Virus removal of 10\% (w/v) HTCC-PVA nanofibers of different compositions. The applied voltage was $20 \mathrm{kV}$, tip-to-collector distance was $5 \mathrm{~cm}$, feed rate was $4.5 \mathrm{ml} / \mathrm{h}$, rotation speed of drum collector was $1500 \mathrm{rpm}$ and volume of electrospinning solution was $2 \mathrm{ml}$. The centrifuged group of virus solutions were centrifuged for $30 \mathrm{~min}$ at $14000 \mathrm{rpm}$ after incubation. The no-centrifuge group was titrated after incubation for $10 \mathrm{~min}$ without centrifugation. All data points are the average of three separate tests and error bars represent the standard deviation.

\subsection{Crosslinked HTCC-PVA nanofibers}

Although the fresh electrospun HTCC-PVA nanofibers showed a rather high virus removal result, there was a problem of stability of nanofibers against water to be solved since both HTCC and PVA are water-soluble. HTCC-PVA nanofibers readily dissolved when immersed in water, which will limit the application of the electrospun HTCC-PVA nanofibers in water. In order to retain their unique nanofibrous structure, several methods of crosslinking of electrospun HTCC-PVA nanofibers have been performed. 


\subsubsection{Characterization of the crosslinked HTCC-PVA nanofibers}

\subsubsection{Photo-mediated, maleic acid and glutaraldehyde solution crosslinking}

Our attempts to crosslink the HTCC-PVA electrospun nanofibers with photocrosslinker, maleic acid and glutaraldehyde solution was unsuccessful and the results are shown in Figure 4.10. The photo-mediated crosslinked HTCC-PVA nanofibers started dissolving after water contact (Figure 4.10D). Compared with the successful report of photo-mediated crosslinking (Ignatova et al. 2006), the power of the UV-lamp in our lab was lower, which may be the possible reason that led to the failure in the experiment due to lack of enough energy to initiate the photo-crosslinking reaction. Similarly, the maleic acid crosslinked HTCC-PVA nanofibers started dissolving when filtered with water (Figure 4.10E). It was probably due to the low $\mathrm{pH}$ value already below 1 without adding catalyst sulfuric acid in our experiment, compared with the successful reported $\mathrm{pH}$ value of maleic acid crosslinked PVA electrospinning solution within 5 (Han et al. 2003; Qin and Wang 2008). Less maleic acid and several drops of $10 \%(\mathrm{w} / \mathrm{w})$ sodium hydroxide solution were added to adjust the $\mathrm{pH}$ value, but no further improvement of the result was found. For the glutaraldehyde solution, the HTCC-PVA electrospun nanofibers were immersed in $10 \%$ (v/v) glutaraldehyde aqueous solution (Mello et al. 2006) and the fibers dissolved before they reacted with the glutaraldehyde, as shown in Figure 4.10C. 


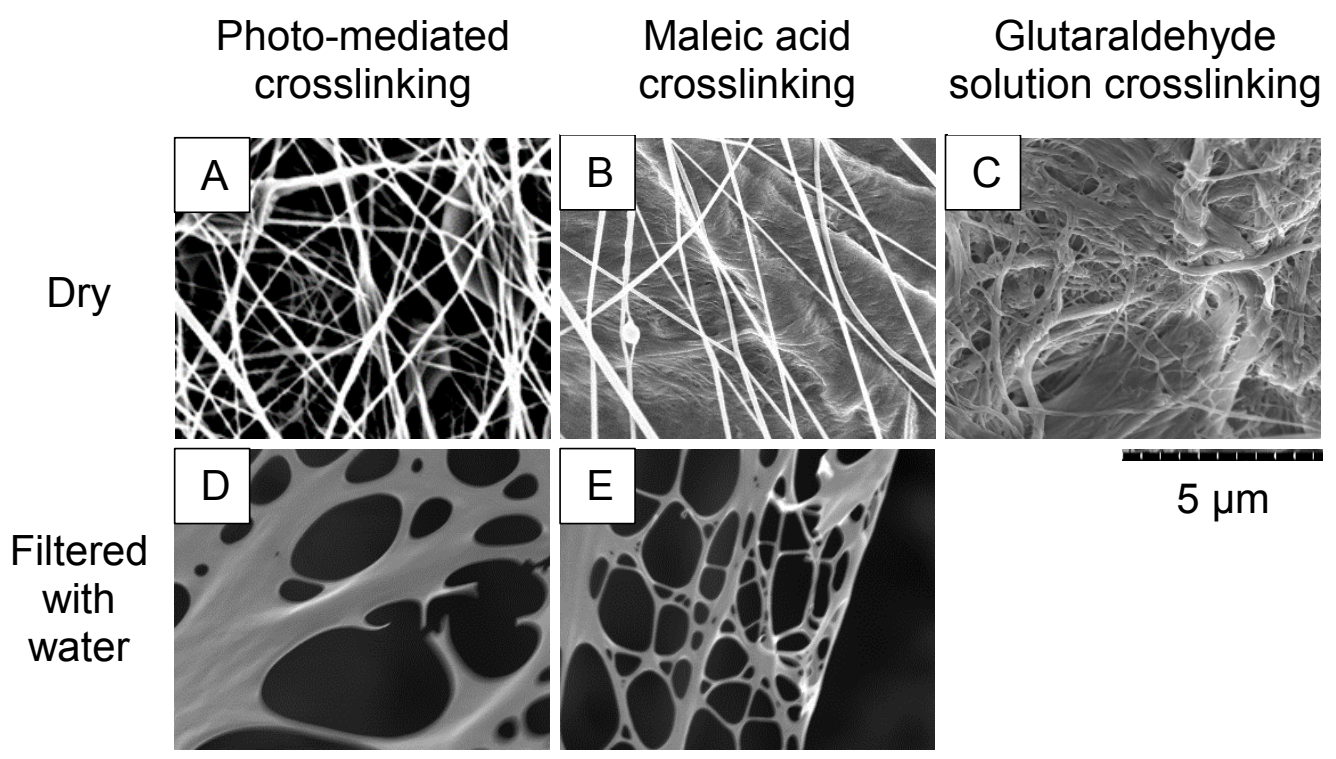

Figure 4.10 SEM-micrographs of 10\% (w/v) 3:7 HTCC-PVA nanofibers of different crosslinking methods. (A) Photo-mediated crosslinked nanofibers, (B) maleic acid crosslinked nanofibers, (C) glutaraldehyde solution crosslinked sample, (D) filtered sample A, (E) filtered sample B. The applied voltage was $20 \mathrm{kV}$, tip-to-collector distance was $5 \mathrm{~cm}$, feed rate was $4.5 \mathrm{ml} / \mathrm{h}$, rotation speed of drum collector was $1500 \mathrm{rpm}$ and volume of electrospinning solution was $3 \mathrm{ml}$.

\subsubsection{Glutaraldehyde vapor crosslinking}

In order to treat the HTCC-PVA nanofibers with glutaraldehyde before contacting the fibers with water, glutaraldehyde vapor (Alipour et al. 2009) was used. In order to obtain the best crosslinking condition for fibers, different crosslinker concentration and crosslinking time was performed and the result is shown in Figure 4.11. To determine the stability of crosslinked HTCC-PVA nanofibers against water, they were filtered with water and were immersed in water for $10 \mathrm{~min}$.

The control samples Figure 4.11P, $\mathbf{Q} \& \mathbf{R}$ showed the fresh electrospun HTCCPVA nanofibers dissolving in water. For the uncrosslinked membrane, both the polymer of HTCC and PVA swells and the distance between any two polymer chains increases as the adsorbed water molecules increase (Han et al. 2003). Once the attractive forces between these two polymers chains is not sufficient to keep them together until a critical distance, the polymer will dissolve in water (Han et al. 2003).

To stabilize the fibers, glutaraldehyde vapor was used to crosslink the fibers. This gave the fibers stability in water since the aldehyde group of glutaraldehyde will react with the unbound hydroxyl groups of both the HTCC and PVA to form crystallizations 
zones (Young and Lovell 2011). Water caused fibers swelling in different degrees for all cases due to different degrees of crosslinking. Even the glutaraldehyde vapor slightly swell the fibers. As it shown in Figure 4.11G, H \& I, 30\% 4 h crosslinked fibers swell the least and seem like the most stable fibers when contacting with water within 10 min. This could also be confirmed in Figure 4.12, which graphically shows the diameter of the fibers. The diameters of 30\% $4 \mathrm{~h}$ crosslinked nanofibers (dry, filtration and immerse 10 $\mathrm{min}$ ) are the closest to the diameter of fresh electrospun nanofibers. Both $10 \% 4 \mathrm{~h}$ and $30 \% 2 \mathrm{~h}$ crosslinked fibers started dissolving when contacted with water for $10 \mathrm{~min}$ and some coalescence of fibers was observed in Figure 4.11A, B \& C and Figure 4.11M, N \& O. From Figure 4.11 and Figure 4.12, it could be noted that the fiber stability increased with the increase of crosslinker concentration and crosslinking time, due to the corresponding diameter decreased with the increase of crosslinker concentration and crosslinking time. In addition, the diameter of fibers increase with the increase of water contacting time as a result of the swelling of fibers due to adsorbing water.

To study the stability of the $30 \% 4 \mathrm{~h}$ crosslinked HTCC-PVA nanofibers against water, the membrane was immersed in water for different lengths of time within $6 \mathrm{~h}$. The morphology of the fibers is shown in Figure 4.13. The corresponding average fiber diameter distribution and the change of swelling degree calculated from fiber diameter are shown in Figure 4.14. It was found that 30\% $4 \mathrm{~h}$ crosslinked fibers kept their morphology and did not dissolve within $6 \mathrm{~h}$ of contact with water. The fibers swelled in water and the equilibrium swelling degree was approximately a $30 \%$ increase in diameter. 
Filtered

Immersed for

Dry

with water $10 \mathrm{~min}$ in water
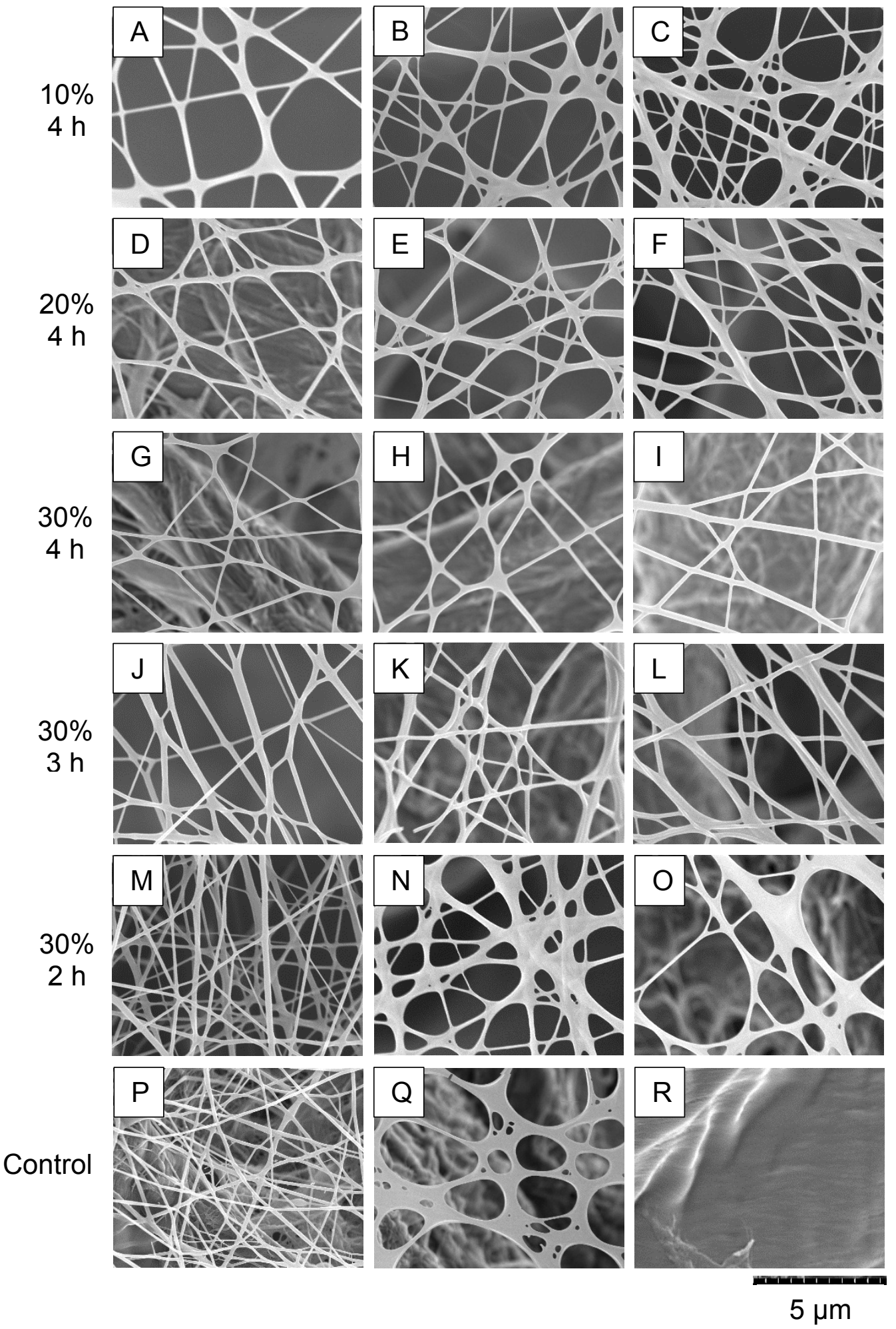
Figure 4.11 SEM-micrographs of 10\% (w/v) 4:6 glutaraldehyde vapor crosslinked HTCC-PVA nanofibers. Crosslinker concentration and crosslinking time with different treatment is (A) $10 \%$ h, (B) filtered sample A with water, (C) immersed sample A for 10 min in water; (D) $20 \% 4 \mathrm{~h}$, (E) filtered sample D with water, (F) immersed sample D for 10 min in water; $(\mathrm{G}) 30 \%$ 4h, (H) filtered sample $\mathrm{G}$ with water, (I) immersed sample $\mathrm{G}$ for $10 \mathrm{~min}$ in water; (J) $30 \% 3 \mathrm{~h}$, (K) filtered sample $\mathrm{J}$ with water, $(\mathrm{L})$ immersed sample $\mathrm{J}$

for 10 min in water; (M) $30 \% 2 \mathrm{~h}$, (N) filtered sample $\mathrm{M}$ with water, (O) immersed sample $\mathrm{M}$ for $10 \mathrm{~min}$ in water. (P) Fresh electrospun nanofibers without crosslinking, (Q) filtered sample $P$ with water, $(\mathrm{R})$ immersed sample $P$ for $10 \mathrm{~min}$ in water. The applied voltage was $20 \mathrm{kV}$, tip-to-collector distance was $5 \mathrm{~cm}$, feed rate was $4.5 \mathrm{ml} / \mathrm{h}$, rotation speed of drum collector was $1500 \mathrm{rpm}$ and volume of electrospinning solution was $3 \mathrm{ml}$.

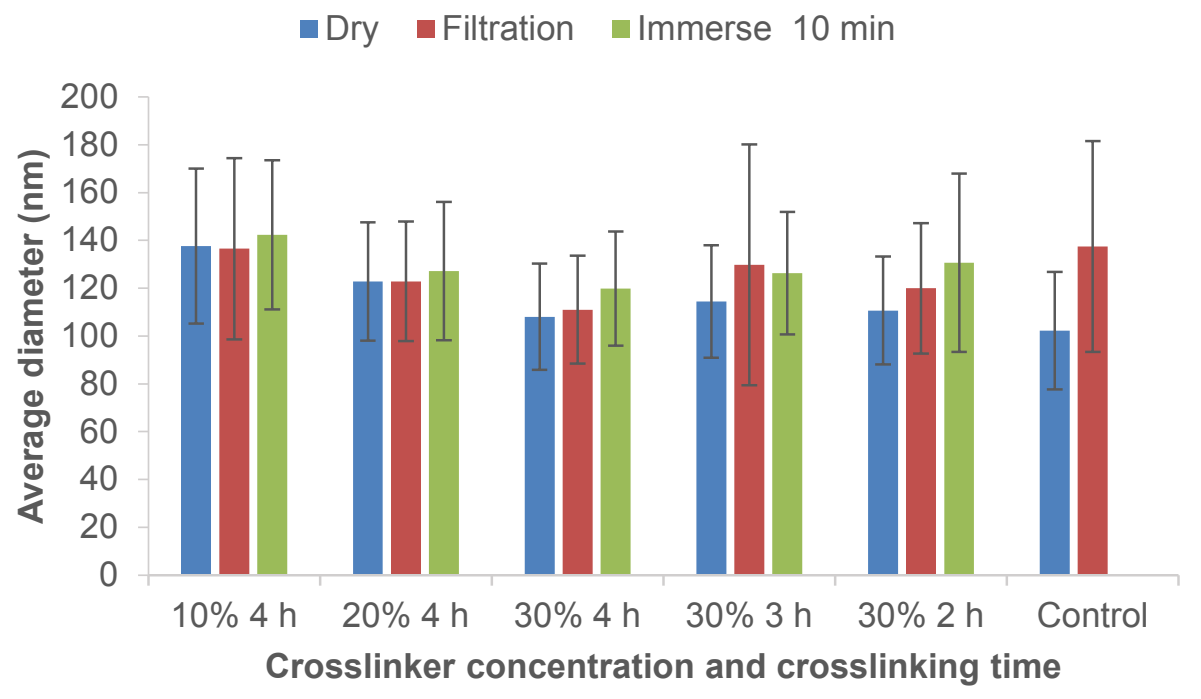

Figure 4.12 Average diameter distribution of $10 \%(\mathrm{w} / \mathrm{v})$ 4:6 glutaraldehyde vapor crosslinked HTCC-PVA nanofibers. The applied voltage was $20 \mathrm{kV}$, tip-to-collector distance was $5 \mathrm{~cm}$, feed rate was $4.5 \mathrm{ml} / \mathrm{h}$, rotation speed of drum collector was $1500 \mathrm{rpm}$ and volume of electrospinning solution was $3 \mathrm{ml}$. Error bars are the standard deviation of 300 fibers measured. 

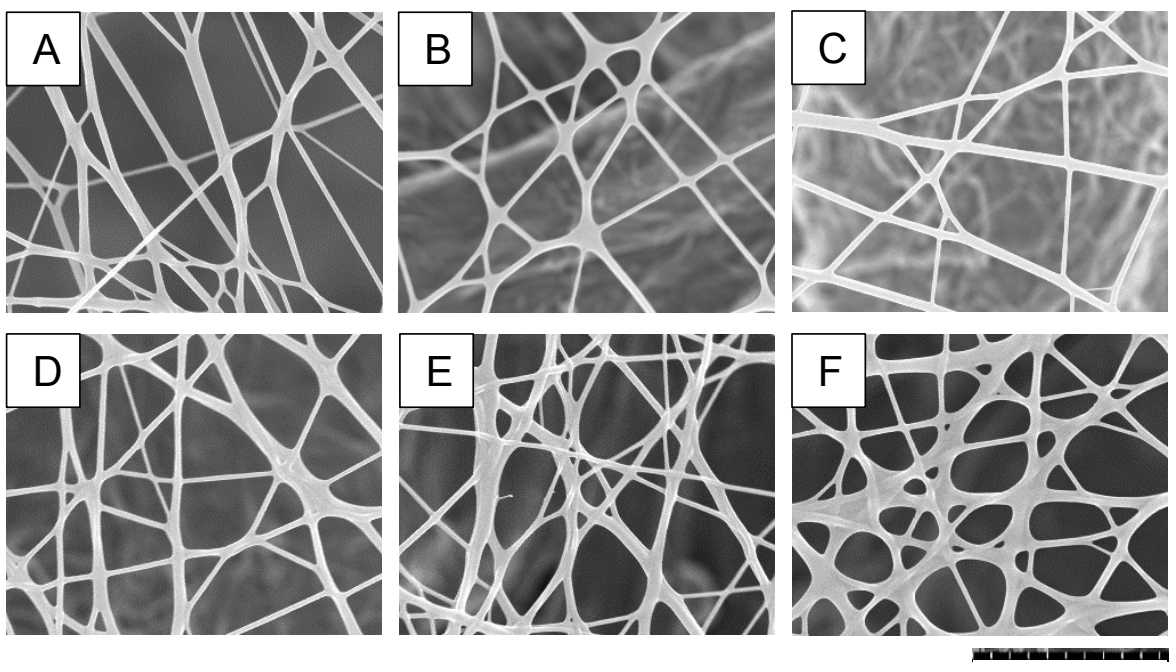

$5 \mu \mathrm{m}$

Figure 4.13 SEM-micrographs of 10\% (w/v) 4:6 30\% 4h glutaraldehyde vapor crosslinked HTCC-PVA nanofibers of different lengths of contact with water. (A) Dry crosslinked nanofibers, (B) filtered sample A with water, (C) immersed sample A for 10 min in water, (D) immersed sample A for $30 \mathrm{~min}$ in water, (E) immersed sample A for 60 min in water; (F) immersed sample A for $360 \mathrm{~min}$ in water. The applied voltage was 20 $\mathrm{kV}$, tip-to-collector distance was $5 \mathrm{~cm}$, feed rate was $4.5 \mathrm{ml} / \mathrm{h}$, rotation speed of drum collector was $1500 \mathrm{rpm}$ and volume of electrospinning solution was $3 \mathrm{ml}$. 


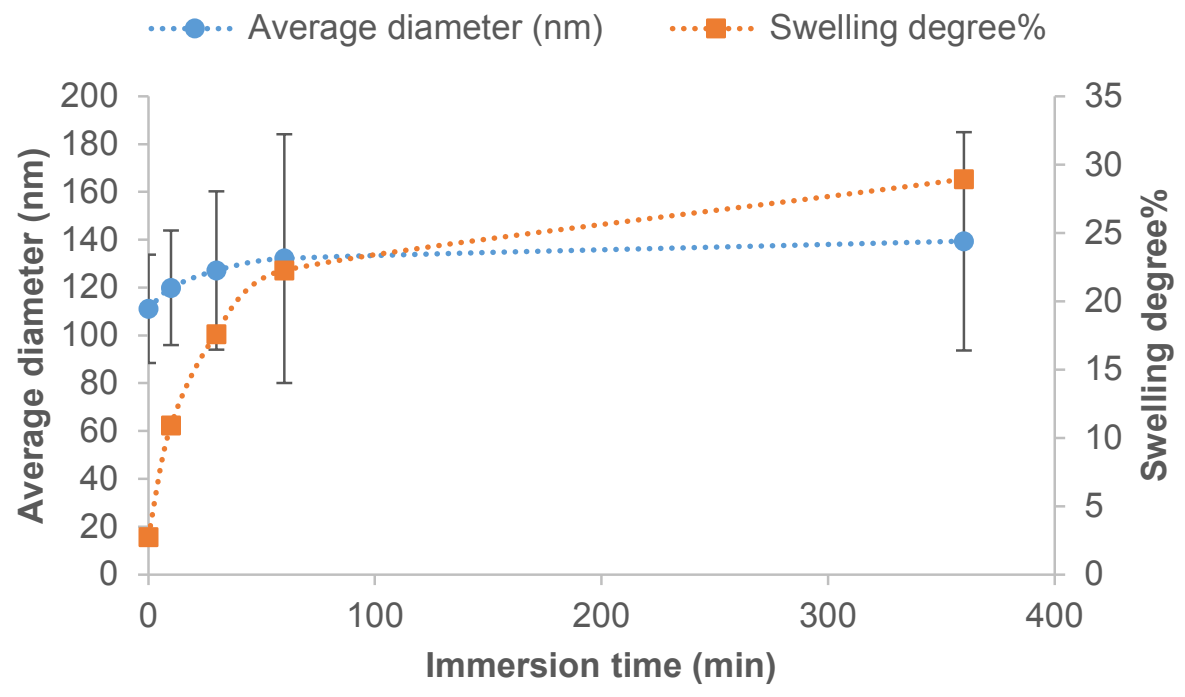

Figure 4.14 Average diameter distribution and swelling degree of 10\% (w/v) 4:6 30\% 4h glutaraldehyde vapor crosslinked HTCC-PVA nanofibers of different lengths of contact with water. The applied voltage was $20 \mathrm{kV}$, tip-to-collector distance was $5 \mathrm{~cm}$, feed rate was $4.5 \mathrm{ml} / \mathrm{h}$, rotation speed of drum collector was $1500 \mathrm{rpm}$ and volume of electrospinning solution was $3 \mathrm{ml}$. Error bars are the standard deviation of 150 fibers measured.

The effects of two key electrospinning parameters which are the applied voltage and the feed rate on fiber morphology were studied with the stable $30 \% 4 \mathrm{~h}$ crosslinked nanofibers. The fiber morphology was shown in Figure 4.15 and the fiber diameter distribution was shown in Figure 4.16. It could be found that the average diameters of nanofibers significantly decreased with an increase in the applied voltage, which is identical to the data found in the previous paper (Alipour et al. 2009; Ignatova et al. 2006). This is possibly because that an increase in the applied voltage will increase the charge density and the greater Coulombic repulsive forces causing the jet to accelerate faster and to stretch more (Lee et al. 2007). In addition, the average diameter of nanofibers obviously increased with an increase in the feed rate. This could be because of insufficient time available to allow for the electrospinning solution to evaporate resulting in fusing the fibers together at high feed rate, thereby formation of fibers with large diameters (Han et al. 2008). 


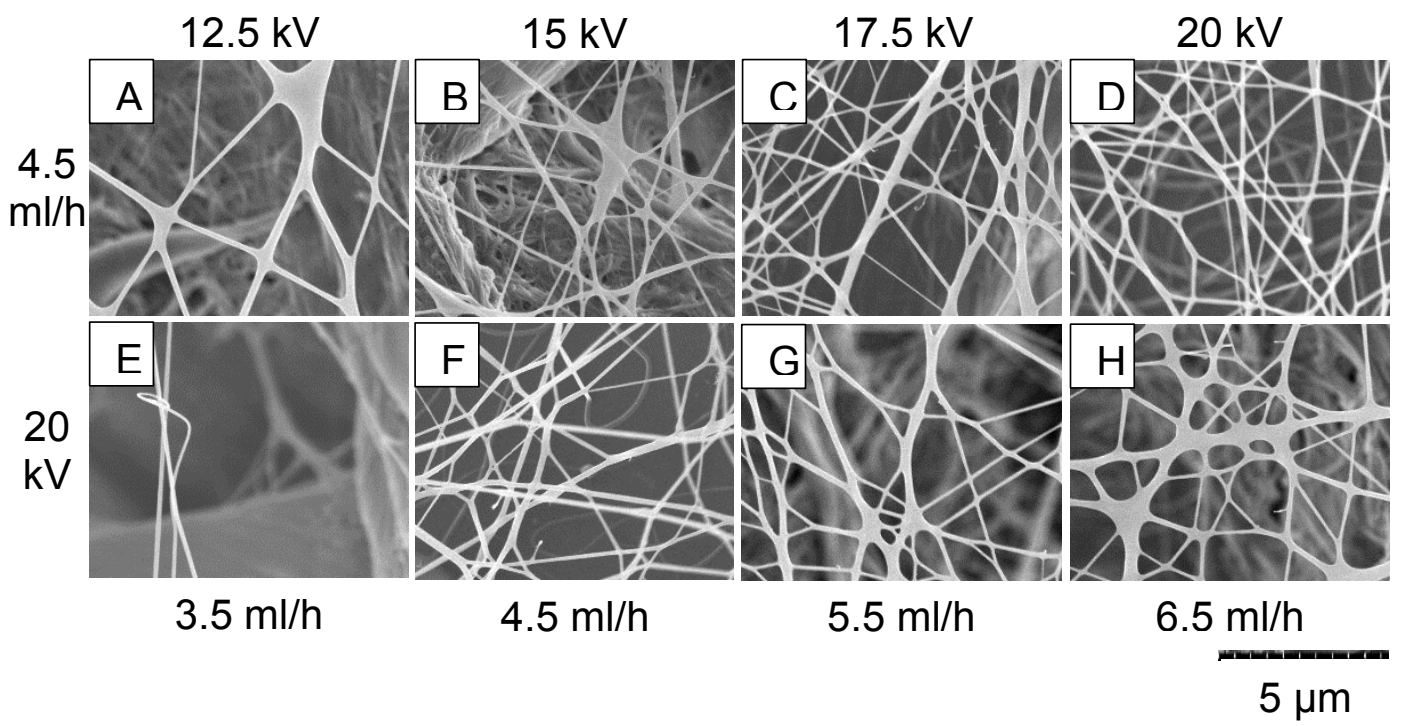

Figure 4.15 SEM-micrographs of 10\% (w/v) 4:6 30\% 4h glutaraldehyde vapor crosslinked HTCC-PVA nanofibers of different electrospinning conditions. (A) $12.5 \mathrm{kV}$, (B) $15 \mathrm{kV}$, (C) $17.5 \mathrm{kV}$, (D) $20 \mathrm{kV}$, (E) $3.5 \mathrm{ml} / \mathrm{h}$, (F) $4.5 \mathrm{ml} / \mathrm{h}$, (G) $5.5 \mathrm{ml} / \mathrm{h}$, (H) $6.5 \mathrm{ml} / \mathrm{h}$. The feed rate of sample (A), (B), (C) and (D) was $4.5 \mathrm{ml} / \mathrm{h}$ and the applied voltage for sample $(\mathrm{E}),(\mathrm{F}),(\mathrm{G})$ and $(\mathrm{H})$ was $20 \mathrm{kV}$. The remaining electrospinning parameters were the same: tip-to-collector distance was $5 \mathrm{~cm}$, rotation speed of drum collector was 1500 rpm and volume of electrospinning solution was $3 \mathrm{ml}$.

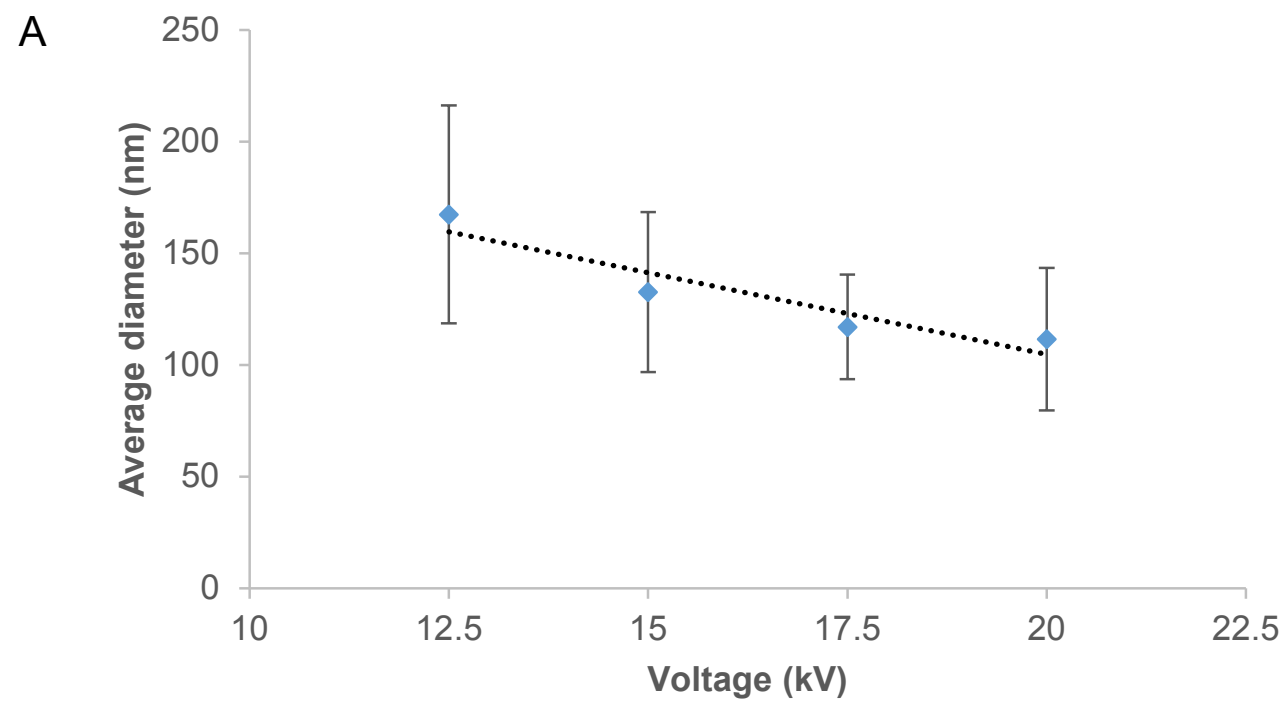




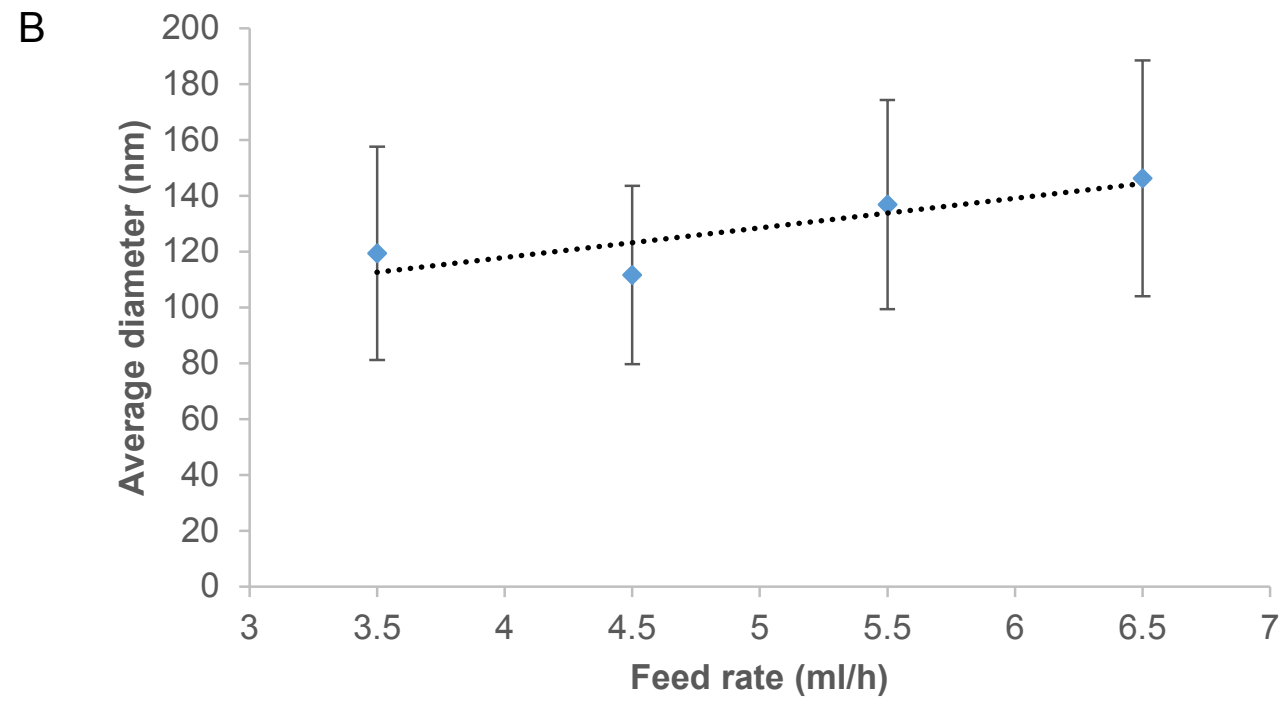

Figure 4.16 Average diameter distribution of 10\% (w/v) 4:6 30\% 4h glutaraldehyde vapor crosslinked HTCC-PVA nanofibers of different electrospinning conditions. Unless the specific voltage or feed rate labeled, the remaining electrospinning parameters were the same: the applied voltage was $20 \mathrm{kV}$, tip-to-collector distance was $5 \mathrm{~cm}$, feed rate was $4.5 \mathrm{ml} / \mathrm{h}$, rotation speed of drum collector was $1500 \mathrm{rpm}$ and volume of electrospinning solution was $3 \mathrm{ml}$. Error bars are the standard deviation of 150 fibers measured.

To study the relationship between pore size and fiber diameter, HTCC electrospun membranes were assessed by filtration with $2 \mathrm{ppm}$ of $1.01 \mu \mathrm{m}$ and $4.16 \mu \mathrm{m}$ diameter of polystyrene latex beads, respectively.

First, the standard curve of fluorescent polymer beads solution concentration vs. fluorescence was obtained by plotting a known concentration vs. fluorescence, shown in Figure 4.17A. Then, the concentration of the polystyrene latex beads solution was determined before and after filtration with membrane with different diameters according to fluorescence and the percent removal of the beads was calculated, shown in Figure 4.17B. The higher of bead removal means the smaller of the pore size. It was found that the pore sizes of membranes decreased with an increase of fiber diameters. It is likely because that thicker fibers take up more room and decrease the corresponding room for pores (Bai 2012). However, the result was not linear relationship possibly due to leaking of polymer beads from the edge of membranes.

In addition, the pore size of $30 \%$ h glutaraldehyde vapor crosslinked $10 \%(\mathrm{w} / \mathrm{v})$ of HTCC-PVA 4:6 nanofibers (electrospun at $20 \mathrm{kV}$, tip-to-collector distance $5 \mathrm{~cm}$, feed rate $4.5 \mathrm{ml} / \mathrm{h}$, rotation speed of drum collector $1500 \mathrm{rpm}$ and volume of electrospinning solution $3 \mathrm{ml}$ ) were calculated to be $1.121 \pm 0.078 \mu \mathrm{m}$ based on six SEM images. The 
membrane pore size is in the range of typical MF membranes $(0.1-10 \mu \mathrm{m})$ (Bjorge et al. 2009). This shows that our membrane pore size is much large than the sizes of PPV (18$26 \mathrm{~nm}$ ) (Morrica et al. 2003) and suggests that PPV cannot be removed by size-exclusion alone filtration.

A

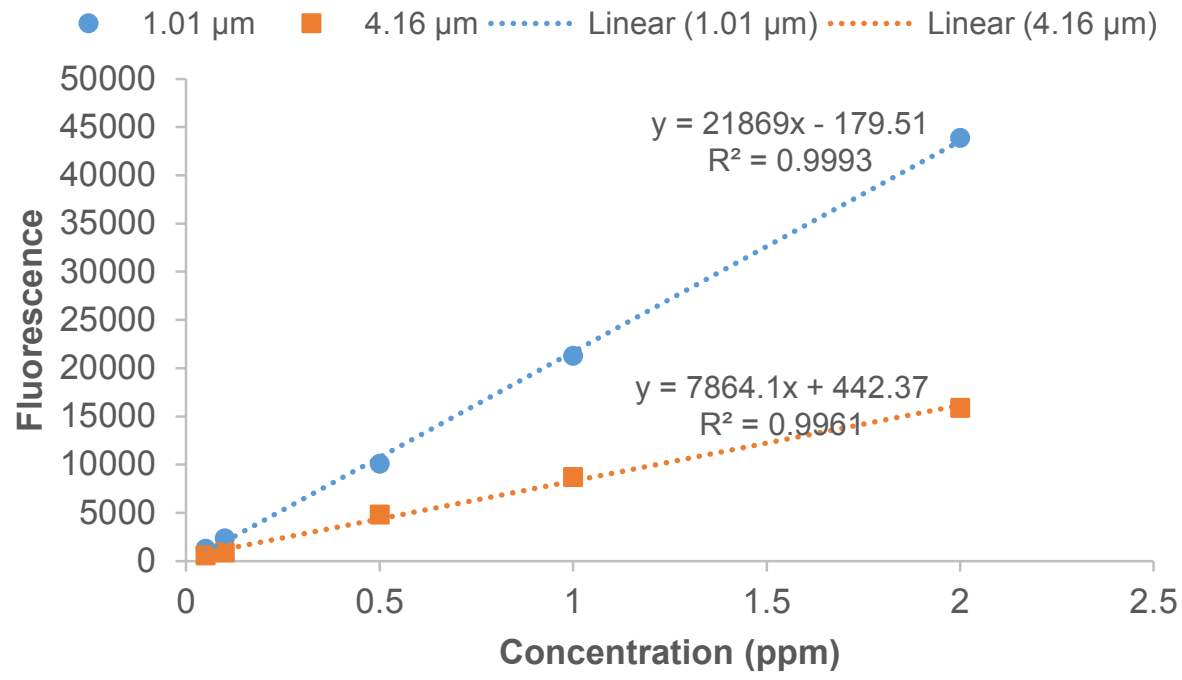

B

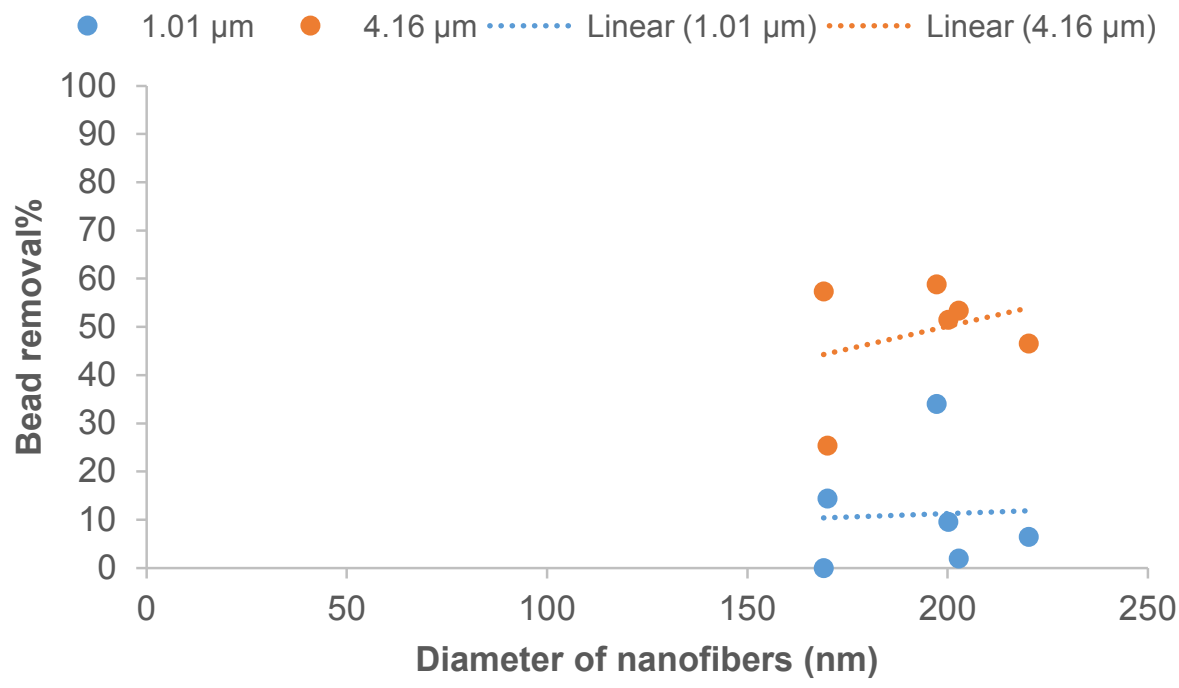

Figure 4.17 The relationship between pore size and fiber diameter. (A) Standard curve of fluorescent polymer beads solution concentration vs. fluorescence. (B) Relationship between bead removal and fiber diameter. The $30 \% 4 \mathrm{~h}$ crosslinked membranes were electrospun at the applied voltage from $15 \mathrm{kV}$ to $20 \mathrm{kV}, 5 \mathrm{~cm}$ of tip-to-collector distance, feed rate ranging from $3.5 \mathrm{ml} / \mathrm{h}$ to $6.5 \mathrm{ml} / \mathrm{h}, 1500 \mathrm{rpm}$ of rotation speed of drum collector. The volume of electrospinning solution was $3 \mathrm{ml}$. 


\subsubsection{Virus removal of crosslinked HTCC-PVA nanofibers}

For the virus clearance studies of the stable crosslinked nanofibers, both the incubation and filtration of PPV was performed by crosslinked HTCC-PVA nanofibers since the goal of this project is to create functionalized electrospun membranes that can remove viruses from drinking water by adsorption and filtration. Prior to contacting the crosslinked membranes with virus, electrospun mats after crosslinking with glutaraldehyde vapor were washed with water for $20 \mathrm{~min}$ or washed with $0.1 \mathrm{M}$ glycine for $10 \mathrm{~min}$ and water for $10 \mathrm{~min}$, respectively. This pre-treatment is to remove the unreacted glutaraldehyde on filters. The reason why we did the pre-treatment is that glutaraldehyde vapor treated blank filter paper also showed a high virus removal result around 3 LRV. Washing the fibers is to remove the disturbed factor of crosslinker on virus removal result.

\subsubsection{Virus removal by incubation of nanofibers}

For incubtion of crosslinked HTCC-PVA nanofibers with PPV, the virus binding ability of 1 layer of $0.5024 \mathrm{~cm}^{2}$ selected of critical crosslinked $10 \%(\mathrm{w} / \mathrm{v})$ of HTCC-PVA 4:6 nanofibers running centrifuge after incubation for $10 \mathrm{~min}$ was tested and shown in Figure 4.18. It could be found that the $30 \% 4 \mathrm{~h}$ glutaraldehyde vapor crosslinked HTCCPVA electrospun nanofibers washed by water were able to remove $3.3 \mathrm{LRV}$ of virus. The virus removal ability of nanofibers increased with an increase of crosslinker concentration and crosslinking time which resulted in an increase in the stability of nanofibers. Both the water-washed fibers and glycine-washed fibers showed the same trend with the variation of crosslinker concentration and crosslinking time. It can be seen that all the crosslinked filter paper controls are able to remove less than 1 LRV of virus. Therefore, the additional LRV was due to the stable electrospun HTCC-PVA nanofibers possibly because of the positively charged quaternary amine in HTCC able to bind negatively charged virus particles. The filter paper control showed a virus removal by $0.0098 \mathrm{LRV} \pm 0.0170$ and the low binding tube control was tested be $0 \mathrm{LRV}$ of virus. 


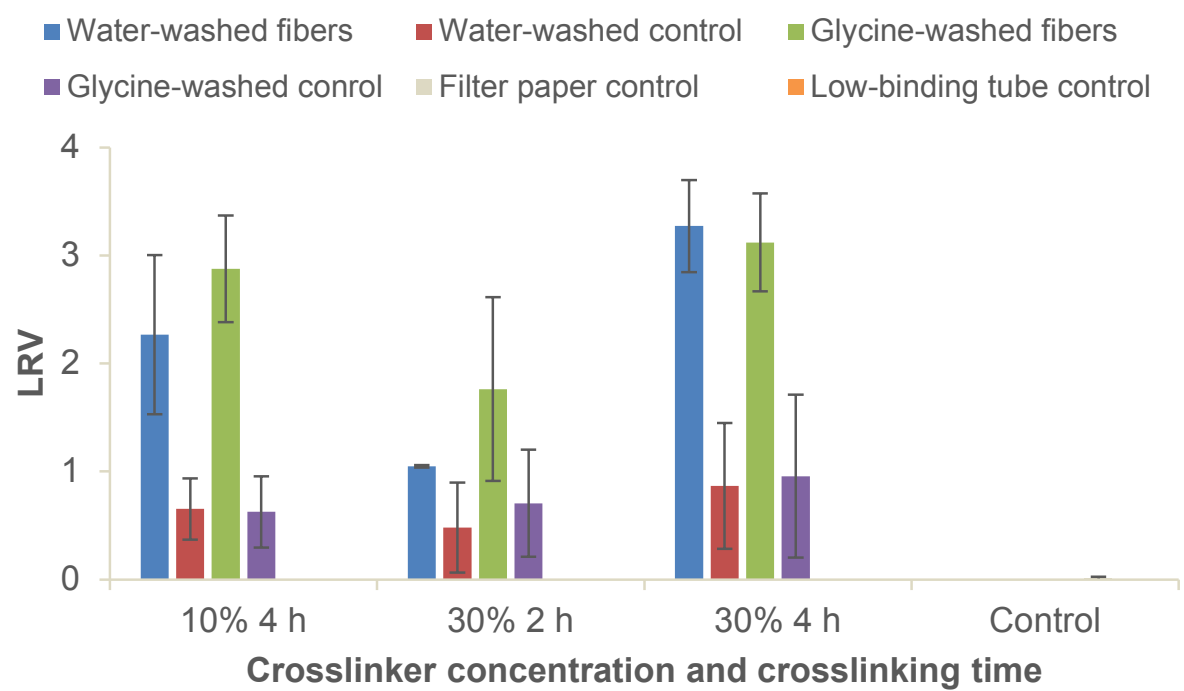

Figure 4.18 Virus removal of crosslinked 10\% (w/v) 4:6 HTCC-PVA nanofibers. The applied voltage was $20 \mathrm{kV}$, tip-to-collector distance was $5 \mathrm{~cm}$, feed rate was $4.5 \mathrm{ml} / \mathrm{h}$, rotation speed of drum collector was $1500 \mathrm{rpm}$ and volume of electrospinning solution was $3 \mathrm{ml}$. One layer of $0.5024 \mathrm{~cm}^{2}$ selected of critical crosslinked $10 \%(\mathrm{w} / \mathrm{v})$ of HTCCPVA 4:6 nanofibers was centrifuged for $30 \mathrm{~min}$ after incubation for $10 \mathrm{~min}$. All data points are the average of three separate tests and error bars represent the standard deviation.

Afterwards, the highest virus removed condition was applied to test how the fiber morphology affects the virus binding ability of nanofibers. Crosslinked HTCC-PVA nanofibers electrospun at different electrospinning conditions resulting in different fiber diameters and fiber densities were incubated with PPV. The fiber densities were obtained by weighing the filter paper before and after collecting fibers. The virus removal result is shown in Figure 4.19. LRV increased with the increase of density and diameter of fibers. Higher density of fibers means more amounts of positive charges on a specific area and larger diameter of fibers provides a larger surface area of HTCC-PVA nanofibers to bind virus. 

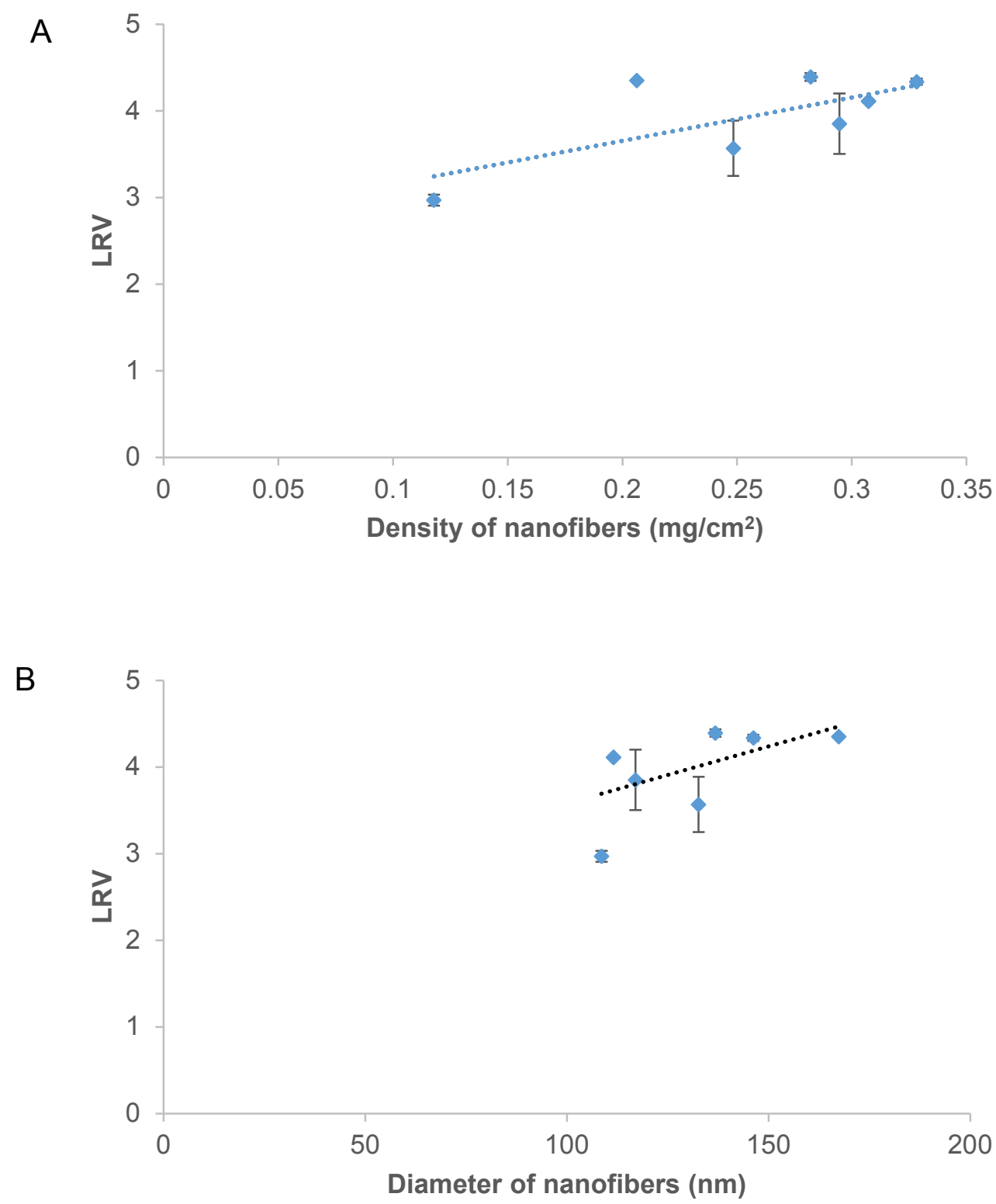

Figure 4.19 Virus removal of crosslinked 10\% (w/v) 4:6 HTCC-PVA nanofibers of different electrospinning conditions. (A) Virus removal of nanofibers of different diameters. (B) Virus removal of nanofibers of different densities. The $30 \% 4 \mathrm{~h}$ crosslinked membranes were electrospun at the applied voltage from $15 \mathrm{kV}$ to $20 \mathrm{kV}, 5$ $\mathrm{cm}$ of tip-to-collector distance, feed rate ranging from $3.5 \mathrm{ml} / \mathrm{h}$ to $6.5 \mathrm{ml} / \mathrm{h}, 1500 \mathrm{rpm}$ of rotation speed of drum collector. The volume of electrospinning solution was $3 \mathrm{ml}$. One

layer of $0.5024 \mathrm{~cm}^{2}$ selected of critical crosslinked 10\% (w/v) of HTCC-PVA 4:6 nanofibers was centrifuged for $30 \mathrm{~min}$ after incubation for $10 \mathrm{~min}$. All data points are the average of two separate tests and error bars represent the variance. 
The kinetic adsorption of HTCC-PVA nanofibers was studied by incubation of $30 \% 4 \mathrm{~h}$ crosslinked 10\% (w/v) 4:6 HTCC-PVA nanofibers washed by water with 6 logs (MTT/ml) of PPV in water for different incubation time. The effect of incubation time on the adsorption of virus particles onto HTCC-PVA nanofibers is shown in Figure 4.20D. It can be seen that the adsorption of PPV occurred rapidly and reaching adsorption equilibrium after $10 \mathrm{~min}$. The adsorption of different heavy metals nickel, cadmium, lead and copper ions onto electrospun chitosan/PEO nanofibers was reported to occur fast within the first $60 \mathrm{~min}$ and reach the equilibrium after $120 \mathrm{~min}$ (Aliabadi et al. 2013). To study the adsorption kinetics of PPV particles with the HTCC-PVA nanofibers, the experimental data were analyzed using three kinetic models, zero-order, first-order and second-order models (Fogler 2006).

The zero-order rate equation is generally expressed in linear form as follows:

$$
C=C_{0}-k_{0} t
$$

Where, $k_{0}=$ rate constant of zero - order adsorption $\left(\log _{10}\left(\frac{\mathrm{MTT}_{50}}{\mathrm{ml}}\right) / \mathrm{min}\right)$

The plot of $\mathrm{C}$ vs. $\mathrm{t}$ should give a linear relation from which $\mathrm{k}_{0}$ could be determined from the slope and is shown in Figure 4.20A.

The first-order rate equation is generally expressed in linear form as follows:

$$
\ln C=\ln C_{0}-k_{1} t
$$

Where, $k_{1}=$ rate constant of first - order adsorption $\left(\mathrm{min}^{-1}\right)$

The plot of $\operatorname{lnC}$ vs. $t$ should give a linear relation from which $\mathrm{k}_{1}$ could be determined from the slope and is shown in Figure 4.20B.

The second-order rate equation is generally expressed in linear form as follows:

$$
\frac{1}{C}=\frac{1}{C_{0}}+k_{2} t
$$
$\left.\min ^{-1}\right)$

Where, $k_{2}=$ rate constant of second - order adsorption $\left(\log _{10}\left(\frac{\mathrm{MTT}_{50}}{\mathrm{ml}}\right)^{-1}\right.$.

The plot of $1 / \mathrm{C}$ vs. $t$ should give a linear relation from which $\mathrm{k}_{2}$ could be determined from the slope and is shown in Figure 4.20C.

Where for all the orders of rate equations,

$$
\begin{aligned}
& t=\text { incubation time }(\mathrm{min}) \\
& C_{0}=\text { intial virus concentration }\left(\log _{10}\left(\frac{\mathrm{MTT}_{50}}{\mathrm{ml}}\right)\right)
\end{aligned}
$$




$$
\begin{aligned}
& C=\text { virus concentration after virus removal }\left(\log _{10}\left(\frac{\mathrm{MTT}_{50}}{\mathrm{ml}}\right)\right) \\
& r=\text { rate of adsorption }\left(\log _{10}\left(\frac{\mathrm{MTT}_{50}}{\mathrm{ml}}\right)^{-1} \cdot \mathrm{min}^{-1}\right)
\end{aligned}
$$

The correlation coefficient $\left(\mathrm{R}^{2}\right)$ value for second-order model is the highest; moreover, the experimental LRV values are very close to the calculated LRV values from the second-order model, suggesting that the second-order kinetic model can well-describe the kinetics of PPV adsorption in our case.

Both the calculated LRV from the first and second-order adsorption rate model was shown in Figure 4.20D. The possible reason why the second-order kinetic model is more fitted than first-order kinetic model is that two virus particles might bind each other before adsorbed by the sites of nanofibers. The rate of adsorption for each model was determined in Figure 4.20A, B \& C. The calculated second-order kinetic rate constant is $0.0143 \log _{10}\left(\frac{\mathrm{MTT}_{50}}{\mathrm{ml}}\right)^{-1} \cdot \mathrm{min}^{-1}$, which is equal to $0.059-0.00059\left(\frac{\mathrm{mg}}{\mathrm{g}}\right)^{-1} \cdot \mathrm{min}^{-1}$ (since numbers of infectious PPV particles are not an accurate number, and they fall in a range. See details below.). This is much larger than the reported second-order kinetic rate constant value of $0.0001\left(\frac{\mathrm{mg}}{\mathrm{g}}\right)^{-1} \cdot \mathrm{min}^{-1}$, reported for the adsorption of different heavy metals onto electrospun chitosan/PEO nanofibers (Aliabadi et al. 2013). This indicates that the adsorption of PPV onto HTCC-PVA nanofibers is faster than the heavy metal adsorption onto chitosan/PEO nanofibers. This is possibly because that the positive charge which HTCC carries is much stronger than that which chitosan carries. Also, the virus has multiple charge sites that are available for binding to the polymer, much more than heavy metals.

The unit conversion of the second-order kinetic rate constant is shown as follows:

$$
\begin{aligned}
& 1 \log _{10}\left(\frac{\mathrm{MTT}_{50}}{\mathrm{ml}}\right)=1 \log _{10}\left(\frac{\mathrm{MTT}_{50}}{\mathrm{ml}}\right) \times \frac{10^{7} \frac{\mathrm{pfu}}{\mathrm{ml}}}{7.8 \log _{10}\left(\frac{\mathrm{MTT}_{50}}{\mathrm{ml}}\right)} \times
\end{aligned}
$$

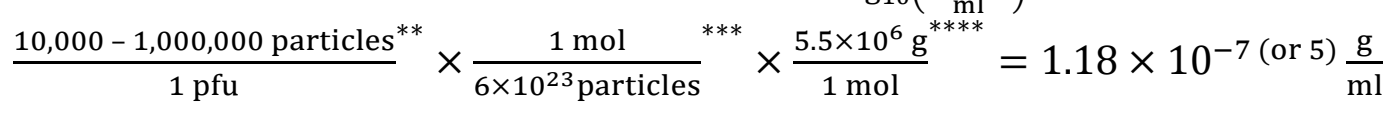

$$
\begin{aligned}
& \text { * } 7 \log _{10}\left(\frac{\mathrm{pfu}}{\mathrm{ml}}\right)=7.8 \log _{10}\left(\frac{\mathrm{MTT}_{50}}{\mathrm{ml}}\right)\left(\text { Heldt et al. 2006), thus } 10^{7} \frac{\mathrm{pfu}}{\mathrm{ml}}=\right. \\
& 7.8 \log _{10}\left(\frac{\mathrm{MTT}_{50}}{\mathrm{ml}}\right) \\
& * * \text { Infectivity ratio }=\frac{\text { infectious particles }}{\text { total particles }}=10,000-1,000,000 \text { (Heldt 2008), } \\
& \text { thus } 1 \mathrm{pfu}=10,000-1,000,000 \text { particles } \\
& * * * \text { Avogadro's constant }=6 \times 10^{23} \mathrm{~mol}^{-1} \text { (Prausnitz et al. 1999), thus } \\
& 1 \mathrm{~mol}=6 \times 10^{23} \text { particles } \\
& * * * * \text { Molecular weigh of PPV }=5.5 \times 10^{6} \mathrm{~g} / \mathrm{mol} \text { (Cotmore and Tattersall } \\
& \text { 2007), thus } 1 \mathrm{~mol} \text { PPV }=5.5 \times 10^{6} \mathrm{~g}
\end{aligned}
$$


In our case, the calculated second-order kinetic rate constant is 0.0143 $\log _{10}\left(\frac{\mathrm{MTT}_{50}}{\mathrm{ml}}\right)^{-1} \cdot \mathrm{min}^{-1}$, which is based on $0.5 \mathrm{ml}$ of initial PPV virus and $0.1507 \mathrm{mg}$ of HTCC-PVA nanofibers.

$$
\begin{aligned}
& \text { Therefore, } k_{2}=0.0143 \log _{10}\left(\frac{\mathrm{MTT}_{50}}{\mathrm{ml}}\right)^{-1} \cdot \mathrm{min}^{-1}=0.0143 \times 1.18 \times
\end{aligned}
$$

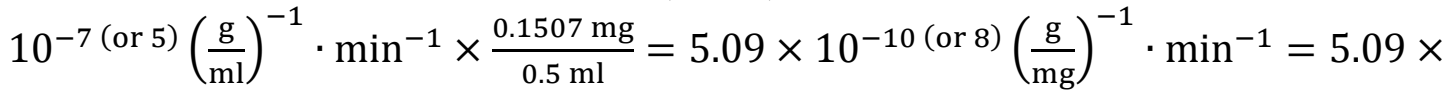

$$
\begin{aligned}
& 10^{-4(\text { or } 2)}\left(\frac{\mathrm{mg}}{\mathrm{g}}\right)^{-1} \cdot \mathrm{min}^{-1}=0.00059-0.059\left(\frac{\mathrm{mg}}{\mathrm{g}}\right)^{-1} \cdot \mathrm{min}^{-1}
\end{aligned}
$$

A

Zero-order

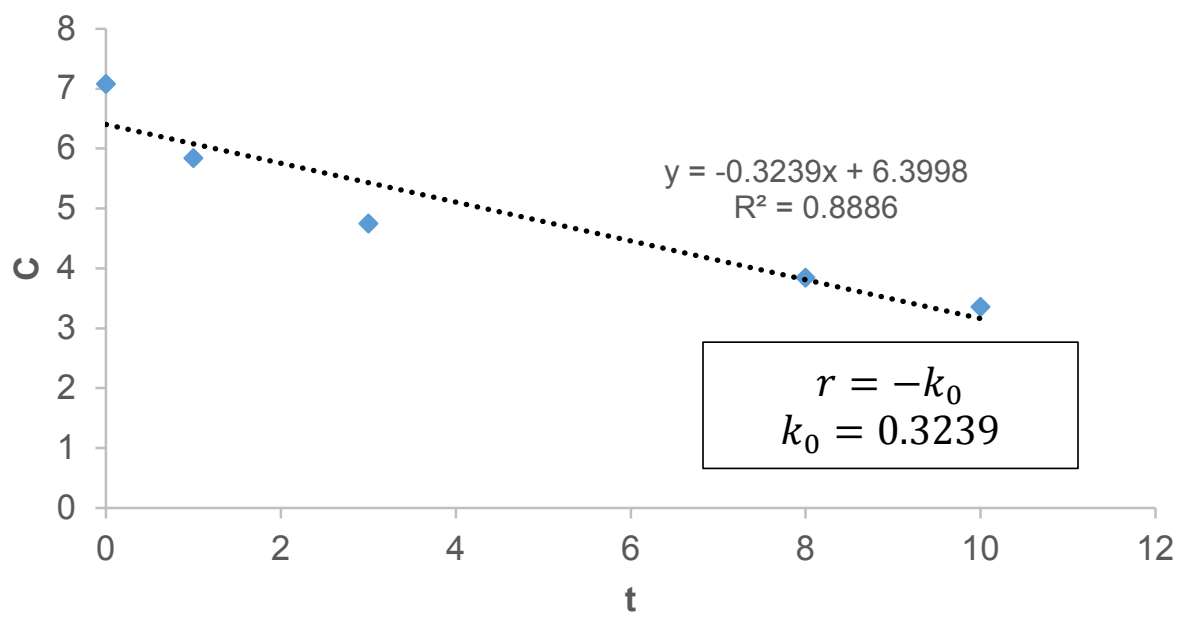


B

First-order

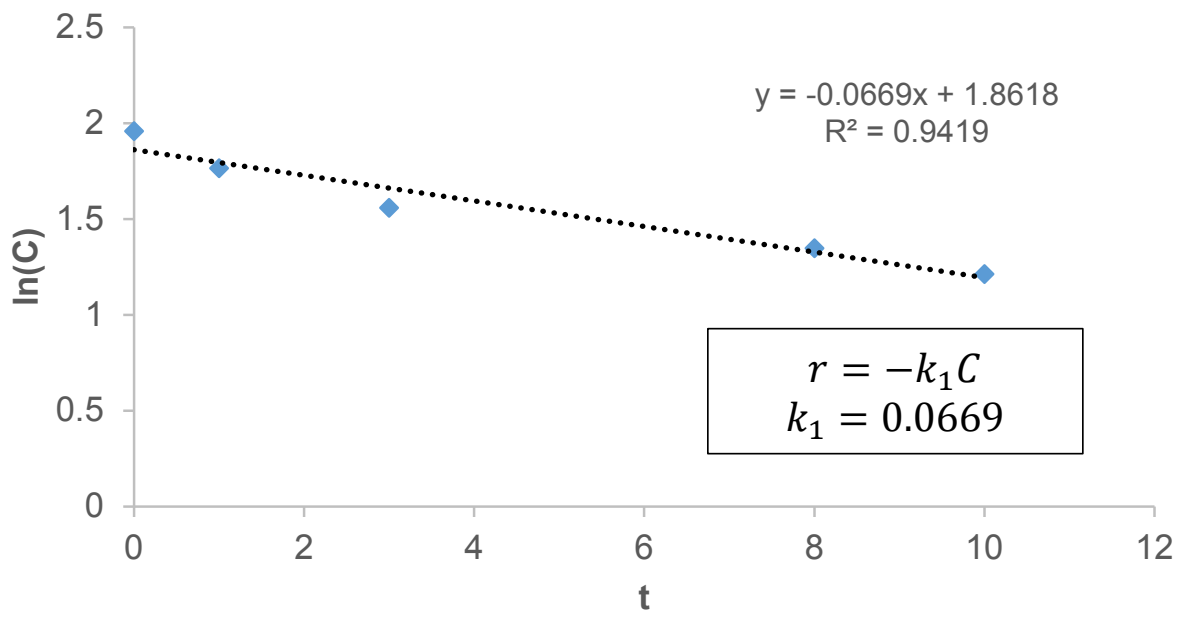

C

Second-order

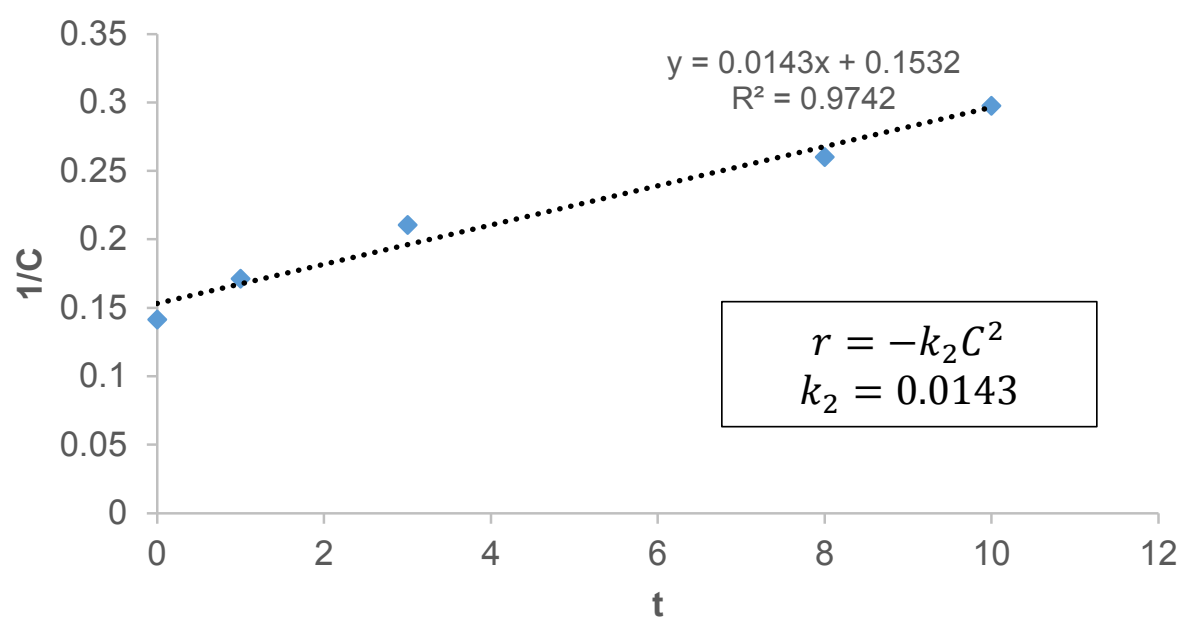




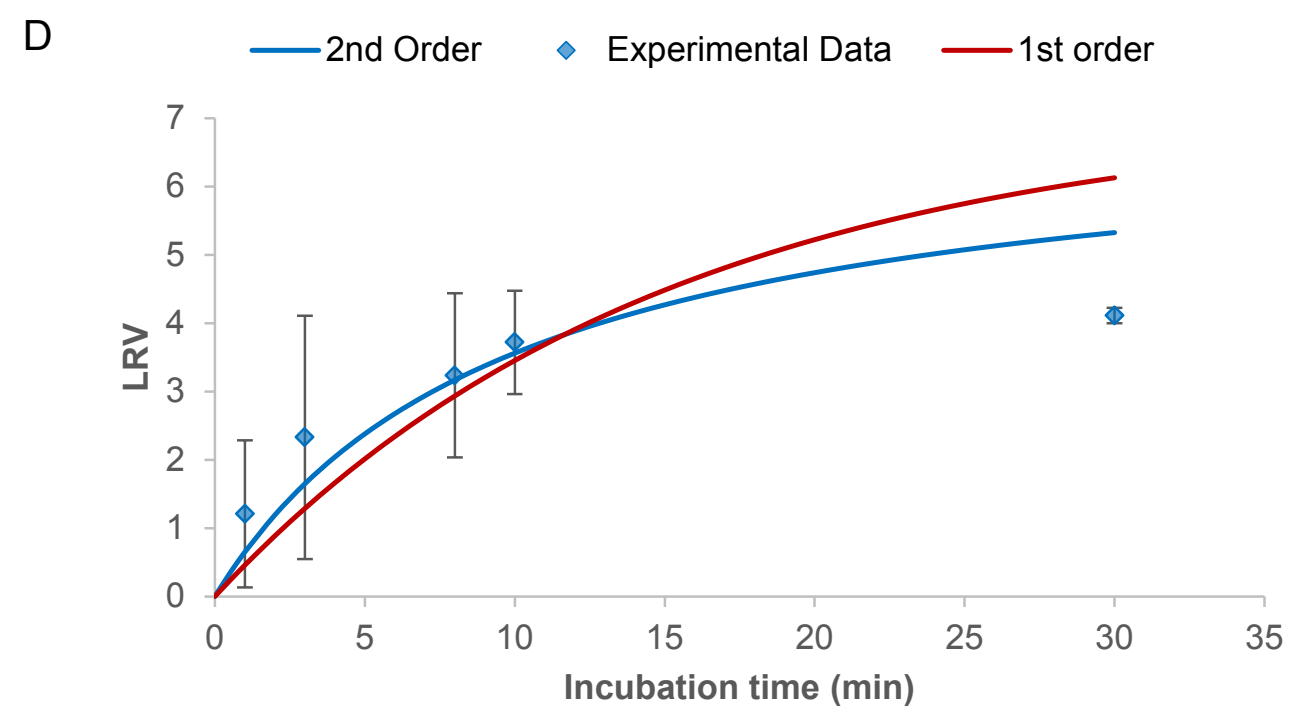

Figure 4.20 The kinetic adsorption of 30\% $4 \mathrm{~h}$ crosslinked 10\% (w/v) 4:6 HTCC-PVA nanofibers. (A) The zero-order kinetics plot for adsorption of PPV particle onto HTCCPVA nanofibers. (B) The first-order kinetics plot for adsorption of PPV particle onto HTCC-PVA nanofibers. (C) The second-order kinetics plot for adsorption of PPV particle onto HTCC-PVA nanofibers. (D) The experimental and calculated LRV vs. incubation time t. One layer of $0.5024 \mathrm{~cm}^{2}$ of nanofibers was centrifuged for $30 \mathrm{~min}$ after incubation for different lengths of time. The applied voltage was $20 \mathrm{kV}$, tip-to-collector distance was $5 \mathrm{~cm}$, feed rate was $4.5 \mathrm{ml} / \mathrm{h}$, rotation speed of drum collector was $1500 \mathrm{rpm}$ and volume of electrospinning solution was $3 \mathrm{ml}$. All data points are the average of three separate tests and error bars represent the standard deviation.

The adsorption isotherm of PPV onto HTCC-PVA nanofibers was analyzed in terms of the Langmuir, Freundlich, and Temkin isotherm models. This was conducted by incubation of $30 \% 4 \mathrm{~h}$ crosslinked 10\% (w/v) 4:6 HTCC-PVA nanofibers washed by water for $10 \mathrm{~min}$ at different start concentrations of virus.

The Langmuir isotherm is used for monolayer sorption onto a homogeneous surface containing a finite number of identical sites (Ozdemir et al. 2012). The linear form of the Langmuir isotherm equation is given as follows:

$$
\frac{C_{e}}{q_{e}}=\frac{C_{e}}{q_{m}}+\frac{1}{q_{m} K_{L}}
$$

Where,

$$
C_{e}=\text { the unbound concentration of virus in solution }\left(\log _{10}\left(\frac{\mathrm{MTT}_{50}}{\mathrm{ml}}\right)\right)
$$




$$
\begin{aligned}
& q_{e}=\text { the adsorption of virus bound to the nanofibers }\left(\frac{\log _{10}\left(\frac{\mathrm{MTT}_{50}}{\mathrm{ml}}\right)}{\mathrm{cm}^{2}}\right) \\
& q_{m}=\text { the maximum capacity of the nanofibers }\left(\frac{\log _{10}\left(\frac{\mathrm{MTT}_{50}}{\mathrm{ml}}\right)}{\mathrm{cm}^{2}}\right) \\
& K_{L}=\text { the Langmuir adsoption constant }\left(\log _{10}\left(\frac{\mathrm{MTT}_{50}}{\mathrm{ml}}\right)^{-1}\right)
\end{aligned}
$$

The values of $q_{m}$ and $K_{L}$ can be obtained from the slope and intercept of the liner plot of $\frac{C_{e}}{q_{e}}$ vs. $C_{e}$, as shown in Figure 4.21A.

The Freundlich isotherm is an empirical equation which is used for adsorption on a heterogeneous surface with different adsorption sites (Ozdemir et al. 2012). The linear form of the Freundlich isotherm equation is expressed as follows:

$$
\log q_{e}=\log K_{f}+\frac{1}{n} \log C_{e}
$$

Where,

$C_{e}=$ the unbound concentration of virus in solution $\left(\log _{10}\left(\frac{\mathrm{MTT}_{50}}{\mathrm{ml}}\right)\right)$

$q_{e}=$ the adsorption of virus bound to the nanofibers $\left(\frac{\log _{10}\left(\frac{\mathrm{MTT}_{50}}{\mathrm{ml}}\right)}{\mathrm{cm}^{2}}\right)$

$n=$ the Freundlich isotherm constant related to adsorption intensity

$K_{f}=$ the Freundlich isotherm constant related to adsorption capacity

The values of $n$ and $K_{f}$ can be calculated from the slope and intercept of the liner plot of $\log q_{e}$ vs. $\log C_{e}$, as shown in Figure 4.21B.

The Temkin isotherm takes into account adsorbing species-adsorbate interactions. This isotherm assumes that the heat of adsorption would decrease linearly with increasing coverage of adsorbate ( $\mathrm{Vu}$ et al. 2012). The linear form of the Temkin isotherm equation is given as follows:

$$
q_{e}=B \ln K_{T}+B \ln C_{e}
$$

Where,

$$
\begin{aligned}
& C_{e}=\text { the unbound concentration of virus in solution }\left(\log _{10}\left(\frac{\mathrm{MTT}_{50}}{\mathrm{ml}}\right)\right) \\
& q_{e}=\text { the adsorption of virus bound to the nanofibers }\left(\frac{\log _{10}\left(\frac{\mathrm{MTT}_{50}}{\mathrm{ml}}\right)}{\mathrm{cm}^{2}}\right) \\
& B=\text { the isotherm constant related to adsorption heat } \\
& K_{T}=\text { the equilibrium constant related to the maximum binding energy }
\end{aligned}
$$

The values of $B$ and $K_{T}$ can be determined from the slope and intercept of the liner plot of $q_{e}$ vs. $\ln C_{e}$, as shown in Figure 4.21C. 
The results of isotherm constants calculated from the slopes and intercepts of the linear plots (Figure 4.21) are summarized in Table 4.1. As shown in the table, the correlations coefficients $\left(\mathrm{R}^{2}\right)$ for the Freundlich and Temkin isotherm are much higher than the values obtained for the Langmuir isotherm. In addition, the isotherm constants obtained from the Langmuir isotherm is negative, which indicates the Langmuir isotherm is not a good isotherm model for PPV adsorption onto HTCC-PVA nanofibers. What's more, the Freundlich isotherm constant $(n)$ obtained from the linear plot is 0.5 , however, it should have values ranging from 1 to 10 (Alagumuthu et al. 2010). This suggests that the Temkin isotherm is the best-fit isotherm for the adsorption of PPV onto HTCC-PVA nanofibers. This indicates that our adsorption of PPV onto the nanofibers is due to charge-charge interaction and the heat of adsorption would decrease linearly with increasing coverage of PPV. The calculated Temkin isotherm constant $\left(K_{T}\right)$ is 0.55 $\log _{10}\left(\frac{\mathrm{MTT}_{50}}{\mathrm{ml}}\right)^{-1}$, which is equal to $6.49 \times 10^{-9}-6.49 \times 10^{-11} \frac{\mathrm{L}}{\mathrm{g}}$, much smaller than the reported Temkin isotherm constant value $2.6 \frac{\mathrm{L}}{\mathrm{g}}$, from the adsorption of heavy metal copper ions onto electrospun $\mathrm{TiO}_{2}$ nanofibers ( $\mathrm{Vu}$ et al. 2012). This is possibly due to not reaching a high enough concentration of virus to saturate the system of HTCC-PVA fibers (which is typical for virus) (Heldt et al. 2012) thus the Temkin constant was underestimated.

The unit conversion of Temkin isotherm constant (similar to unit conversion of kinetic rate constant) is shown as follows:

$$
\begin{array}{r}
K_{T}=0.55 \log _{10}\left(\frac{\mathrm{MTT}_{50}}{\mathrm{ml}}\right)^{-1}=0.55 \times 1.18 \times 10^{-7} \text { (or 5) }\left(\frac{\mathrm{g}}{\mathrm{ml}}\right)^{-1}=6.49 \times \\
10^{-8(\text { or } 6)}\left(\frac{\mathrm{g}}{\mathrm{ml}}\right)^{-1}=6.49 \times 10^{-8(\text { or } 6)} \frac{\mathrm{ml}}{\mathrm{g}}=6.49 \times 10^{-11}-6.49 \times 10^{-9} \frac{\mathrm{L}}{\mathrm{g}}
\end{array}
$$

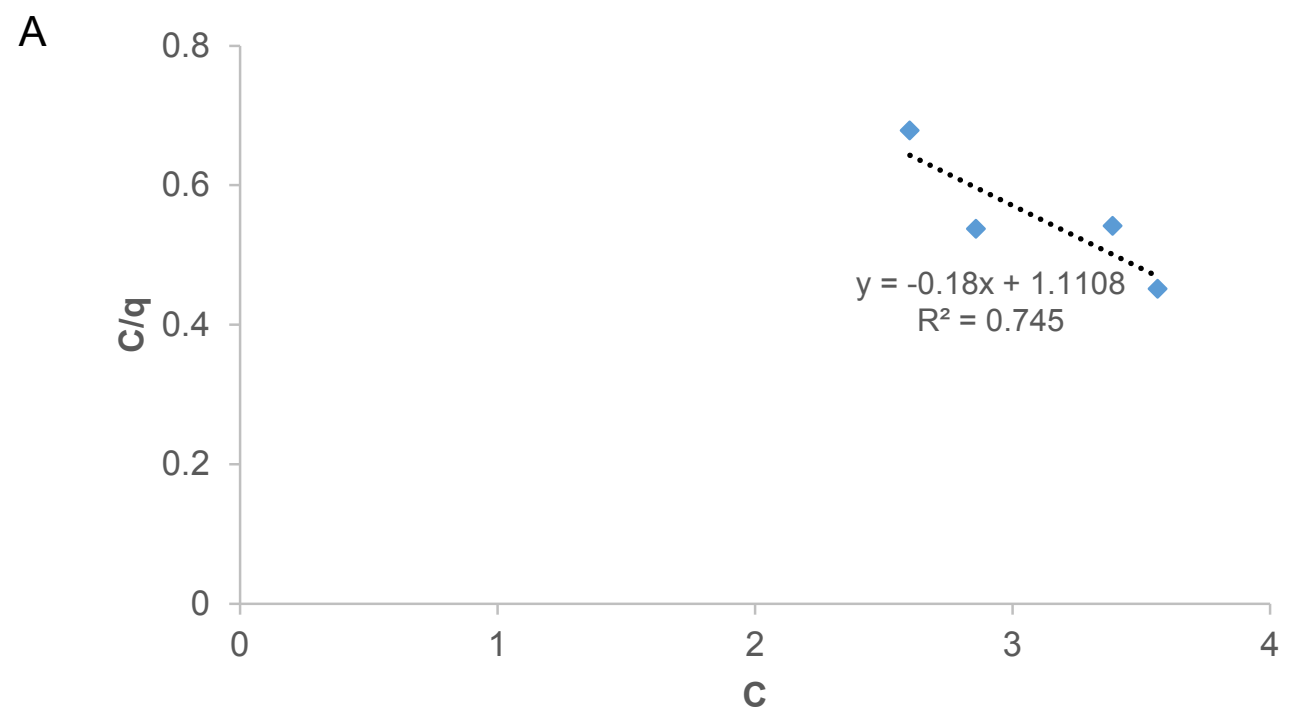


B
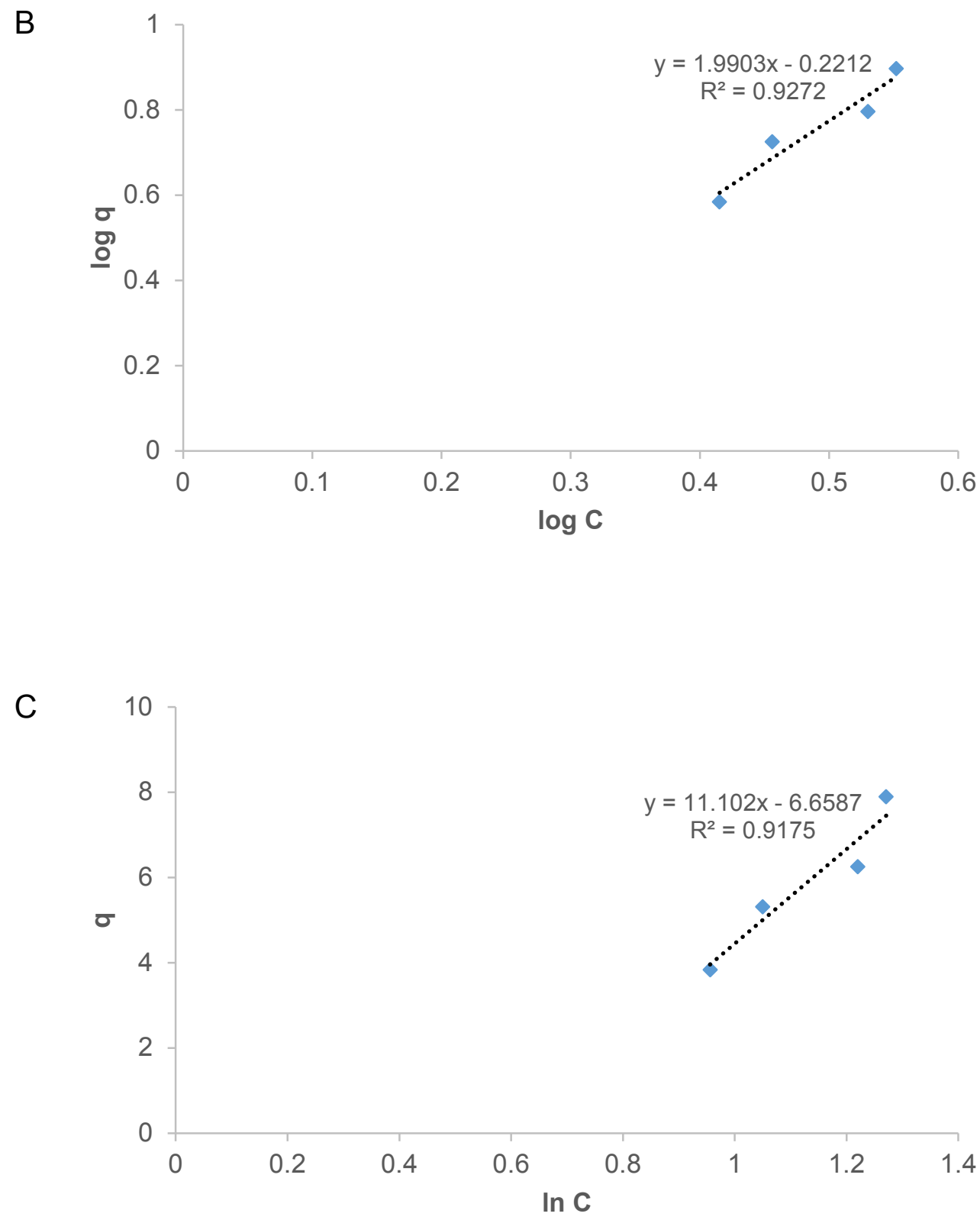
D

— The Freundlick isotherm — The Temkin isotherm

- Experimental Data

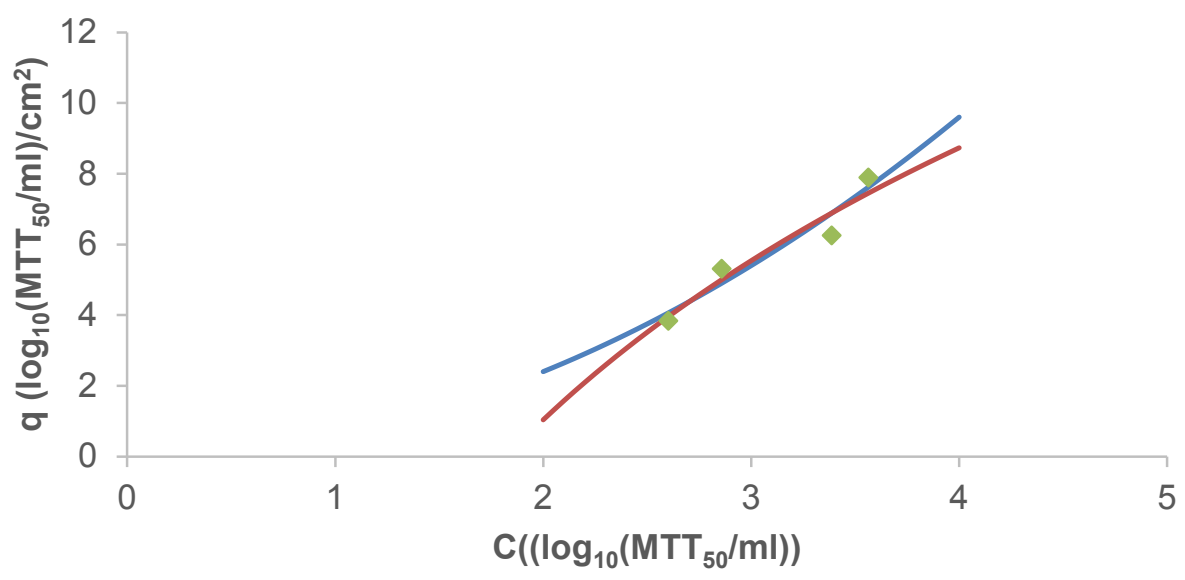

Figure 4.21 The adsorption isotherms of PPV onto 30\% $4 \mathrm{~h}$ crosslinked 10\% (w/v) 4:6 HTCC-PVA nanofibers incubation for 10 min. (A) Langmuir isotherm for adsorption of PPV particle onto HTCC-PVA nanofibers. (B) Freundlich isotherm for PPV particle adsorption by HTCC-PVA nanofibers. (C) Temkin isotherm for PPV particle adsorption onto HTCC-PVA nanofibers. (D) The experimental and calculated adsorption of virus bound to the nanofibers vs. unbound concentration of virus in solution. One layer of $0.5024 \mathrm{~cm}^{2}$ of nanofibers was centrifuged for $30 \mathrm{~min}$ after incubation at different start concentrations of virus solution. The applied voltage was $20 \mathrm{kV}$, tip-to-collector distance was $5 \mathrm{~cm}$, feed rate was $4.5 \mathrm{ml} / \mathrm{h}$, rotation speed of drum collector was $1500 \mathrm{rpm}$ and volume of electrospinning solution was $3 \mathrm{ml}$.

Table 4.1 Parameters of the adsorption isotherm for PPV adsorption

\begin{tabular}{|c|c|c|c|}
\hline $\begin{array}{c}\text { Isotherm } \\
\text { models }\end{array}$ & Langmuir isotherm & $\begin{array}{c}\text { Freundlich } \\
\text { isotherm }\end{array}$ & $\begin{array}{c}\text { Temkin } \\
\text { isotherm }\end{array}$ \\
\hline $\begin{array}{c}\text { Isotherm } \\
\text { constant } \\
\mathbf{1}\end{array}$ & $q_{m}=-5.56\left(\frac{\log _{10}\left(\frac{\mathrm{MTT}}{\mathrm{ml}}\right)}{\mathrm{cm}^{2}}\right)$ & $n=0.50$ & $B=11.10$ \\
\hline $\begin{array}{c}\text { Isotherm } \\
\text { constant } \\
\mathbf{2}\end{array}$ & $K_{L}=-0.16\left(\log _{10}\left(\frac{\mathrm{MTT}_{50}}{\mathrm{ml}}\right)^{-1}\right)$ & $K_{f}=0.60$ & $K_{T}=0.55$ \\
\hline $\mathbf{R}^{\mathbf{2}}$ & 0.745 & 0.9272 & 0.9175 \\
\hline
\end{tabular}




\subsubsection{Virus removal by filtration with nanofibers}

For filtraton with crosslinked HTCC-PVA nanofibers with PPV, the virus removal ability of 5 layers of $0.3167 \mathrm{~cm}^{2}$ selected of critical crosslinked $10 \%(\mathrm{w} / \mathrm{v})$ of HTCC-PVA 4:6 nanofibers is shown in Figure 4.22. It shows that the $30 \% 4 \mathrm{~h}$ glutaraldehyde vapor crosslinked HTCC-PVA electrospun nanofibers washed by water was able to remove 3.6 LRV of virus. The virus removal ability of nanofibers increased with an increase of crosslinker concentration and crosslinking time which resulted in an increase in the stability of nanofibers. Both the water-washed fibers and glycine-washed fibers showed the same trend with the variation of crosslinker concentration and crosslinking time. It can also be found that all the crosslinked filter paper controls are able to remove less than 2 LRV of virus. Thus the additional LRV was due to the stable electrospun HTCC-PVA nanofibers possibly because of the positively charged quaternary amine in HTCC able to bind negatively charged virus particles.

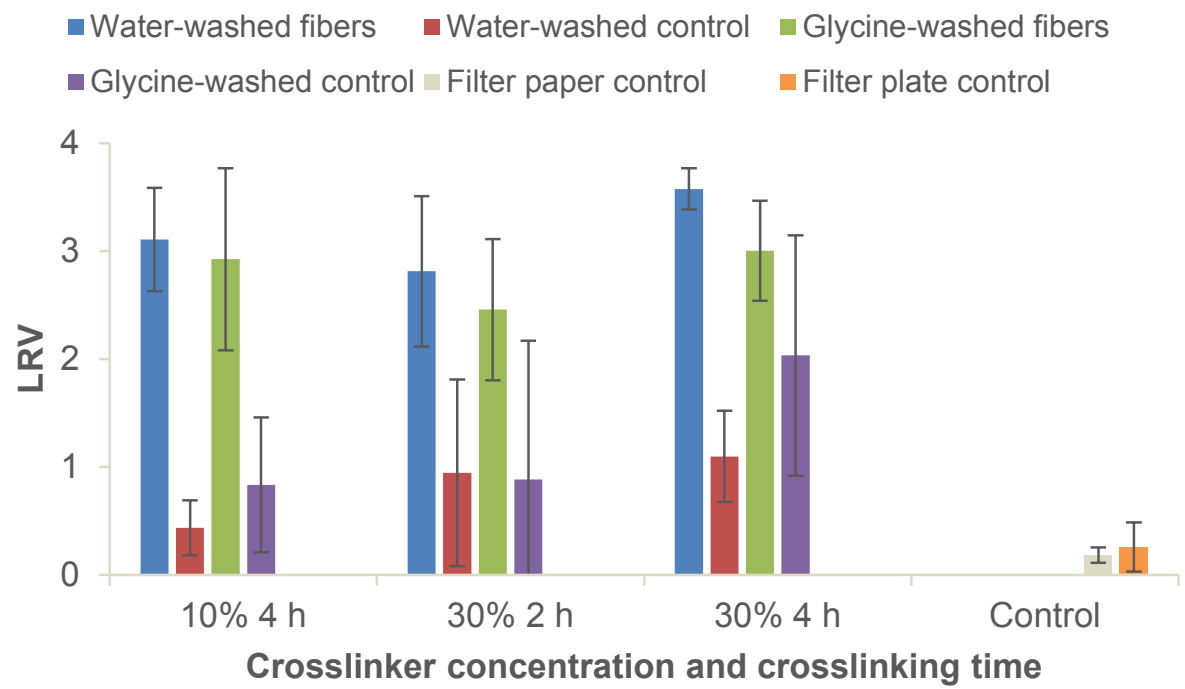

Figure 4.22 Virus removal of crosslinked 10\% (w/v) 4:6 HTCC-PVA nanofibers. The applied voltage was $20 \mathrm{kV}$, tip-to-collector distance was $5 \mathrm{~cm}$, feed rate was $4.5 \mathrm{ml} / \mathrm{h}$, rotation speed of drum collector was $1500 \mathrm{rpm}$ and volume of electrospinning solution

was $3 \mathrm{ml}$. Five layers of $0.3167 \mathrm{~cm}^{2}$ selected of critical crosslinked $10 \%$ (w to $\mathrm{v}$ ) of HTCC-PVA 4:6 nanofibers were placed into one well of 96-well filter plate centrifuged at $400 \times \mathrm{g}$ for $10 \mathrm{~min}$. All data points are the average of three separate tests and error bars represent the standard deviation.

Furthermore, the highest virus removal condition was applied to test how the amount of fibers affects the virus removal ability of nanofibers. Different numbers of 
layers of HTCC-PVA nanofibers were filtered with PPV. The virus removal results are shown in Figure 4.23. LRV increased with the increase of layers of filtration nanofibers.

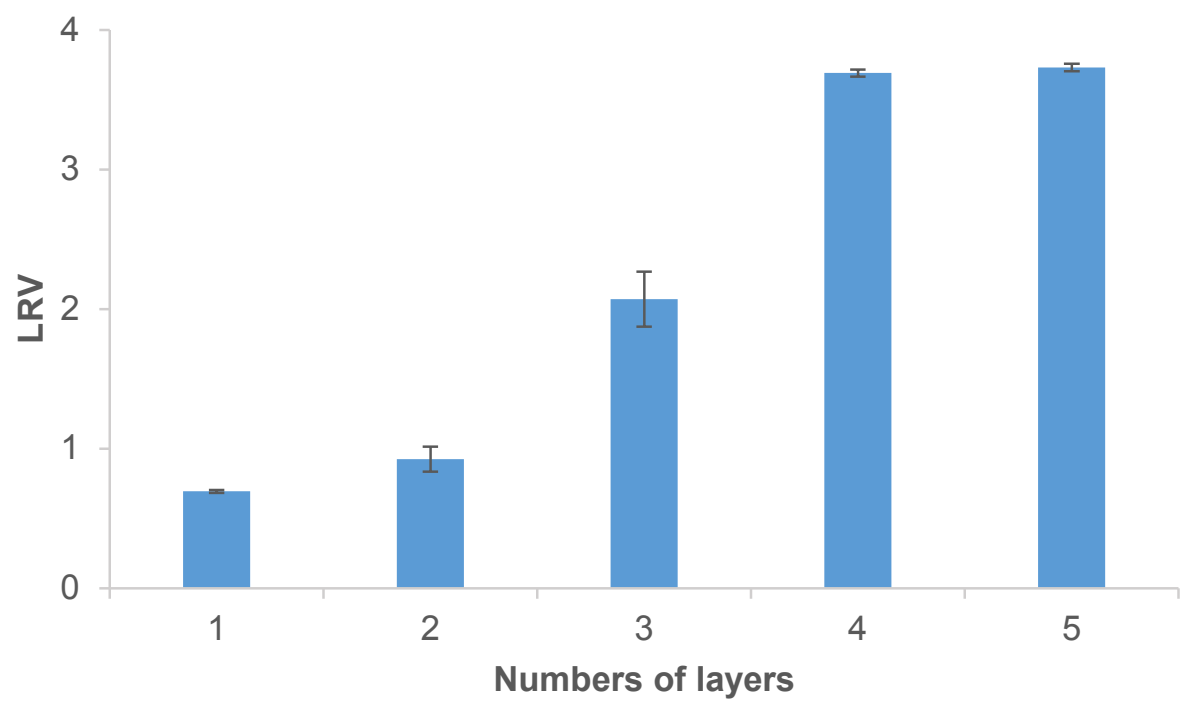

Figure 4.23 Virus removal of 30\% 4 h crosslinked 10\% (w/v) 4:6 HTCC-PVA nanofibers of different layers of fibers. The applied voltage was $20 \mathrm{kV}$, tip-to-collector distance was $5 \mathrm{~cm}$, feed rate was $4.5 \mathrm{ml} / \mathrm{h}$, rotation speed of drum collector was $1500 \mathrm{rpm}$ and volume of electrospinning solution was $3 \mathrm{ml}$. Different layers of $0.3167 \mathrm{~cm}^{2}$ nanofibers were placed into one well of 96-well filter plate centrifuged at $400 \times \mathrm{g}$ for 10 min. All data points are the average of two separate tests and error bars represent the variance. 


\section{Conclusions and Future Work}

\subsection{Conclusions}

A quaternized chitosan, HTCC, has been successful synthesized by introducing quaternary ammonium salt groups on the amino groups of chitosan. However, HTCC is difficult to be electrospun alone, so PVA was chosen as a suitable non-ionogenic partner for producing electrospun HTCC nanofibers. The morphology of HTCC-PVA nanofibers was studied at various blend ratios. Increasing HTCC content reduced the average diameter of the nanofibers as well as the ability to electrospin the blend solution. Fibers made from HTCC blended with PVA without crosslinking have the ability to remove up to $85 \%$ of PPV (the model virus) from in water.

To improve the stability of HTCC-PVA nanofibers against water, we used glutaraldehyde vapor at different concentrations to crosslink the fibers for different crosslinking time. The glutaraldehyde vapor gave fibers stability against water successfully. 30\% $4 \mathrm{~h}$ crosslinked HTCC-PVA nanofibers kept their morphology and did not dissolve after immersion in water for $6 \mathrm{~h}$ and was the best screened crosslinking conditions in our experiments. In addition, the morphology of fibers was investigated at different applied voltage and feed rates. It could be found that the average diameters of nanofibers significantly increased with a decrease in applied voltage and an increase in feed rate. Furthermore, the pore sizes of membranes decreased with an increase of fiber diameters.

We have successfully produced stable, functionalized, electrospun HTCC-PVA nanofibers that can remove viruses from water by adsorption and filtration. The pore size of membranes were calculated to be $1.121 \pm 0.078 \mu \mathrm{m}$, in the range of typical MF membranes $(0.1-10 \mu \mathrm{m})$. The diameters of membrane fall in the range of 108 to $167 \mathrm{~nm}$. The fibers were able to remove $3.3 \operatorname{logs}(99.95 \%)$ of virus after a 10 min incubation. The kinetic adsorption was also studied and experimental data indicated that the adsorption of PPV onto HTCC-PVA nanofibers followed a second-order kinetic model. Besides, the adsorption isotherm was analyzed and the result showed that the Temkin isotherm is the best-fit isotherm for the adsorption of PPV onto HTCC-PVA nanofibers. This indicates that our adsorption of PPV onto the nanofibers is due to charge-charge interaction and the heat of adsorption would decrease linearly with increasing coverage of PPV. In addition, the virus binding ability of nanofibers enhanced with the increase of fiber diameter and fiber density. The fibers were able to remove $3.6 \operatorname{logs}(99.97 \%)$ of virus when the solution was filtered with the membranes. Combined with result of incubation, it could be found that the virus removal ability of nanofibers increased with an increase in crosslinker concentration and crosslinking time in both the cases of incubation and filtration, possible due to increase in the stability of nanofibers. Furthermore, the virus removal ability of nanofibers increased with the increase of layers of filtration nanofibers, which is identical to the result of incubation of fibers at different fiber density, indicating 
the greater number of nanofibers, the better the virus removal. This is the first known report of such a high LRV with nanofibers.

Functionalized electrospun fibers, which have pores that are orders of magnitude greater in size than the virus, have the potential to greatly improve membrane filtration techniques to remove pathogens from drinking water.

\subsection{Future Work}

In the future, we will use other virus models like MS2 virus and Sindbis virus to test the virus removal result of the HTCC-PVA membranes. The HTCC-PVA membrane is expected to remove all the virus effectively from drinking water, thus it need to be tested with other virus models commonly used in viral clearance study. We will try other additives like PVP to increase the fiber formation of the high content of HTCC in blend electrospinning solution. The virus capture ability of HTCC nanofibers showed an improvement with the increase of the content of HTCC in blending electrospinning solution. PVA can obviously aid the fiber formation of HTCC below $40 \%$ of HTCC in blending solution, while PVP was reported to be able to aid the fiber formation of quaternized chitosan at $80 \%$ of quaternized chitosan in blending solution (Ignatova et al. 2007).

In addition, we will test the virus removal ability of HTCC-PVA blend fibers doped with a small amount of graphene. Since graphene has been reported to aid the electrospinning and improve the virus removal result of HTCC nanofibers (Bai 2012), we wanted to reduce the viral load of PPV in drinking water by greater than 4 LRV (99.99\%), which is an EPA regulated virus reduction minimum (EPA. 1974).

Furthermore, we will enhance virus capture of electrospun chitosan nanofibers with addition of small virus-binding peptides. The small peptide ligands (WRW and KYY) that capture PPV from solutions have been reported (Heldt et al. 2008; Heldt et al. 2009). The attachment of these small peptides through the primary amine group on chitosan nanofibers was hypothesized to improve the virus binding ability of chitosan nanofibers and will bring us a more deep understanding of adsorption of virus onto functionalized surfaces. 


\section{Reference List}

Alagumuthu, G., V. Veeraputhiran and R. Venkataraman (2010). "Adsorption isotherms on fluoride removal: batch techniques." Archives of Applied Science Research 2(4): 170 185.

Alexander, J. T., F. I. Hai and T. M. Al-aboud (2012). "Chemical coagulation-based processes for trace organic contaminant removal: Current state and future potential." Journal of Environmental Management 111: 195-207.

Aliabadi, M., M. Irani, J. Ismaeili, H. Piri and M. J. Parnian (2013). "Electrospun nanofiber membrane of $\mathrm{PEO} /$ Chitosan for the adsorption of nickel, cadmium, lead and copper ions from aqueous solution." Chemical Engineering Journal 220: 237-243.

Alipour, S. M., M. Nouri, J. Mokhtari and S. H. Bahrami (2009). "Electrospinning of poly(vinyl alcohol)-water-soluble quaternized chitosan derivative blend." Carbohydrate Research 344(18): 2496-2501.

Antony, A., J. Blackbeard and G. Leslie (2012). "Removal Efficiency and Integrity Monitoring Techniques for Virus Removal by Membrane Processes." Critical Reviews in Environmental Science and Technology 42(9): 891-933.

Bai, B. (2012). Electrospun chitosan nanofibers for virus removal. Master of Science in Chemical Engineering (MSChE). Open Access Theses and Dissertations, Michigan Technological University.

Bjorge, D., N. Daels, S. De Vrieze, P. Dejans, T. Van Camp, W. Audenaert, J. Hogie, P. Westbroek, K. De Clerck and S. W. H. Van Hulle (2009). "Performance assessment of electrospun nanofibers for filter applications." Desalination 249(3): 942-948.

Boisvert, M., S. Fernandes and P. Tijssen (2010). "Multiple Pathways Involved in Porcine Parvovirus Cellular Entry and Trafficking toward the Nucleus." Journal of Virology 84(15): 7782-7792.

Brehant, A., K. Glucina, I. Le Moigne and J. M. Laine (2010). "Risk management approach for monitoring UF membrane integrity and experimental validation using Ms2phages." Desalination 250(3): 956-960.

Choong, T. S. Y., T. G. Chuah, Y. Robiah, F. L. G. Koay and I. Azni (2007). "Arsenic toxicity, health hazards and removal techniques from water: an overview." Desalination 217(1-3): 139-166.

Cotmore, S. F. and P. Tattersall (2007). "Parvoviral Host Range and Cell Entry Mechanisms." 70: 183-232. 
Cramariuc, B., R. Cramariuc, R. Scarlet, L. R. Manea, I. G. Lupu and O. Cramariuc (2013). "Fiber diameter in electrospinning process." Journal of Electrostatics 71(3): 189198.

Deng, H. B., P. H. Lin, S. J. Xin, R. Huang, W. Li, Y. M. Du, X. Zhou and J. H. Yang (2012). "Quaternized chitosan-layered silicate intercalated composites based nanofibrous mats and their antibacterial activity." Carbohydrate Polymers 89(2): 307-313.

Desai, K., K. Kit, J. J. Li, P. M. Davidson, S. Zivanovic and H. Meyer (2009).

"Nanofibrous chitosan non-wovens for filtration applications." Polymer 50(15): 36613669.

Doshi, J. and D. H. Reneker (1995). "Electrospinning Process and Applications of Electrospun Fibers." Journal of Electrostatics 35(2-3): 151-160.

Duan, B., C. H. Dong, X. Y. Yuan and K. D. Yao (2004). "Electrospinning of chitosan solutions in acetic acid with poly(ethylene oxide)." Journal of Biomaterials SciencePolymer Edition 15(6): 797-811.

Elsabee, M. Z., H. F. Naguib and R. E. Morsi (2012). "Chitosan based nanofibers, review." Materials Science \& Engineering C-Materials for Biological Applications 32(7): $1711-1726$.

EPA. (1974). Safe drinking water act.

EPA. (2005). Membrane filtration guidance manual.

Fiksdal, L. and T. Leiknes (2006). "The effect of coagulation with MF/UF membrane filtration for the removal of virus in drinking water." Journal of Membrane Science 279(1-2): 364-371.

Fogler, H. S. (2006). Elements of Chemical Reaction Engineering, Pearson Education, Inc.

Frenot, A. and I. S. Chronakis (2003). "Polymer nanofibers assembled by electrospinning." Current Opinion in Colloid \& Interface Science 8(1): 64-75.

Furuya, K., K. Murai, T. Yokoyama, H. Maeno, Y. Takeda, T. Murozuka, A. Wakisaka, M. Tanifuji and T. Tomono (2006). "Implementation of a 20-nm pore-size filter in the plasma-derived factor VIII manufacturing process." Vox Sanguinis 91(2): 119-125.

Geering, F. (1999). "Ozone applications - The state-of-the-art in Switzerland." OzoneScience \& Engineering 21(2): 187-200.

Gerba, C. P., J. E. Naranjo and E. L. Jones (2008). "Virus removal from water by a portable water treatment device." Wilderness \& Environmental Medicine 19(1): 45-49. 
Ghayeni, S. B. S., P. J. Beatson, A. J. Fane and R. P. Schneider (1999). "Bacterial passage through microfiltration membranes in wastewater applications." Journal of Membrane Science 153(1): 71-82.

Gomez, M., A. de la Rua, G. Garralon, F. Plaza, E. Hontoria and M. A. Gomez (2006). "Urban wastewater disinfection by filtration technologies." Desalination 190(1-3): 16-28.

Greiner, A. and J. H. Wendorff (2007). "Electrospinning: A fascinating method for the preparation of ultrathin fibres." Angewandte Chemie-International Edition 46(30): 56705703.

Gutierrez, L., X. Li, J. W. Wang, G. Nangmenyi, J. Economy, T. B. Kuhlenschmidt, M. S. Kuhlenschmidt and T. H. Nguyen (2009). "Adsorption of rotavirus and bacteriophage MS2 using glass fiber coated with hematite nanoparticles." Water Research 43(20): 51985208.

Haider, S. and S. Y. Park (2009). "Preparation of the electrospun chitosan nanofibers and their applications to the adsorption of $\mathrm{Cu}$ (II) and $\mathrm{Pb}$ (II) ions from an aqueous solution." Journal of Membrane Science 328(1-2): 90-96.

Halder, S., R. Ng and M. Agbandje-McKenna (2012). "Parvoviruses: structure and infection." Future Virology 7(3): 253-278.

Han, B., J. Li, C. Chen, C. Xu and S. R. Wickramasinghe (2003). "Effects of degree of formaldehyde acetal treatment and maleic acid crosslinking on solubility and diffusivity of water in PVA membranes." Chemical Engineering Research \& Design 81(A10): 13851392.

Han, S. O., W. K. Son, J. H. Youk and W. H. Park (2008). "Electrospinning of ultrafine cellulose fibers and fabrication of poly(butylene succinate) biocomposites reinforced by them." Journal of Applied Polymer Science 107(3): 1954-1959.

Heldt, C. L. (2008). Affinity Adsorption of Viruses Using Small Peptide Ligands. phD, North Carolina State University.

Heldt, C. L., P. V. Gurgel, L. A. Jaykus and R. G. Carbonell (2008). "Identification of trimeric peptides that bind porcine parvovirus from mixtures containing human blood plasma." Biotechnology Progress 24(3): 554-560.

Heldt, C. L., P. V. Gurgel, L. A. Jaykus and R. G. Carbonell (2009). "Influence of Peptide Ligand Surface Density and Ethylene Oxide Spacer Arm on the Capture of Porcine Parvovirus." Biotechnology Progress 25(5): 1411-1418.

Heldt, C. L., P. V. Gurgel, L. A. Jaykus and R. G. Carbonell (2012). "Porcine parvovirus removal using trimer and biased hexamer peptides." Biotechnology Journal 7(4): 558565. 
Heldt, C. L., R. Hernandez, U. Mudiganti, P. V. Gurgel, D. T. Brown and R. G. Carbonell (2006). "A colorimetric assay for viral agents that produce cytopathic effects." Journal of Virological Methods 135(1): 56-65.

Hijnen, W. A. M., G. M. H. Suylen, J. A. Bahlman, A. Brouwer-Hanzens and G. J. Medema (2010). "GAC adsorption filters as barriers for viruses, bacteria and protozoan (oo)cysts in water treatment." Water Research 44(4): 1224-1234.

Hogan, C. J. and P. Biswas (2008). "Narrow size distribution nanoparticle production by electrospray processing of ferritin." Journal of Aerosol Science 39(5): 432-440.

Hsu, B. B., S. Y. Wong, P. T. Hammond, J. Z. Chen and A. M. Klibanov (2011). "Mechanism of inactivation of influenza viruses by immobilized hydrophobic polycations." Proceedings of the National Academy of Sciences of the United States of America 108(1): 61-66.

Huang, C. B., S. L. Chen, D. H. Reneker, C. L. Lai and H. Q. Hou (2006). "High-strength mats from electrospun poly(p-phenylene biphenyltetracarboximide) nanofibers." Advanced Materials 18(5): 668-+.

Huang, X. J., D. Ge and Z. K. Xu (2007). "Preparation and characterization of stable chitosan nanofibrous membrane for lipase immobilization." European Polymer Journal 43(9): 3710-3718.

Huhn, W. (1985). "Criteria of Use, Methods of Investigation and Quality Requirements of Activated Carbon for Drinking-Water Treatment." Acta Hydrochimica Et Hydrobiologica 13(4): 435-442.

Ignatova, M., N. Manolova and I. Rashkov (2007). "Novel antibacterial fibers of quaternized chitosan and poly(vinyl pyrrolidone) prepared by electrospinning." European Polymer Journal 43(4): 1112-1122.

Ignatova, M., K. Starbova, N. Markova, N. Manolova and I. Rashkov (2006).

"Electrospun nano-fibre mats with antibacterial properties from quaternised chitosan and poly(vinyl alcohol)." Carbohydrate Research 341(12): 2098-2107.

Ignatova, M. G., N. E. Manolova, R. A. Toshkova, I. B. Rashkov, E. G. Gardeva, L. S. Yossifova and M. T. Alexandrov (2010). "Electrospun Nanofibrous Mats Containing Quaternized Chitosan and Polylactide with In Vitro Antitumor Activity against HeLa Cells." Biomacromolecules 11(6): 1633-1645.

Jia, Z. S., D. F. Shen and W. L. Xu (2001). "Synthesis and antibacterial activities of quaternary ammonium salt of chitosan." Carbohydrate Research 333(1): 1-6.

Jiang, H. L., D. F. Fang, B. J. Hsiao, B. J. Chu and W. L. Chen (2004). "Preparation and characterization of ibuprofen-loaded poly(lactide-co-glycolide)/poly(ethylene glycol)-g- 
chitosan electrospun membranes." Journal of Biomaterials Science-Polymer Edition 15(3): 279-296.

Katsoyiannis, I. A. and A. I. Zouboulis (2013). "Removal of uranium from contaminated drinking water: a mini review of available treatment methods." Desalination and Water Treatment 51(13-15): 2915-2925.

Kempf, C., M. Stucki and N. Boschetti (2007). "Pathogen inactivation and removal procedures used in the production of intravenous immunoglobulins." Biologicals $35(1)$ : $35-42$.

Komulainen, H. (2004). "Experimental cancer studies of chlorinated by-products." Toxicology 198(1-3): 239-248.

Kruithof, J. C., P. C. Kamp, F. H.C., M. M. Nederlof and v. H. S.C.J.M. (2001). "Development of a membrane integrity monitoring strategy for the UF/RO Heemskerk drinking water treatment plant." Water Science and Technology: Water Supply 1: 261271.

Langlet, J., L. Ogorzaly, J. C. Schrotter, C. Machinal, F. Gaboriaud, J. F. L. Duval and C. Gantzer (2009). "Efficiency of MS2 phage and Q beta phage removal by membrane filtration in water treatment: Applicability of real-time RT-PCR method." Journal of Membrane Science 326(1): 111-116.

Larson, A. M., B. B. Hsu, D. Rautaray, J. Haldar, J. Z. Chen and A. M. Klibanov (2011). "Hydrophobic Polycationic Coatings Disinfect Poliovirus and Rotavirus Solutions." Biotechnology and Bioengineering 108(3): 720-723.

Lee, S. J., Y. J. Lee and S. H. Nam (2008). "Improvement in the coagulation performance by combining $\mathrm{Al}$ and $\mathrm{Fe}$ coagulants in water purification." Korean Journal of Chemical Engineering 25(3): 505-512.

Lee, Y. J., D. S. Shin, O. W. Kwon, W. H. Park, H. G. Choi, Y. R. Lee, S. S. Han, S. K. Noh and W. S. Lyoo (2007). "Preparation of atactic poly(vinyl alcohol)/sodium alginate blend nanowebs by electrospinning." Journal of Applied Polymer Science 106(2): 13371342.

Li, D. and Y. N. Xia (2004). "Electrospinning of nanofibers: Reinventing the wheel?" Advanced Materials 16(14): 1151-1170.

Li, H. W., C. Y. Wu, F. Tepper, J. H. Lee and C. N. Lee (2009). "Removal and retention of viral aerosols by a novel alumina nanofiber filter." Journal of Aerosol Science 40(1): $65-71$. 
Li, Q. L., S. Mahendra, D. Y. Lyon, L. Brunet, M. V. Liga, D. Li and P. J. J. Alvarez (2008). "Antimicrobial nanomaterials for water disinfection and microbial control: Potential applications and implications." Water Research 42(18): 4591-4602.

Li, X. B., P. X. Wu, G. F. Gao and S. H. Cheng (2011). "Carbohydrate-Functionalized Chitosan Fiber for Influenza Virus Capture." Biomacromolecules 12(11): 3962-3969.

Liang, D., B. S. Hsiao and B. Chu (2007). "Functional electrospun nanofibrous scaffolds for biomedical applications." Advanced Drug Delivery Reviews 59(14): 1392-1412.

Lim, S. H. and S. M. Hudson (2004). "Synthesis and antimicrobial activity of a watersoluble chitosan derivative with a fiber-reactive group." Carbohydrate Research 339(2): 313-319.

Lovins, W. A., J. S. Taylor and S. K. Hong (2002). "Micro-organism rejection by membrane systems." Environmental Engineering Science 19(6): 453-465.

Lu, B. G., T. Li, H. T. Zhao, X. D. Li, C. T. Gao, S. X. Zhang and E. Q. Xie (2012). "Graphene-based composite materials beneficial to wound healing." Nanoscale 4(9): 2978-2982.

Ma, H. Y., C. Burger, B. S. Hsiao and B. Chu (2011). "Ultra-fine cellulose nanofibers: new nano-scale materials for water purification." Journal of Materials Chemistry 21(21): 7507-7510.

Ma, H. Y., C. Burger, B. S. Hsiao and B. Chu (2011). "Ultrafine Polysaccharide Nanofibrous Membranes for Water Purification." Biomacromolecules 12(4): 970-976.

Ma, H. Y., C. Burger, B. S. Hsiao and B. Chu (2012). "Nanofibrous Microfiltration Membrane Based on Cellulose Nanowhiskers." Biomacromolecules 13(1): 180-186.

Manesh, K. M., P. Santhosh, A. Gopalan and K. P. Lee (2007). "Electrospun poly(vinylidene fluoride)/poly(aminophenylboronic acid) composite nanofibrous membrane as a novel glucose sensor." Analytical Biochemistry 360(2): 189-195.

Marques, B. F., D. J. Roush and K. E. Goklen (2009). "Virus Filtration of HighConcentration Monoclonal Antibody Solutions." Biotechnology Progress 25(2): 483-491.

Matilainen, A., E. T. Gjessing, T. Lahtinen, L. Hed, A. Bhatnagar and M. Sillanpaa (2011). "An overview of the methods used in the characterisation of natural organic matter (NOM) in relation to drinking water treatment." Chemosphere 83(11): 1431-1442.

Matsushita, T., H. Suzuki, N. Shirasaki, Y. Matsui and K. Ohno (2013). "Adsorptive virus removal with super-powdered activated carbon." Separation and Purification Technology 107: 79-84. 
Mazloomi, S., R. Nabizadh, S. Nasseri, K. Naddafi, S. Nazmara and A. H. Mahvi (2009). "Efficiency of domestic reverse osmosis (RO) in removal of trihalomethanes (THMs) from drinking water." Iranian Journal of Environmental Health Science \& Engineering 6(4): 301-306.

Meechaisue, C., R. Dubin, P. Supaphol, V. P. Hoven and J. Kohn (2006). "Electrospun mat of tyrosine-derived polycarbonate fibers for potential use as tissue scaffolding material." Journal of Biomaterials Science-Polymer Edition 17(9): 1039-1056.

Megelski, S., J. S. Stephens, D. B. Chase and J. F. Rabolt (2002). "Micro- and nanostructured surface morphology on electrospun polymer fibers." Macromolecules 35(22): 8456-8466.

Mello, R. S., G. C. Bedendo, F. Nome, H. D. Fiedler and M. C. M. Laranjeira (2006). "Preparation of chitosan membranes for filtration and concentration of compounds under high pressure process." Polymer Bulletin 56(4-5): 447-454.

Meyn, T., T. O. Leiknes and A. Konig (2012). "MS2 removal from high NOM content surface water by coagulation - ceramic microfiltration, for potable water production." Aiche Journal 58(7): 2270-2281.

Miesegaes, G. R., S. Lute, D. M. Strauss, E. K. Read, A. Venkiteshwaran, A. Kreuzman, R. Shah, P. Shamlou, D. Chen and K. Brorson (2012). "Monoclonal antibody capture and viral clearance by cation exchange chromatography." Biotechnology and Bioengineering 109(8): 2048-2058.

Milewska, A., J. Ciejka, K. Kaminski, A. Karewicz, D. Bielska, S. Zeglen, W. Karolak, M. Nowakowska, J. Potempa, B. J. Bosch, K. Pyrc and K. Szczubialka (2013). "Novel polymeric inhibitors of HCoV-NL63." Antiviral Research 97(2): 112-121.

Morrica, A., C. Nardini, A. Falbo, A. C. Bailey and E. Bucci (2003). "Manufacturing process of anti-thrombin III concentrate: viral safety validation studies and effect of column re-use on viral clearance." Biologicals 31(3): 165-173.

NDWC. (1999). Membrane Filtration.

Neemann, J., R. Hulsey, D. Rexing and E. Wert (2004). "Controlling bromate formation during ozonation with chlorine and ammonia." Journal American Water Works Association 96(2): 26-29.

No, H. K., S. P. Meyers, W. Prinyawiwatkul and Z. Xu (2007). "Applications of chitosan for improvement of quality and shelf life of foods: A review." Journal of Food Science 72(5): R87-R100.

Ozdemir, S., F. M. Bekler, V. Okumus, A. Dundar and E. Kilinc (2012). "Biosorption of 2,4-d, 2,4-DP, and 2,4-DB from aqueous solution by using thermophilic anoxybacillus 
flavithermus and analysis by high-performance thin layer chromatography: Equilibrium and kinetic studies." Environmental Progress \& Sustainable Energy 31(4): 544-552.

Park, D., A. M. Larson, A. M. Klibanov and Y. D. Wang (2013). "Antiviral and Antibacterial Polyurethanes of Various Modalities." Applied Biochemistry and Biotechnology 169(4): 1134-1146.

Patterson, C., A. Anderson, R. Sinha, N. Muhammad and D. Pearson (2012).

"Nanofiltration Membranes for Removal of Color and Pathogens in Small Public

Drinking Water Sources." Journal of Environmental Engineering-Asce 138(1): 48-57.

Phillips, M., J. Cormier, J. Ferrence, C. Dowd, R. Kiss, H. Lutz and J. Carter (2005). "Performance of a membrane adsorber for trace impurity removal in biotechnology manufacturing." Journal of Chromatography A 1078(1-2): 74-82.

Pillay, V., C. Dott, Y. E. Choonara, C. Tyagi, L. Tomar, P. Kumar, L. C. du Toit and V. M. K. Ndesendo (2013). "A Review of the Effect of Processing Variables on the Fabrication of Electrospun Nanofibers for Drug Delivery Applications." Journal of Nanomaterials.

Plakas, K. V. and A. J. Karabelas (2012). "Removal of pesticides from water by NF and RU membranes - A review." Desalination 287: 255-265.

Prausnitz, J. M. P., R. N. Lichtenthaler and E. G. Azevedo (1999). Molecular Thermodynamics of Fluid-Phase Equilibria, Prentice Hall PTR.

Qin, X. H. and S. Y. Wang (2008). "Electrospun nanofibers from crosslinked poly(vinyl alcohol) and its filtration efficiency." Journal of Applied Polymer Science 109(2): 951956.

Rabea, E. I., M. E. T. Badawy, C. V. Stevens, G. Smagghe and W. Steurbaut (2003). "Chitosan as antimicrobial agent: Applications and mode of action." Biomacromolecules 4(6): 1457-1465.

Samson, L., I. Czegeny, E. Mezosi, A. Erdei, M. Bodor, B. Cseke, K. D. Burman and E. V. Nagy (2012). "Addition of chlorine during water purification reduces iodine content of drinking water and contributes to iodine deficiency." Journal of Endocrinological Investigation 35(1): 21-24.

Sano, D., Y. Ueki, T. Watanabe and T. Omura (2006). "Membrane separation of indigenous noroviruses from sewage sludge and treated wastewater." Water Science and Technology 54(3): 77-82.

Sato, A., R. Wang, H. Y. Ma, B. S. Hsiao and B. Chu (2011). "Novel nanofibrous scaffolds for water filtration with bacteria and virus removal capability." Journal of Electron Microscopy 60(3): 201-209. 
Schiffman, J. D. and C. L. Schauer (2008). "A review: Electrospinning of biopolymer nanofibers and their applications." Polymer Reviews 48(2): 317-352.

Schmidt, W., U. Bohme, F. Sacher and H. J. Brauch (2000). "Minimization of disinfection by-products formation in water purification process using chlorine dioxide Case studies." Ozone-Science \& Engineering 22(2): 215-226.

Shin, G. A. and M. D. Sobsey (2003). "Reduction of Norwalk virus, poliovirus 1, and bacteriophage MS2 by ozone disinfection of water." Applied and Environmental Microbiology 69(7): 3975-3978.

Son, W. K., J. H. Youk, T. S. Lee and W. H. Park (2004). "Preparation of antimicrobial ultrafine cellulose acetate fibers with silver nanoparticles." Macromolecular Rapid Communications 25(18): 1632-1637.

Subbiah, T., G. S. Bhat, R. W. Tock, S. Pararneswaran and S. S. Ramkumar (2005). "Electrospinning of nanofibers." Journal of Applied Polymer Science 96(2): 557-569.

Tafur, M. F., K. S. Vijayaragavan and C. L. Heldt (2013). "Reduction of porcine parvovirus infectivity in the presence of protecting osmolytes." Antivial Research 99(1): 27-33.

Taylor., G. (1969). "Electrically Driven Jets." Proceedings of the Royal Society of London. 313(1515): 453-475.

Theerawanitchpan, G., N. Saengkrit, W. Sajomsang, P. Gonil, U. Ruktanonchai, S. Saesoo, T. W. Flegel and V. Saksmerprome (2012). "Chitosan and its quaternized derivative as effective long dsRNA carriers targeting shrimp virus in Spodoptera frugiperda 9 cells." Journal of Biotechnology 160(3-4): 97-104.

Thurston-Enriqueza, J. A., C. N. Haas, J. Jacangelo and C. P. Gerba (2005). "Inactivation of enteric adenovirus and feline calicivirus by ozone." Water Research 39(15): 36503656.

Tree, J. A., M. R. Adams and D. N. Lees (2003). "Chlorination of indicator bacteria and viruses in primary sewage effluent." Applied and Environmental Microbiology 69(4): 2038-2043.

Tucker, N., J. J. Stanger, M. P. Staiger, H. Razzaq and K. Hofman (2012). "The History of the Science and Technology of Electrospinning from 1600 to 1995." Journal of Engineered Fibers and Fabrics 7: 63-73.

Van der Bruggen, B. and C. Vandecasteele (2003). "Removal of pollutants from surface water and groundwater by nanofiltration: overview of possible applications in the drinking water industry." Environmental Pollution 122(3): 435-445. 
Vondran, J. L., W. Sun and C. L. Schauer (2008). "Crosslinked, electrospun chitosanpoly(ethylene oxide) nanofiber mats." Journal of Applied Polymer Science 109(2): 968975.

Vu, D., Z. Y. Li, H. N. Zhang, W. Wang, Z. J. Wang, X. R. Xu, B. Dong and C. Wang (2012). "Adsorption of $\mathrm{Cu}$ (II) from aqueous solution by anatase mesoporous $\mathrm{TiO} 2$ nanofibers prepared via electrospinning." Journal of Colloid and Interface Science 367: $429-435$.

Wallace, G. G., M. J. Higgins, S. E. Moulton and C. Wang (2012). "Nanobionics: the impact of nanotechnology on implantable medical bionic devices." Nanoscale 4(15): 4327-4347.

WHO. (2011). Guidelines for drinking-water quality.

WHO. (2013). Water quality and health strategy. 2013-2020.

Xiao, B., Y. Wan, X. Y. Wang, Q. C. Zha, H. M. Liu, Z. Y. Qiu and S. M. Zhang (2012). "Synthesis and characterization of N-(2-hydroxy)propyl-3-trimethyl ammonium chitosan chloride for potential application in gene delivery." Colloids and Surfaces BBiointerfaces 91: 168-174.

Yang, D. Z., Y. Jin, G. P. Ma, X. M. Chen, F. M. Lu and J. Nie (2008). "Fabrication and Characterization of Chitosan/PVA with Hydroxyapatite Biocomposite Nanoscaffolds." Journal of Applied Polymer Science 110(6): 3328-3335.

Yang, J. S., D. X. Yuan and T. P. Weng (2010). "Pilot study of drinking water treatment with GAC, O-3/BAC and membrane processes in Kinmen Island, Taiwan." Desalination 263(1-3): 271-278.

Yokoyama, T., K. Murai, T. Murozuka, A. Wakisaka, M. Tanifuji, N. Fujii and T. Tomono (2004). "Removal of small non-enveloped viruses by nanofiltration." Vox Sanguinis 86(4): 225-229.

You, Y. W., J. Han, P. C. Chiu and Y. Jin (2005). "Removal and inactivation of waterhorne viruses using zerovalent iron." Environmental Science \& Technology 39(23): 9263-9269.

Young, R. J. and P. A. Lovell (2011). Introduction to polymers, CRC Press.

Zhang, Y. Z., C. T. Lim, S. Ramakrishna and Z. M. Huang (2005). "Recent development of polymer nanofibers for biomedical and biotechnological applications." Journal of Materials Science-Materials in Medicine 16(10): 933-946. 
Zhao, S. L., X. H. Wu, L. G. Wang and Y. Huang (2004). "Electrospinning of ethylcyanoethyl cellulose/tetrahydrofuran solutions." Journal of Applied Polymer Science 91(1): 242-246.

Zhu, B. T., D. A. Clifford and S. Chellam (2005). "Comparison of electrocoagulation and chemical coagulation pretreatment for enhanced virus removal using microfiltration membranes." Water Research 39(13): 3098-3108.

Zhu, B. T., D. A. Clifford and S. Chellam (2005). "Virus removal by iron coagulationmicrofiltration." Water Research 39(20): 5153-5161. 